LBL- -29837

DE91 007651

\title{
THIN FILM REACTIONS ON ALLOY SEMICONDUCTOR SUBSTRATES
}

\author{
Dale Abbott Olson \\ Ph.D. Dissertation \\ Department of Materials Science and Engineering \\ University of California, Berkeley \\ and \\ Materials Sciences Division \\ Lawrence Berkeley Laboratory \\ University of California \\ Berkeley, California 94720
}

This work was supported by the Director, Office of Energy Research, Office of Basic Energy Science, Materials Science Division of the Department of Energy under contract DE-AC03-76SF00098, and by Bellcore, Inc.

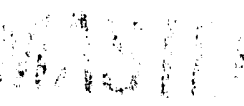




\title{
THIN FILM REACTIONS ON ALLOY SEMICONDUCTOR SUBSTRATES
}

by

\author{
Dale Abbott Olson
}

The interactions between $\mathrm{Pt}$ and $\mathrm{In}_{{ }_{53}} \mathrm{Ga}_{47} \mathrm{As}$ have been studied. In ${ }_{53} \mathrm{Ga}_{47} \mathrm{As}$ substrates with $70 \mathrm{~nm} \mathrm{Pt}$ films were encapsulated in $\mathrm{SiO}_{2}$, and annealed up to $600^{\circ} \mathrm{C}$ in flowing forming gas. The composition and morphology of the reaction product phases were studied using $\mathrm{x}$-ray diffraction, Auger depth profiling, and transmission electron microscopy. The reaction kinetics were examined with Rutherford Backscattering.

Results show that $\mathrm{Pt} / \mathrm{In}_{53} \mathrm{Ga}_{47} \mathrm{As}$ reacts to form many of the reaction products encountered in the $\mathrm{Pt} / \mathrm{GaAs}$ and $\mathrm{Pt} / \mathrm{InP}$ reactions: $\mathrm{PtGa}, \mathrm{Pt}_{3} \mathrm{Ga}$, and $\mathrm{PtAs}_{2}$. In addition, a ternary phase, $\mathrm{Pt}(\mathrm{In}: \mathrm{Ga})_{2}$, develops, which is a solid solution between $\mathrm{PtIn}_{2}$ and $\mathrm{PtGa}_{2}$. The amount of $\mathrm{Ga}$ in the ternary phase increases with annealing temperature, which causes a decrease in the lattice parameter of the phase.

The reaction products show a tendency to form layered structures, especially for higher temperatures and longer annealing times. Unlike the binary case, the PtAss phase is randomly oriented on the substrate, and is intermingle with a significant amount of $\mathrm{Pt}(\mathrm{In}: \mathrm{Ga})_{2}$. Following $\mathrm{Pt} / \mathrm{In}_{53} \mathrm{Ga}_{47} \mathrm{As}$ reactions, two orientation relationships between the $\mathrm{Pt}(\mathrm{In}: \mathrm{Ga})_{2}$ product phase and the substrate were observed, despite the large mismatch with the substrate $(\sim 8 \%)$. At higher annealing temperatures, one of the two orientation relationships becomes dominant. 
For many metal/compound semiconductor interactions, the reaction rate is diffusion limited, i.e. exhibits a parabolic dependence on time. This study shows that the early stages of the $\mathrm{Pt} / \mathrm{In}_{53} \mathrm{Ga}_{47}$ As reaction progress at a rate similar to that of $\mathrm{Pt} / \mathrm{GaAs}$. For longer annealing times, the reaction slows dramatically, to a rate $\sim$ one order of magnitude slower than for $\mathrm{Pt} / \mathrm{GaAs}$. This reduction in reaction rate should prove useful in producing more stable contacts to compound semiconductors by inhibiting contact/substrate reactions.

An additional result of this study was the developrnent of an In-rich layer beneath the reacted layer. The Auger depth profle showed a substantial increase in the sample at this layer. This is a significant result for the production of ohmic contacts, as the Schottky barrier height in this system is lower for higher In concentrations. 


\section{Acknowledgements}

Among the faculty at the University of California, I would like to express my appreciation first of all to my Research Advisor, Prof. Jack Washburn, for his assistance in carrying this project to completion. In addition, I would like to thank Prof. Ron Gronsky, for his considerable guidance and support.

I would like to thank Dr. Tim Sands of Bell Communications Research for his assistance in the form of discussions, specimens, and funding, without which this project would have been impossible.

Among the post-doctoral fellows, I would like to thank Subhash Shindé for his assistance in my entry into this field. I would also like to thank Eric Kvam, for his inexhaustable source of knowledge and advice.

Among my fellow students, I would like to thank Yves Boiteux, Darrel Freer, Thea Buchanan, Chi Sheu, Chris Strell, Tim Kueper, arıd Mike Kollrack. In addition, I offer a special thanks to my office mates, R'Sue Caron-Popowich, Prashant Phatak, and especially Ding Jian.

This work was supported by the Director, Office of Energy Research, Office of Basic Energy Science, Materials Science Division of the Department of Energy under contract [DE-AC03-76SF00098, and by Bellcore, Inc. 


\section{Table of Contents}

1.0 Introduction

1.1 Semiconductor Contacts

1.2 Epitaxial Contacts

1.3 Objective

6

2.0 Contacts to Semiconductors

2.1 Metal/Semiconductor Junctions

2.2 Conduction Behavior

2.3 Practical Contacts

3.0 Epitaxial Contacts

3.1 Conditions for Epitaxy

3.2 Epitaxial Deposition

3.3 Solid Phase Epitaxy

3.4 Solid Phase Reaction Epitaxy

3.5 Phase Separation

4.0 Metallurgy

4.1 Product Phases in $\mathrm{Pt} / \mathrm{In}_{\mathrm{x}} \mathrm{Ga}_{1-\mathrm{x}}$ As

4.2 Phase Separation

4.3 Diffusion

4.4 Kinetics 52

4.5 Diffusion Barriers 57

5.0 Experiment 
5.1 The Contact Metallurgy Experiment .................................................. 60

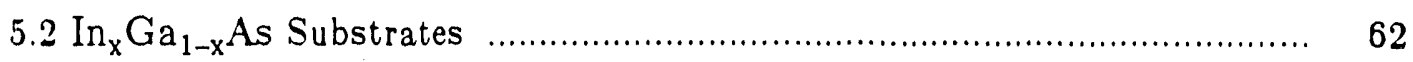

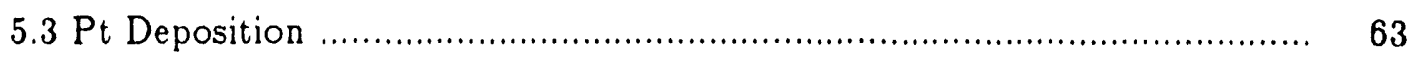

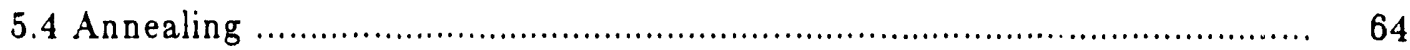

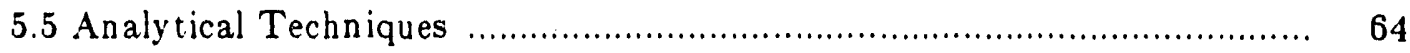

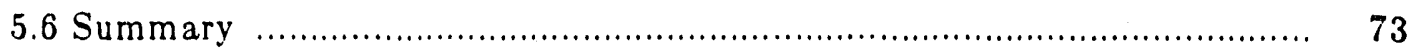

6.0 Results

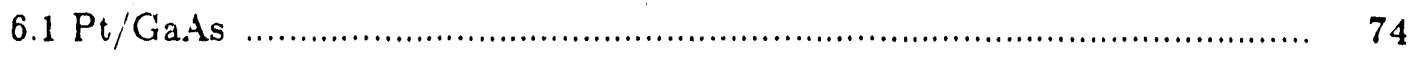

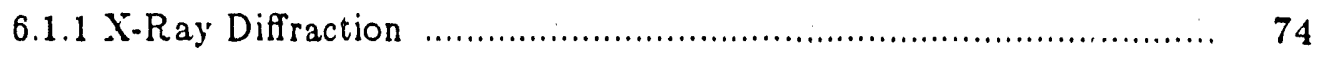

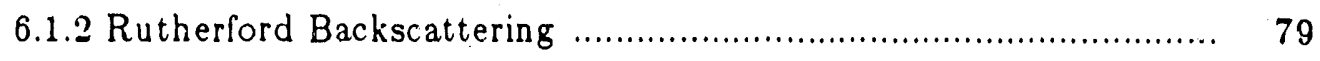

6.1.3 Auger Depth Profile .......................................................... 81

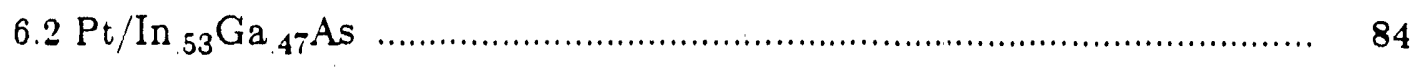

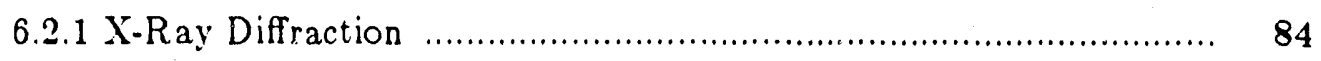

6.2.2 Rutherford Backscattering ............................................. 95

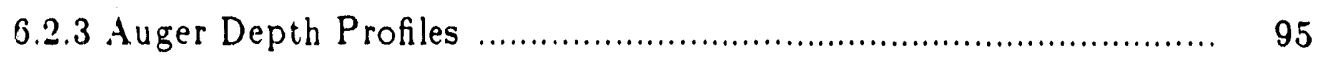

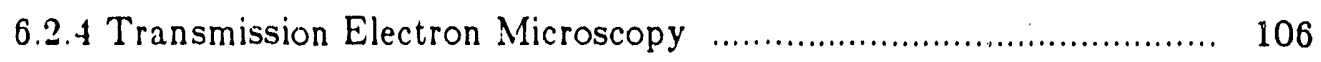

7.0 Discussion

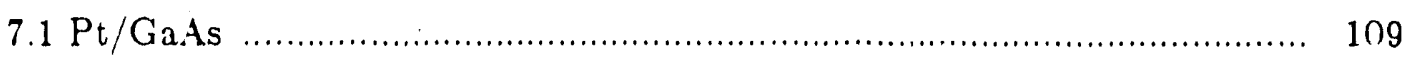

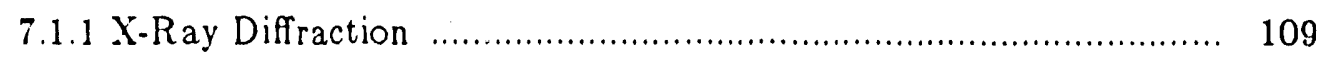

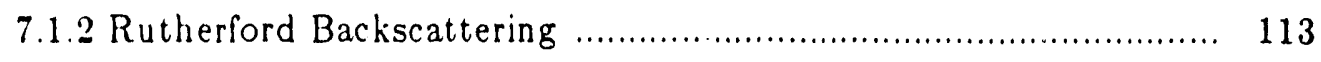

7.1.3 Auger Depth Profile ........................................................ 113

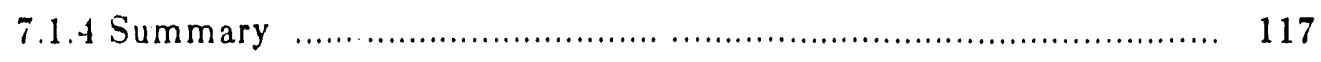

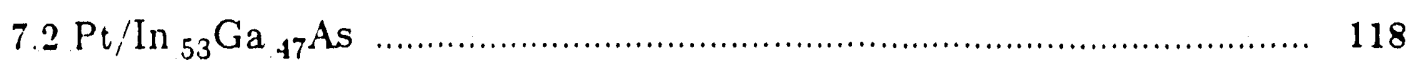

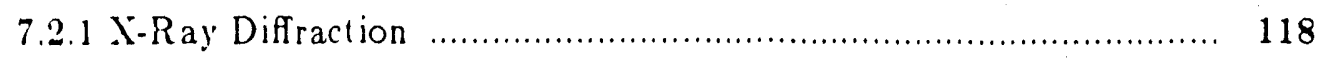


7.2.2 Rutherford Backscattering 129

7.2.3 Auger Depth Profile 132

7.2.4 Transmission Electron Microscopy 137

7.3 Summary 137

7.4 Conclusions 141

7.5 Future Work 141 


\title{
THIN FILM REACTIONS ON ALLOY SEMICONDUCTORS
}

\author{
D. A. Olson \\ Materials and Chemical Sciences Division \\ Lawrence Berkeley Laboratory
}

\subsection{INTRODUCTION}

\subsection{Semiconductor Contacts}

A well-designed metal contact is critical to the proper operation of any semiconductor device (figure 1.1). The contact provides the means for communication with the device, and therefore must exhibit very strictly defined electrical characteristics. In addition, the metallization maintains intimate contact with the semiconductor substrate, of ten at elevated temperatures, and consequently is prone to complex metallurgical interactions which can have a profound effect on the electrical characteristics. Despite these environmental conditions, the contact must maintain its desired characteristics for the projected lifetime of the device.

The electrical characteristics of the contact are determined by the device requirements, and can vary widely. The more basic material requirements, however, are universal: a) the electrical characteristics must be predictably and reproducibly attainable, b) the electrical characteristics of a given contact type must be uniform across each device, and across each wafer, c) once the desired characteristics have been achieved, they must not be affected by subsequent processing (e.g. annealing temperatures up to $400^{\circ} \mathrm{C}$ for packaging, or $850^{\circ} \mathrm{C}$ for ion implantation activation anneals), and, d) the contact must be stable; i.e., the properties of the contact should not change over the lifetime of the device. 


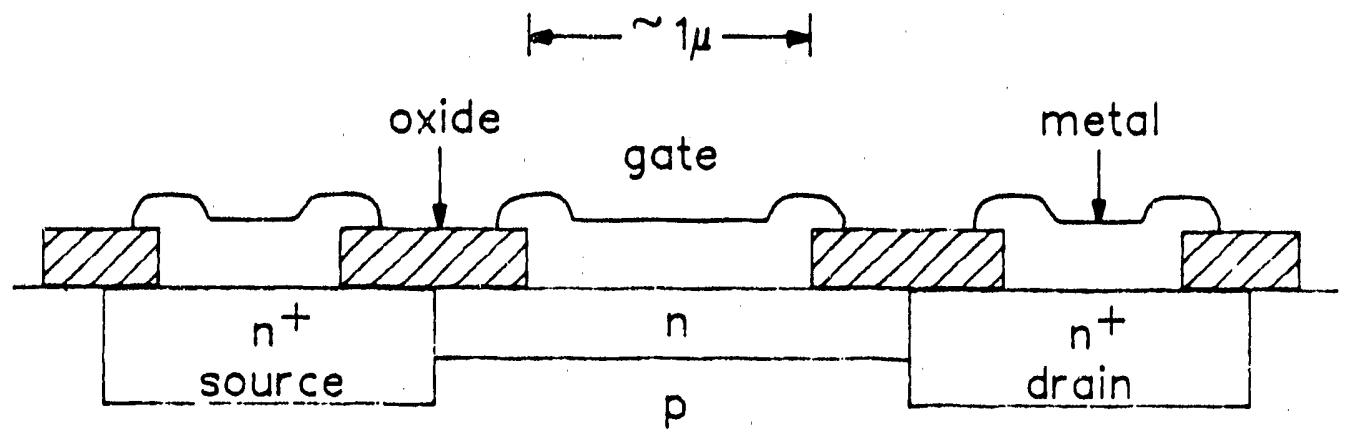

Figure 1.1: Schematic of an FET, showing the approximate dimensions and geometry. 
From the metallurgical perspective, satisfying these requirements is quite difficult, as there are many possible interactions which would interfere with the device operation. The characteristics are generally dependent on the phases and the morphology of the metal/semiconductor interface [WM79, SP80b, FR81, BI82, LL84, RO85]. If the metal reacts with the substrate, the electrical characteristics of the device may be degraded. Reaction with the metal layer can lead to the formation of electrically active defects in the substrate, or to the formation of new interfacial phases with undesirable electrical properties [WM79, SP80b, FR81]. If extensive chemical reaction occurs, definition of the contact dimensions will be difficult to maintain; the reaction may even consume critical device features. Contact areas can impinge, thereby destroying the device. During reaction, morphological changes disrupt the uniformity of the interface.

Liquid phases which may develop during processing are undesirable, as they lead to sensitivity to processing parameters (e.g. annealing temperature and time, heating and cooling rates) and rough interfaces [GR80]. Liquid phases also make control of lateral dimensions difficult, a critical parameter for VLSI devices, where control down to the submicron scale is required.

The grain boundaries of a polycrystalline contact material are also detrimental. They can provide diffusion paths for undesirable reactions, leading to the introduction of unwanted elements from metal overlayers (e.g. Au) into active regions of the device. Reactions which proceed by grain boundary (vs. bulk) diffusion will generally result in rough interfaces, and may result in localized penetration of active layers, i.e. spiking. Rough interfaces and spiking can interfere with the proper operation of the device by intruding into conducting channels. A rough interface can result in an unpredictable contact depth [BH87], while spiking can lead to short circuits and the destruction of device.

There are many other potentially damaging interactions. Excessive reaction with the substrate may consume important features, as active layers of the device may be within one micron of the surface. New phases that are the products of 
contact/substrate interactions may possess undesirable electrical properties. If the contact structure is not thermodynamically stable, reactions may continue during operation of a device at an unacceptable rate, compromising the reliability of the device. This is especially serious for the specialized applications of many compound semiconductors, such as satellites or trans-oceanic optical communications devices, where replacement is expensive or impossible.

The general requirements discussed above are applicable to compound as well as elemental semiconductors, but for compound semiconductors there are two more factors which must be considered. First, the extra elements in the substrate increase the opportunity for undesirable interactions, since each additional element allows the possibility of an additional phase. Second, the stoichiometry of the semiconductor substrate must be controlled during any interactions that may occur; if the elements are removed from the compound substrate at different rates, the electrical properties of the semiconductor itself will change. It should be noted that this change in electrical behavior can be beneficial or detrimental, depending on the circumstances.

While taking all of these problems into account, the goal of contact design is the ideal contact. This contact would be thermodynamically stable, would have a smooth, abrupt interface with the substrate, would not consume excessive amounts of the substrate during fabrication, would not involve liquid phases during processing, would have no grain boundaries, and could be fabricated by conventional techniques.

\subsection{Epitaxial Contacts}

This is a complex set of requirements whith cannot be met by simple contact structures; particularly since most single-element metallizations react with GaAs substrates [LA85]. However, more complex metallizations may result in a structure which satisfies many of the requirements of an ideal contact. For example, introduction of a thin, stable intermediate layer which inhibits diffusion between the metal contact and the semiconductor substrate would increase the lifetime of the device by reducing 
further reactions. If this phase were an epitaxial single crystal, it would eliminate the grain boundaries and rough interfaces associated with a polycrystalline reaction layer. A large-grained, polycrystalline layer could be similarly advantageous, as it would reduce the number of high-diffusivity paths (i.e. grain boundaries).

\section{Deposition}

One promising technique to achieve near-ideal contact structures is direct deposition of suitable compounds on the semiconductor surface (e.g. AuGa $/ \mathrm{GaSb}_{2}$ [LC85], $\mathrm{RhGa} / \mathrm{GaAs}$ [GU88a], YbAs/GaAs [RI88], ErAs/GaAs [PA88b]). These compounds were chosen because they were stable in contact with the substrate, and had appropriate crystal structures and lattice parameters for epitaxial growth. In order to obtain epitaxial growth, these compounds must be directly deposited on the atomically clean semiconductor surface, and therefore require ultra-high vacuum (UHV) deposition techniques ( $<10^{-9}$ Torr), such as molecular beam epitaxy (MBE). UHV is necessary because all compound semiconductor surfaces develop a thin oxide layer (1-2nm) after even a short exposure to air [WI85]. The contacts were prepared by first treating the semiconductor surface in the MBE chamber to remove the native oxide, then depositing the desired compound. The disadvantage of this technique is the strict vacuum requirements and high cost of $\mathrm{MBE}$, and consequent incompatibility with conventional patterning techniques.

\section{Reaction}

An alternate technique for producing the ideal epitaxial contact structure, without the high cost and strict vacuum requirements mentioned above, is to use a controlled metal/semiconductor interaction to form desirable structures. An elemental metallic layer can be deposited by conventional high vacuum techniques $\left(\sim 10^{-6} \mathrm{Torr}\right)$, then annealed to induce a solid phase reaction. Although it may not be possible to attain a monocrystalline, epitaxial layer, considerable improvement of the contact structure 
could still be obtained by meducing interfacial roughness and polycrystallinity; such an inprovement might be attained by local epitaxy of the individual grains of the polycrystal.

There are several compounds which have the potential to satisfy the requirements for an ideal contact. In many metal $/ \mathrm{A}^{\mathrm{III}} \mathrm{B}^{\mathrm{V}}$ systems, the metal and semiconductor react to form : layered structure, with a stable metal- $\mathrm{B}^{\mathrm{V}}$ or metal- $\mathrm{A}^{\mathrm{III}}$ phase present at the semiconductor interface. These phases provide candidates for an inert barrier layer. Many of them are subic, and have lattice parameters within the range of important compound semiconductors. Preferred orientation relationships are of ten exhibited between theis reaction product phases and the substrate, even some with high lattice mismatch; by ieducing the lattice mismatch hetween the substrate and the product phase, it may be possible to create a stable layer which is effective at inhibiting contact/device metallurgical inteructions.

\subsection{Objective}

The focus of this study is on the second method for improving the stability of a contact: controlling the metal/substrate reaction to produce desirable microstructures. In his experiment, the metallurgical eliects of changing the substrate composition have beer examined. This consists of varying the substrate composition and monitoring the effects on: a) phase formation, b) morphology of the reaction products, and c) kinetics of the metal/semiconductor reaction.

Terna $\cdots$ substrates are the focus of this study, as they can be manipulated more easily to match the required characteristics. In many of these systems, the lattice parameter follow's Vegard's law, and varies linearly between the two pure binary values. This facilitates controi of the lattice mismatch between the substrate and the product phases. 
The $\mathrm{Pt} / \mathrm{In}_{\mathrm{x}} \mathrm{Ga}_{1-\mathrm{x}}$ As system was selected for examination in this study, As will be discussed in subsequent sections, this system satisfies many of the requirements for potential solid phase epitaxial growth. In the sections that follow, the general issues faced by designers of stable contacts will be discussed, followed by specific discussions of the $\mathrm{Pt} / \mathrm{In}_{\mathrm{x}} \mathrm{Ga}_{1-\mathrm{x}}$ As system. 


\subsection{CONTACTS TO SEMICONDUCTORS}

This study has examined the development of stable contact structures by controlled reaction, in order to evaluate the potential of this technique for use in actual contact structures. In this chapter, current schemes for producing practical contact structures will be discussed. In order to provide a basis for understanding the motivations for the design of these structures, a summary of the electrical characteristics of metal contacts to semiconductors is presented.

\subsection{Metal/Semiconductor Junctions [SZ81, RO85, RH88]}

Wher a metal and a semiconductor are brought into contact, equilibrating processes occur that accommodate the electrical properties of the two dissimilar materials. The most significant result is the development of an electronic potential barrier at the interface, which can be utilized to control electrical conduction across the couple. Various models have been proposed to describe this equilibration, and to predict the height of the potential barrier, $\phi_{\mathrm{B}}$, which develops.

\section{Schottky Limit [SO38, MO38]}

If a metal and a semiconductor are in electrical contact, the equilibrium condition must be satisfied, i.e. the Fermi levels in the metal and semiconductor must be everywhere equal $\left(E_{f}^{m}=E_{f}^{s}\right)$. Under the appropriate conditions (e.g. n-type semiconductor, no surface states, flat band, $\phi_{m}>\phi_{s}$, where $\phi_{m}$ and $\phi_{s}$ are the work functions of the metal and semiconductor), electrons will flow from the semiconductor in to the metal. This will result in an electric field directed from the semiconductor to the metal. Excess negative charge will accumulate on the surface of the metal, in the form of a narrow band of conduction electrons. A corresponding positive charge will build up on the surface of the n-type semiconductor in the form of uncovered positive ion cores. Because of the much lower concentration of charge carriers in semiconductor relative to the metal, the width of the charge compensating region (i.e. the depletion width, w) 
will be much greater in the semiconductor. The charge build-up results in an upward bending of the semiconductor energy bands. When the metal and semiconductor are brought into intimate contact, a potential barrier situated in the semiconductor will be present, with a magnitude that can be modelled as:

$$
\phi_{\mathrm{B}}=\phi_{\mathrm{m}}-\chi_{\mathrm{s}}
$$

i.e the Schottky barrier. $\chi_{s}$ is the electron affinity of the semiconductor, and corresponds to the potential difference between the bottom of the concuction band and the vacuum level.

This model for the formation of $\phi_{\mathrm{B}}$ does not predict the barrier heights very successfully. It implies that the Schottky barrier depends on $\phi_{m}$, while in practice, $\phi_{B}$ for a given semiconductor is insensitive to the choice of overlaying metal.

\section{Bardeen Limit [BD47]}

Another model proposes that electronic states at the metal/semiconductor interface accommodate the differences in $\phi_{\mathrm{m}}$ and $\chi_{\mathrm{s}}$, producing a metal-independent barrier height for a given semiconductor. Several models have been proposed to explain the origination of these charged surface states, attributing them to intrinsic surface defects, such as $\mathrm{V}^{\prime I I}$ or $\mathrm{V}^{\mathrm{V}}$ [SP80], metal-induced states [LO76], or interfacial phases (WO81).

These states may exist within the forbidden energy gap of the semiconductor, and play a role in the shape of the energy bands near the surface. If the surface is charge neutral, those states located at energies lower than $\phi_{0}$ (the neutral level) will be filled, while those above $\phi_{\circ}$ will be empty.

If the density of these states, $N_{s s}$, is high enough, the Fermi level of the semiconductor can be pinned to the neutral level. Under these conditions, the model predicts that the barrier height of the contact will be given as:

$$
\phi_{\mathrm{B}}=\mathrm{E}_{\mathrm{g}}-\phi_{\mathrm{O}}
$$


There are approximately $10^{15}$ surface atoms per square centimeter on a typical semiconductor; $10^{13}$ surface states per square centimeter (i.e one out of every 100 surface atoms) would be sufficient to pin the Fermi level [RO85].

\section{Experimental Evidence}

In reality, the behavior of the metal-semiconductor contact falls somewhere in between these two extremes, although the dependence of $\phi_{B}$ on the material parameters $\phi_{m}, \chi_{s}$, and $E_{g}$ has not yet been satisfactorily described.

Experimentally, some $\mathrm{A}^{\mathrm{III}}-\mathrm{B}^{\mathrm{V}}$ semiconductors do exhibit pinning of the Fermi level by charged surface states [BR86]. In the case of $\mathrm{GaAs}, \mathrm{E}_{f}$ is found to be pinned at $\sim 0.8 \mathrm{eV}$ below the conduction band edge. In cont yast to the strict Bardeen limit, the barrier height of metals on GaAs does vary slightly with the deposited metal and surface preparation, by about $0.1 \mathrm{eV}$ [BR86]. This variation is unacceptable for the production of many devices, which may require control to within $0.02 \mathrm{eV}$ (BR86). By comparison, it has been shown that the Fermi level of $\operatorname{In}_{\mathbf{x}} \mathrm{Ga}_{1-\mathbf{x}}$ As does not pin for atomically clean surfaces, but does for air-exposed [BI86a,b].

\subsection{Conduction Behavior}

There are two different types of contacts to semiconductors: ohmic and rectifying. In the first case, the current-voltage behavior is linear, with the slope deined as the total contact resistance, $r_{c}$. This contact resistance characterizes the ohmic contact. In the second case, the current-voltage characteristic under forward-bias is exponential, while under reverse-bias, the current saturates at a very low value at low voltage. The rectifying junction is characterised by the Schoitky barrier height, $\phi_{B}$, which appears in the argument of the exponential term. For metal-semiconductor contacts, the rectifying contact is often referred to as a Schottky contart. 
Charge carriers can cross the Schottky barrier that develops at metal/semiconductor interfaces by four means: 1) by acquiring sufficient energy to jump over the barrier (thermionic emission), 2) by quantum-mechanical tunneling through the barrier (field emission), 3) by recombination in the space charge layer, and 4) by minority carrier injection from the metal into the semiconductor and recombination. The last two modes are significant only under reverse bias.

For thermionic emission, the current density between the semiconductor and the metal is determined by the concentration of carriers which have sufficient energy to jump over the intervening barrier. For carriers entering the semiconductor from the metal, the barrier is $\phi_{\mathrm{B}}$. This potential is relatively independent of applied voltage, and will not change much with the bias. For carriers entering the metal from the semiconductor, the barrier is the diffusion potential, $V_{d}$, which represents the difference between the conduction band minimum in the bulk semiconductor and the Schottky barrier height.

$V_{d}$ can be affected by bias. Under forward bias, $V_{d}$ is diminished, allowing increased flow of electrons from the semiconductor to the metal. As $\phi_{\mathrm{B}}$ is relatively independent of bias, the reverse current from the metal to semiconductor current is unaffected. Under reverse bias, $V_{d}$ is increased, which decreases the flow of electrons from the semiconductor to the metal.

The metal/semiconductor current under bias $\mathrm{V}$ can be described with an exponential function:

$$
J=J_{s}[\exp (q V / n k T)-1]
$$

where

$$
\mathrm{J}_{\mathrm{s}} \equiv \mathrm{A}^{*} \mathrm{~T}^{2} \exp \left(-\mathrm{q} \phi_{\mathrm{B}} / \mathrm{kT}\right)
$$

$J_{S}$ is the saturation current, i.e. the current under reverse bias. The constant $A^{*}$ is known as the Richardson constant, and depends in part on the effective mass of the 
majority carrier. The $\mathrm{n}$ in the second exponential is known as the ideality factor, and is a measure of the deviation from an ideal, thermionic diode. For an ideal diode, $n=1$, for thermionic-dominant, $\mathrm{n} \approx 1.02$, while in typical diodes, $\mathrm{n}>1(\approx 1.2)$.

Under reverse bias $(\mathrm{V}<0)$, the carriers in the metal must still possess energy greater than $q \phi_{B}$ in order to pass into the semiconductor. Therefore, the current under reverse bias will remain at a small, constant value, thus giving the contact its rectifying characteristics. It is important to note the good rectifying contacts require a sufficiently high $\phi_{\mathrm{B}}$, otherwise an unacceptably large concentration of carriers in the metal will have sufficient energy to jump over the barrier in reverse bias. This leads to a large reverse leakage current, which may render the device unusable. The critical parameter for Schottly rectifying contacts is the contact barrier height, $\phi_{\mathrm{B}}(\mathrm{eV})$; good contacts generally have $\phi_{\mathrm{B}} \geq 0.7 \mathrm{eV}$.

The second means by which carriers may cross the barrier is by field emission, also known as tunneling. This mode recomes dominant at high doping and low temperatures. Increasing the doping level in the semiconductor below the contact will decrease the width of the depletion layer, and hence the width of the Schottky barrier. If the doping is sufficientiy high, the depletion layer will be thin enough to allow field emission of carriers across the barrier. At intermediate doping levels, sone carriers will have sufficient energy to tunnel through the barrier near the top where it is thinner. This process is known as thermionic-field emission. Both of these processes can give rise to ohmic behavior of the contact.

The critical parameter for ohmic contacts is the specific contact resistance, $r_{c}\left(\Omega \mathrm{cm}^{2}\right)$. For ohmic contacts with non-zero $\phi_{B}, r_{c}$ depends on $\phi_{B}$, the effective mass of the carrier, $\mathrm{m}^{\prime \prime}$, the permittivity of the semiconductor, $\epsilon_{\mathrm{s}}$, and the net doping concentration, $\mathrm{N}\left(\mathrm{cm}^{-3}\right)=\left|\mathrm{N}_{\mathrm{a}}-\mathrm{N}_{\mathrm{d}}\right|$. Assuming that the tunneling process dominates, the dependence of the specific resistance on the interfacial parameters is:

$$
r_{\mathrm{c}} \alpha \exp \left[\frac{2 \sqrt{\epsilon_{\mathrm{s}} \mathrm{m}^{*}}}{\mathrm{~h}}\left(\frac{\phi_{\mathrm{Bn}}}{\sqrt{N}}\right)\right]
$$


Therefore, the specific contact resistance depends exponentially on the inverse square root of the doping concentration for a given barrier height.

For high doping concentrations, $r_{c}$ does not depend on temperature, while for low doping concentrations, the dependence is exponential. This difference in temperature dependence arises because conduction by thermionic-field emission becomes more significant as the width of the barrier increases. For field-emission ohmic contacts in III-V semiconductors, doping concentrations of $10^{19} \mathrm{~cm}^{-3}$ and above are required. In practice, however, achieving doping levels this high is quite difficult ( e.g. [PA85], p. 219)

Ohmic conduction will also occur when $\phi_{\mathrm{B}}=0$. In these contacts, the currentvoltage behavior is linear, i.e. ohmic. This is found, for example, in the case of InAs, where the Fermi level pins in the conduction band. Ohmic contacts on all other Iñ-V semiconductors are of the tunneling type previously described.

\section{$\operatorname{In}_{x} \mathrm{Ga}_{1-x} \mathrm{As}$}

The endpoints of the InAs-GaAs alloy system are very different in their contact behavior. The electronic band structures are qualitatively very similar, although the minimum energy gap between the conduction and valance bands (both are direct) are quite different [PH73]. At $300 \mathrm{~K}, \mathrm{E}_{\mathrm{g}}$ for $\mathrm{GaAs}$ is $1.43 \mathrm{eV}$, while for $\mathrm{InAs}, \mathrm{E}_{\mathrm{g}}$ is $0.36 \mathrm{eV}$. $E_{g}$ for $\operatorname{In}_{x} \mathrm{Ga}_{1-\mathrm{x}}$ As varies continuously between these endpoints (Figure 2.1), and can be expressed empirically as [MD82]:

$$
\mathrm{E}_{\mathrm{g}}(\mathrm{eV})=1.43-1.39 \mathrm{x}+0.32 \mathrm{x}^{2}
$$

In $_{x} \mathrm{Ga}_{1-\mathrm{x}} \cdot 4 \mathrm{~s}$ presents some difficulties to the formation of good rectifying contacts to both p- and n-type material because of its small band gap. The GaAs band gap is fairly large, and so does not present such a problem. For GaAs, $\mathrm{q} \phi_{\mathrm{Bn}} \approx 0.8 \mathrm{eV}$, and $\mathrm{q}_{\mathrm{Bp}} \approx 0.5 \mathrm{eV}$ (e.g. MC87). At the other end of the alloy system, the metal/p-InAs, the barrier height has been reported as $\approx 0.4 \mathrm{eV}$ (WA71). This is significant, as $\mathrm{q} \phi_{\mathrm{Bp}}$ is 


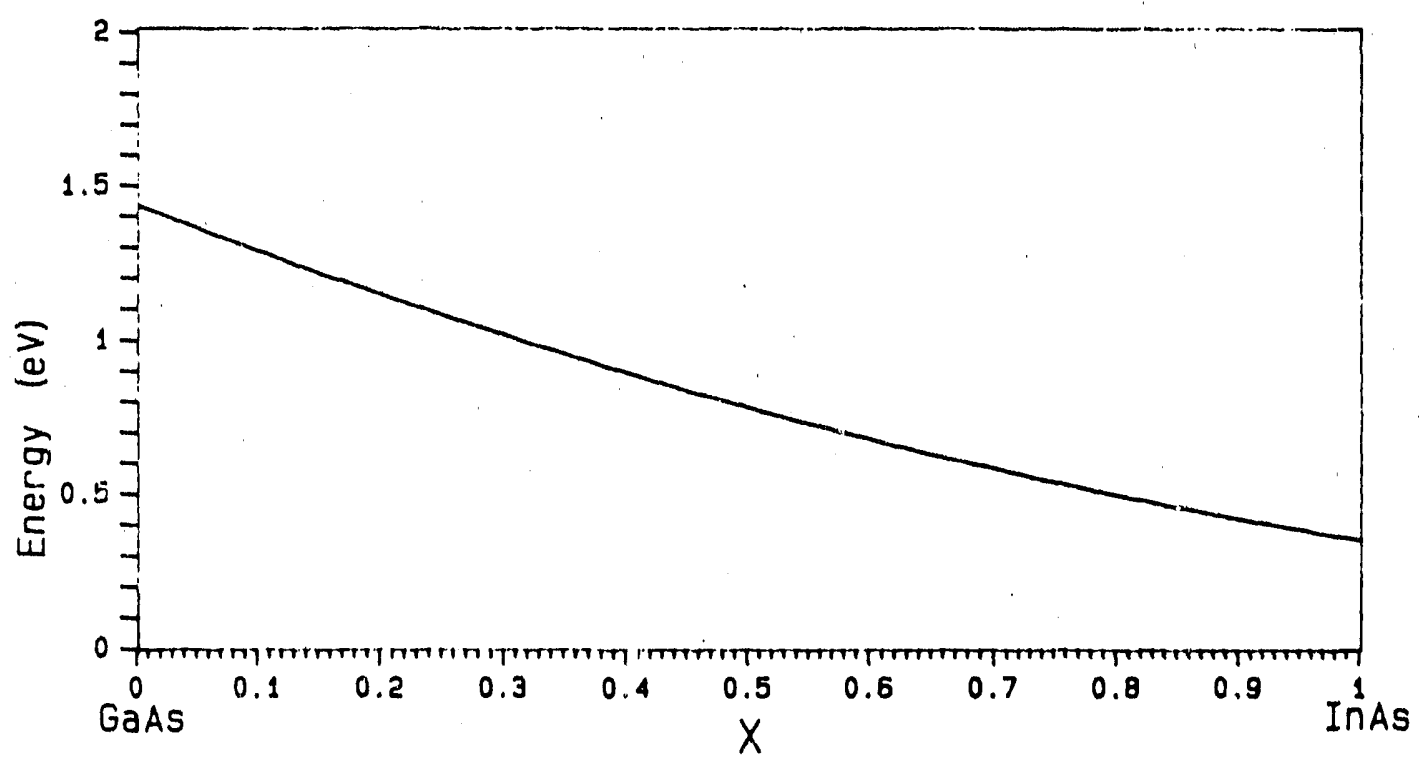

Figure 2.1: Plot of the energy gap of $\operatorname{In}_{\mathrm{x}} \mathrm{Ga}_{1-\mathrm{x}}$ As vs. $x$. Calculated from equation 2.6. After Madelung, 1982 (MD82): 
larger than $E_{g}$. Assuming that the sum of the $n$ - and p-type barrir heights is the band gap [e.g. RH88, p.25], $\phi_{\mathrm{Bn}}$ should be negative. In fact, the metal/n-InAs contact is ohmic.

For intermediate $\mathrm{In}_{\mathrm{x}} \mathrm{Ga}_{1-\mathrm{x}} \mathrm{As}$ compositions, the band gap is necessarily less than that of GaAs. For $\operatorname{In}_{.53} \mathrm{Ga}_{.47} \mathrm{As}$, which is a useful composition as it is lattice matched to InP, $\mathrm{E}_{\mathrm{g}}(300 \mathrm{~K})=0.75 \mathrm{eV}$. Consequently, the Schottky barriers on $\mathrm{n}$-type material are quite small: $\mathrm{q} \phi_{\mathrm{Bn}} \approx 0.2 \mathrm{eV}[\mathrm{KA73}], \mathrm{q} \phi_{\mathrm{Bp}} \approx 0.55 \mathrm{eV}$ [VE82]. For this substrate composition, good ohmic and poor rectifying contacts are attainable on n-type, while poor ohmic and good rectifying contacts are attainable on p-type.

Kajiyama et al. [KA73] measured the Schottky barrier heights of air-exposed $\mathrm{Au} / \mathrm{n}-\mathrm{In}_{\mathrm{x}} \mathrm{Ga}_{1-\mathrm{x}}$ As contacts as a function of $\mathrm{x}$. They found that $\mathrm{q} \phi_{\mathrm{B}}$ tracked the conduction band edge, with a spacing of approximately $0.5 \mathrm{eV}$, and that the barrier height relationship could be described empirically (Figure 2.2):

$$
\phi_{\mathrm{B}}(\mathrm{eV})=0.95-1.90 \mathrm{x}+0.90 \mathrm{x}^{2}
$$

Combining this result with the relationship between the barrier heights and the band gaps as a function of $\mathrm{x}$, the largest In concentration that will allow a reasonable $\phi_{\mathrm{B}}$ for both $\mathrm{n}$ - and p-type material is for $\mathrm{x} \approx 0.25\left(\mathrm{q} \phi_{\mathrm{Bn}} \approx 0.53 \mathrm{eV}, \mathrm{q} \phi_{\mathrm{Bp}} \approx 0.52 \mathrm{eV}\right.$ ).

Brillson et al. [BI86a, b) measured the Fermi level stabilization energies of four different metals ( $\mathrm{Au}, \mathrm{Al}, \mathrm{In}$, and $\mathrm{Ge}$ ) on four different compositions of $\mathrm{In}_{\mathrm{x}} \mathrm{Ga}_{1-\mathrm{x}} \mathrm{As}$. They reported that the Fermi level stabilization energies for a given substrate composition $x$ varied considerably with the deposited metal. They attributed this variation to the formation of different interfacial phases with different metal depositions, in some cases As-rich, and in others As-deficient. In agreement with Kajiyama's results, they found that the Fermi level tracked the conduction band edge for $\mathrm{Au}, \mathrm{Al}$, and In. However, they found considerably different values for $\phi_{\mathrm{Bn}, \mathrm{Aul}}$. They attributed this difference to surface preparation, i.e. air-exposed $[K A 73\}$ vs. clean $[B I 86 a, b]$, and suggested that air-exposure of the surfaces led to pinning. 


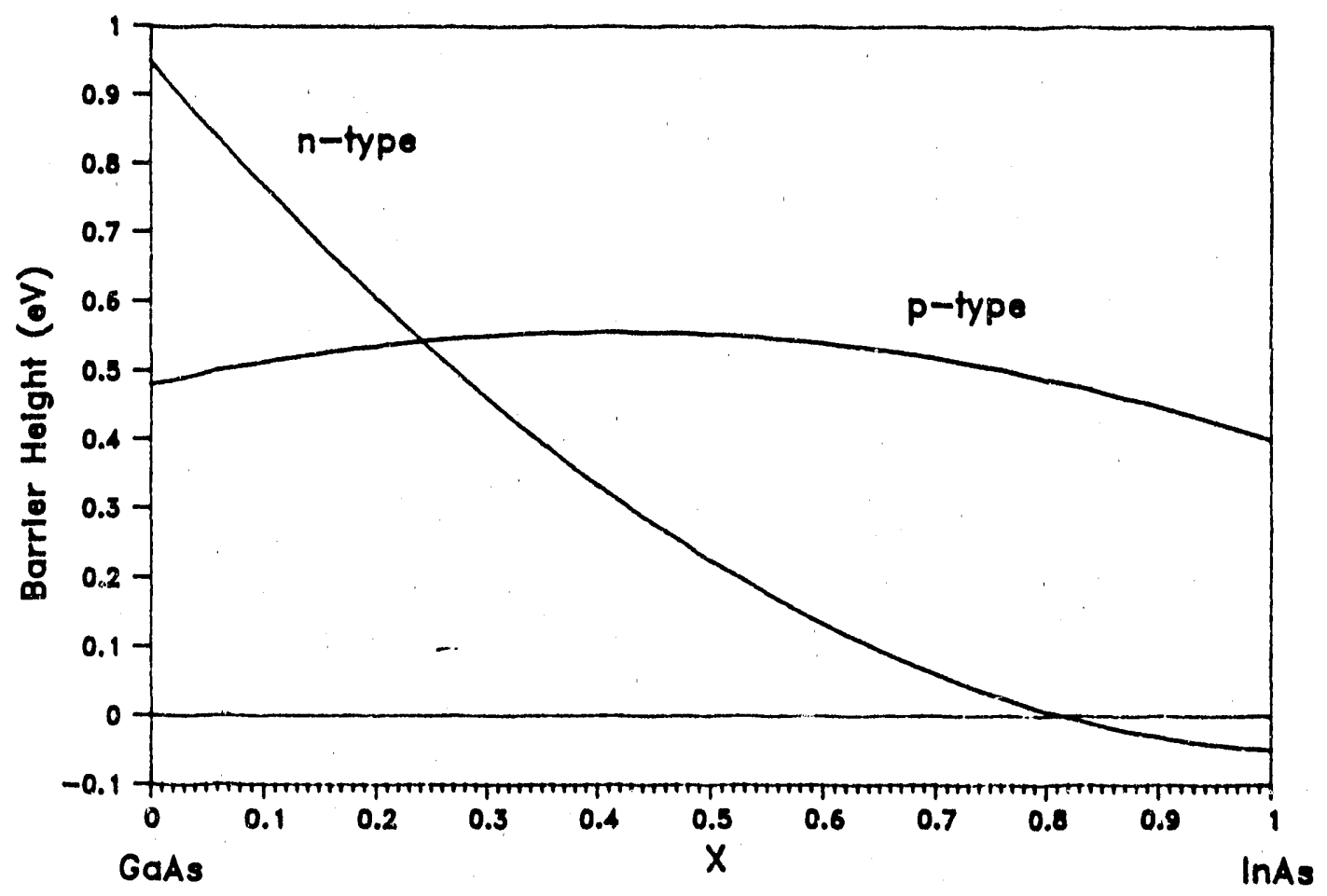

Figure 2.2: The Schottky barrier height of $A u$ on $\operatorname{In}_{x} \mathrm{Ga}_{1-\mathrm{x}} \mathrm{As}$ vs. $\mathrm{x}$. As measured by Kajiyama, 1973 [KA73]. 
In summary, for some metals on $\operatorname{In}_{x} \mathrm{Ga}_{1-\mathrm{x}} \mathrm{As}, \phi_{\mathrm{B}}$ shows a definite functional relationship with $x$. For variations in the choice of overlaying metal on UHV clean surfaces, $\phi_{B}$ is not constant, i.e. $E_{f}$ is not pinned. For air-exposed surfaces, there is evidence of pinning.

\subsection{Practical Contacts}

For both ohmic and rectifying contacts, the requirements for contact behavior, i.e. $\mathrm{r}_{\mathrm{C}}$ and $\phi_{\mathrm{B}}$, are largely determined by the specific device in question. The information provided below applies specifically to GaAs, but can be extended to other $\mathrm{A}^{\mathrm{III}}-\mathrm{B}^{\mathrm{V}}$ substrates.

\section{Rectifying Contacts}

The rectifying contact is characterized by the Schottky barrier height $\phi_{\mathrm{Bn}, \mathrm{p}}$, the ideality factor, $\mathrm{n}$, and the sheet resistance. For conventional devices (e.g. FETs), barrier heights above $0.7 \mathrm{eV}$ are acceptable, although higher barriers are more desirable.

The reverse saturation current, $J_{s} \equiv A^{*} T^{2} \exp \left(-q \phi_{B} / k T\right)$, increases with increasing $T$. Therefore, for a given application, higher operating temperatures require higher barrier heights. Conversely, for very low $\mathrm{T}$ applications, lower barrier heights may be acceptable. Additional requirements are imposed by high radiation environments (e.g. for sateilite and military applications), which can also excite electrons over the barrier.

The general requirements for rectifying contacts are as follows. $\phi_{\mathrm{B}}$ must be high enough to prevent significant reverse bias current, so that as little current as possible is injected into the device through the gate (which operates under reverse bias). The barrier heights must be uniform across the device wafer. Circuits are designed to accommodate the characteristics of the rectifying contacts; if the parameters change across the device, it will not function properly. For the same reason, the barrier height must be reproducibly attainable; if the parameters change from run to run, the same 
problem will arise. Higher barrier heights are better; they allow lower saturation currents, and reduce the uniformity and reproducibility requirements. The optimum contact would be single-phase, epitaxial, have an atomically abrupt interface, and have $\mathrm{q} \phi_{\mathrm{B}}>1.0 \mathrm{~V}$

Since most materials deposited on to GaAs form Schottky barriers, development of rectifying contacts has focussed on the high temperature stability and electrical properties of the contact material, rather than on beneficial reactions with the substrate. Materials for rectifying contacts must withstand high temperatures during processing. For self-aligned gates, the contact acts ari a mask for ion-implantation, a process which requires subsequent annealing at high temperature in order to "heal" substrate lattice damage and activate the implanted species. Consequently, the contact material must be stable at high temperature, and must not react strongly with the substrate.

Elemental contacts are ineffective under these conditions, as most single-element contacts react with compound substrates [LA85]. Compound metallizations are therefore desirable, but they must not decompose or react at high temperature, and must have appropriate electrical characteristics. The refractory metal silicides and nitrides are the most promising contacts for in these aspects [WL83, WU87).

The refractory contacts are deposited by chemical vapor deposition, with nitrogen present in some form $\left(\mathrm{NH}_{3}\right.$ for $\mathrm{TiN}$ (WL83], $\mathrm{N}_{2}$ for $\mathrm{NbN}$ [WU87]) in the deposition chamber. The TiN-GaAs $q \phi_{\mathrm{B}}$ was reported as $0.83 \mathrm{eV}$, the $\mathrm{NbN}-\mathrm{GaAs} \mathrm{q} \phi_{\mathrm{B}}$ as $0.73 \mathrm{eV}$. In the case of the $\mathrm{NbN}$ contact, some improvement in the ideality factor and increase in the barrier height were observed after annealing, possibly as a result of healing the damage introduced during deposition. 


\section{Ohmic contacts}

In contrast to rectifying contacts, ohmic contacts require considerable interaction with the substrate in order to achieve optimum characteristics. For ohmic contacts, the basic requirement is that the voltage drop across the interface is insignificant compared to the volt,age drop across the device. As described above, all contacts to $A^{I I I}-B^{V}$ semiconductors (except InAs) will exhibit a potential barrier. Examination of equation 1.1 suggests two schemes for creating low-resistance ohmic contacts: either by reducing the width of the barrier by increasing the doping concentration immediately below the contact (field emission), or by lowering the barrier height by introducing an intermediate layer of another semiconductor which has lower contact barrier heights (thermionic emission).

The requirements for the resistance of the contact are determined by the particular device. An important relation is that: $R_{c}=r_{c} / A$, where $R_{c}$ is the total contact resistance, and $r_{c}$ is the specific contact resistance $\left(\Omega \mathrm{cm}^{2}\right)$. This relationship allows for a large range of acceptable specific contact resistances, depending on the device application. Devices such as lasers and light emitting diodes have large contact areas (typically about $10^{-3} \Omega \mathrm{cm}^{2}$ ), so that contact resistances in the range of $10^{-2}-10^{-5} \Omega \mathrm{cm}^{2}$ are adequate, giving a total contact resistance on the order of $1 \Omega$.

As minimizing the size of the device becomes more important (e.g. MESFETS and MOSFETS), the required specific contact resistance must also decrease. For typical devices, an acceptable $r_{c}$ is on the order of $10^{-6} \Omega \mathrm{cm}^{2}$. This is determined by the limitation of the resistivity of the sontact materials. This requires a doping concentration of greater than $5 \times 10^{19} \mathrm{~cm}^{-3}$, which is higher than the solid solubility limit of the dopants (BR86). In order to achieve these doping levels, special epitaxial techniques (e.g. $\mathrm{MBE}$ ) are required. Even when sufficiently high doping levels are achieved, making the dopant species electrically active can be challenging [PA85]. Both Ge and $\mathrm{Si}$ are used as amphoteric dopants in $\mathrm{A}^{\mathrm{III}}-\mathrm{B}^{\mathrm{V}}$ compounds. On the $\mathrm{A}^{\mathrm{III}}$ site, they act as shallow donors, while on the $\mathrm{B}^{\mathrm{V}}$ site, they act as shallow acceptors. Once the solubility 
limit has been surpassed, the dopants may begin to form electrically inactive pairs [S.A88].

Most conventional ohmic contacts are of the tunneling type. For these contacts, an alloy containing the contact metal and a suitable dopant are deposited on to the substrate, and then heated to incorporate the dopant into the semiconductor (PA85). Alloyed contarts are heated sufficiently to melt some of the components to assist in the doping, while sintered contacts rely on solid-state diffusion. The most common ohmic contacts cuntain $\mathrm{Ge}$ or $\mathrm{Si}$ (for doping), $\mathrm{Pd}$ or $\mathrm{Ni}$ (to enhance uniformity by breaking up the native oxide) and $\mathrm{Au}$ or $\mathrm{Ag}$ (for the interconnection and low eutectic temperature) [RO85].

The Au-Ni-Ge contact is an example of this type [BR67]. The dopant is incorporated in to the substrate by dissolution of the GaAs during annealing. When the substrate recrystallizes, the high solubility of $\mathrm{Ga}$ in the metal alloy leads to the formation of As-rich material. $\mathrm{Ge}_{\mathrm{Ga}}^{+}$sites are thereby produced in the substrate. $\mathrm{Ge}_{\overline{A s}}^{-}$can be produced by annealing abcve $500^{\circ} \mathrm{C}$ to create As vacancies [SA88].

A new type of ohmic contact that is very promising is the regrown In-based contact [e.g. MU88]. In these contacts, Ni-In-W was deposited on to GaAs and annealed at high temperature $\left(800-1000^{\circ} \mathrm{C}\right)$. The contacts exhibit contact resistances equal to or better than the Au-Ni-Ge contact, with much better thermal stability. The contacts are believed to operate by the regrowth of a low-barrier $\operatorname{In}_{\mathrm{x}} \mathrm{Ga}_{1-\mathrm{x}} \mathrm{As}$ phase at the contact interface, with excess In forming a refractory compound.

Heteroepitaxial contacis have been made with $\mathrm{r}_{\mathrm{c}} \approx 10^{-7} \Omega \mathrm{cm}^{2}$ [PA85]. These were achieved with highly doped $\left(>10^{20} \mathrm{~cm}^{-3}\right)$ Ge or low $\phi_{\mathrm{R}} \operatorname{In}_{\mathrm{x}} \mathrm{Ga}_{1-\mathrm{x}}$ As layers deposited epitaxially onto the substrate prior to metallization. Unfortunately, these contacts are limited by fabrication problems. They are deposited by MBE, where patterning of the contact is not practical [SA88\}. 


\section{Contacts to $\operatorname{In}_{x} \mathrm{Ga}_{1-x}$ As}

Excellent Schottky barrier diodes have been produced for $\mathrm{p}-\mathrm{In}{ }_{.53} \mathrm{Ga}{ }_{.47} \mathrm{As}$ [SE85]. Barrier heights of $\approx 0.7 \mathrm{eV}$ with ideality factors of $\approx 1.2$ were made by evaporating $\mathrm{Al}, \mathrm{Ti}, \mathrm{Au}$, and $\mathrm{Ni}$ on to $\mathrm{Ar}^{+}$sputter-etched surfaces.

Very low contact resistance ohmic contacts have been developed to $\mathrm{In}_{.53} \mathrm{Ga}_{.47} \mathrm{As}$ [KR85]. The contacts were fabricated by alloying techniques, by depositing layers of $\mathrm{Ni} / \mathrm{Au}-\mathrm{Sn} / \mathrm{Ni}$ and $\mathrm{Ni} / \mathrm{Au}-\mathrm{Zn} / \mathrm{Ni}$ (on substrates doped to $10^{18} \mathrm{~cm}^{-3}$ ) and annealing at $400^{\circ} \mathrm{C}$ for 1 to 2 minutes. The best contact resistances reported were $4 \times 10^{-8} \Omega \mathrm{cm}^{2}$ for $\mathrm{Ni} / \mathrm{Au}-\mathrm{Sn} / \mathrm{Ni}$ on $\mathrm{n}-\mathrm{In}_{.53} \mathrm{Ga}_{.47} \mathrm{As}$ and $2 \times 10^{-5} \Omega \mathrm{cm}^{2}$ for $\mathrm{Ni} / \mathrm{Au}-\mathrm{Zn} / \mathrm{Ni}$ on p-In ${ }_{53} \mathrm{Ga}_{47} \mathrm{As}$. 


\subsection{Epitaxial Contacts}

The most commonly used scheme for producing an ohmic contact to a III-V semiconductor is the Au-Ni-Ge type, which has been described previously. Although this contact can yield low contact resistance $\left(\sim 10^{-6} \Omega \mathrm{cm}^{2}\right)$, it suffers from non-uniformity (by deep diffusion of $A u$ (GY71)) and excessive penetration in to the substrate material (up to $100 \mathrm{~nm}$ (KU83)). As well as causing rough interfaces, Au has been well documented as a source of failure in opto-electronic devices by the formation of nonradiative recombination centers (e.g. [UE84]). In addition, the $\mathrm{Au}-\mathrm{Ni}$-Ge contact is very sensitive to annealing conditions, and not very thermally stable [KU83].

One of the most important requirements is that the contact avoids any liquid phases during processing, since these lead to sensitivity to processing parameters (e.g. temperature, time, and heating/cooling rates) and rough interfaces [GR80). In order to improve reliability, uniformity, and dimensional control, various groups have developed methods for producing contacts with flat, abrupt interfaces. The basis of these schemes is the introduction of a stable, epitaxial contact layer on to the semiconductor substrate. In this way, atomically abrupt interfaces may be produced. Currently, there are three scheines for producing this contact layer: epitaxial deposition of suitable compounds, solid-state diffusion with epitaxial precipitation, and reaction to form epitaxial products.

It should be noted that "epitaxial" refers to overlayers which at least have a polycrystalline structure with one or two specific orientation relationships with the substrate, or at best, a monocrystalline layer with a specific orientation relationship with the substrate.

\subsection{Conditions for Epitaxy [KH70, MT75, part B]}

The issue of epitaxial growth between two crystals can be quantified by examining the free energy of an interface between given planes of the phases. If a well-defined 
minimum in the interfacial free energy of the bicrystal vs. orientation exists, then coherent overgrowth can occur. The broader this minimum is, the greater variation in angular alignment there will be around the minimum energy configuration.

The simplest free energy approximation is based on the geometry of the couple: if a plane of crystal A can be layed on a plane of crystal B so that there is considerable overlap of A and B lattice sites (coincidence), the couple is likely to have lower energy than a random configuration. This is more likely to occur under the circumstances where the atomic configurations of the two crystal planes is similar (e.g. square lattice on square lattice), and where the dimensions are compatible (small lattice mismatch). Symmetry also plays an important role [VT74]. If the symmetry of the overlaying material is less than that of the substrate, variant domains will likely result. The number of variants is determined by the number of symmetry elements present in the substrate that are absent in che overlayer. The boundaries between the domains will not in general be incoherent, but are related by the symmetry elements in the system.

In the case of identical crystal structures, the possibility of identical orientations is clear. Good matches can also be found in seemingly incompatible crystal structures: hexagonal (0001) on cubic (111) for instance, or cubic on cubic where the ratio of the lattice parameters is a suitable value (e.g. $\sqrt{ } 2$ or some rational number). However, consideration of the geometry of potential phases is only a rough approximation for predicting epitaxial growth.

\subsection{Epitaxial Deposition}

Epitaxial contact structures can be developed most easily by the direct deposition of a suitable compound. A candidate for the epitaxial phase must satisfy certain requirements: a) it must have a lattice parameter and crystal structure appropriate for epitaxial growth on the desired substrate, b) it must have satisfactory electrical characteristics, c) it must be stable at subsequent fabrication temperatures, d) it must not react strongly with the substrate, and e) it must be compatible with the deposition 
technique.

Because of the native oxides and contamination present on air-exposed semiconductor surfaces, epitaxial deposition requires UHV techniques such as MBE. MBE allows for much more precise control of the growth conditions than is available for conventional techniques, but as a consequence leads to throughput and patterning problems. There are advantages to forming epitaxial contact layers by deposition. Most important is the potential for forming buried contact layers, by creating epitaxial semiconductor/metal/semiconductor structures. More precise control of the deposition conditions afforded by MBE allows for the subsequent deposition of device-quality semiconductor material, a requirement for 3-dimensional device structures.

\section{Elemental Substrates}

Epitaxial deposition of several compounds on (111) $\left(\mathrm{CoSi}_{2}\right.$ [TN82a], $\mathrm{NiSi}_{2}$ [TN82b], $\mathrm{CaF}_{2}$ [IS82], $\mathrm{CrSi}_{2}$ [FA88], $\mathrm{ErSi}_{2}$ (AV89]) and (100) $\left(\mathrm{CaF}_{2}\right.$ (IS82]) Si substrates has been reported. In these examples, the epitaxial layers were formed by the codeposition of the metal and $\mathrm{Si}$ in the MBE chamber. However, it is much more common to form epitaxial silicides by MBE deposition of the pure metal, and annealing to form the corresponding silicide.

In general, deposition of the silicide produces better crystalline quality than deposition followed by reaction, but not always (e.g. $\mathrm{NiSi}_{2}$, (TN82b]). In some cases, the deposition of the silicide results in a low quality crystalline $\left(\mathrm{CaF}_{2},(\mathrm{PF} 85)\right)$ or amorphous layer $\left(\mathrm{ErSi}_{2},[\mathrm{~A} V 89]\right)$. In these cases, improvement in the quality of the layer was obtained by annealing the specimen after deposition.

The deposited compounds are generally cubic structures, with lattice parameters close to that of silicon (e.g. $\mathrm{CoSi}_{2}$ and $\mathrm{NiSi}_{2}$ ). Hexagonal compounds have also been grown epitaxially (e.g. $\mathrm{CrSi}_{2}$ and $\mathrm{ErSi}_{2}$ ), by taking advantage of the three-fold symmetry of the (111) Si orientation. 


\section{Compound Substrates}

The technique of depositing epitaxial contact structures has been applied to compound semiconductors as well. The requirements for suitable compounds are the same as those mentioned above (section 2.4.1), although the extra substrate element makes the search more difficult. Since most elemental metals react with compound semiconductors, research in this area has focussed on the deposition of stable compounds. One complication of direct deposition is the necessity for precise control over the relative flux ratio $(\alpha)$ of the elements in the compound [LC85]. Deviations from the optimum ratio can lead to undesirable reactions with the substrate; unlike the silicide/silicon case where variations in the flux ratio will result only in additional silicon or silicide.

Lince and Williams [LC85] have identified one such compround for deposition on GaSb. $\mathrm{AuGa}_{2}$ has a cubic fluorite structure, with a lattice mismatch to GaSb of only $0.3 \%$. According the the Au-Ga-Sb ternary phase diagram, a tie-line connects the $\mathrm{GaSb}$ and $\mathrm{AuGa}_{2}$ phases, which means they are stable in contact with each other. Lince and Williams were successful in forming a $\mathrm{AuGa}_{2}$ layer by codepositing $\mathrm{Au}$ and $\mathrm{Ga}$, but found the crystallinity of the product was poor. In arldition, they discovered that an excess $\mathrm{Ga}$ flux led to the formation of liquid $\mathrm{Ga}$ metal, while a Ga-deficient flux led to the formation of both $\mathrm{AuGa}$ and $\mathrm{AuGa}_{2}$.

$\mathrm{AuGa}_{2}$ was also deposited on GaAs substrates [LC86], but in this case the lattice mismatch was very high, $\approx 7 \%$. Lince, et al. found that a dominant orientation relationship ((001) planes of the crystallites parallel to the substrate surface) was exhibited between the deposited $\mathrm{AuGa}_{2}$ and the substrate, although other orientations were also present in the polycrystalline film. During annealing above the melting temperature of $\mathrm{AuGa}_{2}$, the deposited film broke up into islands, which exhibited the dominant orientation relationship.

Guivarc'h, et al. have experimented with rhodium compounds on GaAs [Gu88b). Based on lattice mismatch of $0.4 \%$, ard a cubic crystal structure, $\alpha \mathrm{Rh}_{2} \mathrm{As}$ would be a 
likely candidate for epitaxy. The lack of success of this attempt illustrates the difficulty of predicting epitaxial growth from geometric factors. They found that rather than forming an epitaxial layer with the cube axes parallel, the deposited compound was polycrystalline with four different orientation relationships present: two with (001) $\alpha \mathrm{Rh}_{2} \mathrm{As} \|(001) \mathrm{GaAs}$, and two with (011) $\alpha \mathrm{Rh}_{2} \mathrm{As} \|(001) \mathrm{GaAs}$. Most of the $\alpha \mathrm{Rh}_{2} \mathrm{As}$ grains belonged to the latter type of orientation. They suggested that the rotated relationship was favored by the alignment of the dense-packed atomic rows in the two crystal structures.

Guivarc'h, et al. also have deposited $\mathrm{RhGa}$ on GaAs [GU88a]. In this case, the lattice mismatch between the two phases is quite large $\left(a_{\circ}\right.$ of $0.301 \mathrm{~nm}$ for RhGa vs. $0.565 \mathrm{~nm}$ for $\mathrm{GaAs}$ ), although the $\mathrm{RhGa}$ is much more stable in contact with GaAs than is $\alpha R h_{2} A s$. By codepositing $R h$ and $G a$ by MBE, the authors were successful in growing a highly textured film, with two orientations of the type $[100](011)_{\mathrm{RhGa}} \|$ $[110](001)_{\mathrm{GaAs}}$ present. Upon annealing at $550^{\circ} \mathrm{C}$, however, the deposition recrystallized, resulting in a polycrystalline layer with only one orientation.

The deposition of single-crystal rare earth arsenides on GaAs has been reported (YbAs [RI88], Er.As [PA88b]). This materials have high melting points, cubic crystal structures, and acceptable electrical properties. In both cases, the rare earth and As were codeposited in MBE. Both experiments were successful in forming single crystals of the arsenide on the substrate. Palmstrom, et al. also attempted to grow a subsequent GaAs layer, but were unsuccessful due to the formation of islands. The same authors were also successful in growing high quality CoGa layers on GaAs (PA89).

Buried metallic layer heterostructures have been produced on compound substrates [HB88, TA38|. The authors utilized the techniques of epitaxial deposition and subsequent semiconductor growth by MBE. The compound they selected for their scudy was $\mathrm{NiAl}$ (grown on $\mathrm{AlAs}$ ), which has a high melting temperature, low resistivity, and is stable in contact with the semiconductor. 


\subsection{Solid Phase Epitaxy}

The concept of formation of an epitaxial phase utilizing only solid state diffusion has been verified. The simplest case, Solid Phase Epitaxy (SPE), involves the diffusion of appropriate element through a solid layer, and epitaxial precipitation at the transport layer/semiconductor interface. A more difficult process requires not only diffusion, but reaction in the solid state, Solid Phase Reaction Epitaxy (SPRE).

\section{Elemental substrates}

Growth of epitaxial layers on semiconductors by solid phase epitaxy (SPE) has been demonstrated by several authors ([SA73], (CA75], [LA77]). Early examples of this sechnique involve the dissolution of the semiconductor substrate in some suitable material, and precipitation of an epitaxial layer upon cooling, e.g. Al-Ge [CY72] or AlSi [SA73]. The epitaxial layer incorporates some of the solute material, which can be chosen so as to dope the substrate. This technique suffers from a lack of uniformity, because of the presence of native oxide layers, which inhibit dissolution and regrowth, and result in the formation of island structures [LA78]. The problem is especially severe with $\mathrm{Si}$ substrates. In addition, the semiconductor has a tendency to precipitate within the metal layer as polycrystallites when a satisfactory semiconductor interface for growth is unavailable [OT74].

The dissolution/regrowth mechanism can be extended to more complex structures. In these systems, an amorphous semiconductor layer is deposited on top of a transport layer (e.g. Al [MA72], a germanide (MJ77], or a silicide (LA77)), and then annealed. Upon annealing, the amorphous layer decomposes and recrystallizes on the crystalline semiconductor surface. The driving force for the reaction has been attributed to the reduction in free energy associated with the change in state from amorphous to crystalline $[\mathrm{CATA}]$. 
There are two mechanisms for the transport of the amorphous material. In the case of an elemental transport layer (a-Ge/Al/c-Ge (MR72)), the mechanism is certainly diffusion of Ge through the intermediate layer. Systems with compound transport layers (e.g. a-Si/silicide/c-Si (LA77)) are more complicated, with both mechanisms possible. In the dissociation mechanism [PR76], the silicide at the crystalline semiconductor interface decomposes, with the silicon atoms growing epitaxially on the substrate. The metal atoms then diffuse through the silicide layer to the amorphous material, and react to form more silicide. Alternately, the amorphous Si can diffuse directly through polycrystalline silicide to grow epitaxially on the substrate [LA77].

The silicide layer plays an important role in the solid phase epitaxy. In order to produce this layer, the appropriate metal (e.g. Pd) is deposited on a cleaned Si substrate, commonly by electron-beam evaporation. The amorphous $\mathrm{Si}$ is then deposited on the Pd. In all of the SPE systems, the ratio of amorphous material to metal must be greater than one. The silicide $\left(\mathrm{Pd}_{2} \mathrm{Si}\right)$ is formed by annealing the specimen (e.g. $280^{\circ} \mathrm{C}$ for 20 minutes for $\sim 50 \mathrm{~nm} \mathrm{Pd}$ ). Studies show that the $\mathrm{Pd}$ consumes equal amounts of amorphous and crystalline $\mathrm{Si}$ in order to form the silicide ([CA75], (PR76]). By consum $\mathrm{g}$ both amorphous and crystalline material, the silicide formation ensures a high quality interface for the nucleation and growth of the epitaxial layer [CA75]. SPE with elemental transport layers can be hampered by the presence of native oxide layers [LAT8], especially on Si. Therefore, the silicide (or compound forming) layer provides two functions. One is to provide a dissolution and transport medium for the amorphous semiconductor. The other is to provide a clean interface suitable for epitaxial growth by consumption of the original surface $[\mathrm{MJ} 7 \mathrm{~T})$.

This technique can be further refined to dope the regrown semiconductor [LA76]. Lau, et al, were able to dope the SPE Si n-type by introducing a thin Sb layer in the system: amorphous-Si/Sb/Pd/crystalline-Si $(970 \mathrm{~nm} / .5 \mathrm{~nm} / 97 \mathrm{~nm})$ and annealing. Upon annealing, the Sb atoms were incorporated into the epitaxial Si layer. Other studiss show that during SPE, $\mathrm{Pd}$ is incorporated in to the epitaxial layer, and $\mathrm{Si}$ is trapped in 
the silicide $[\mathrm{CA} 75]$.

\section{Conspound Substrates}

The techniques of SPE also have been successfully applied to producing workable contacts on compound substrates by Marshall et al. [MA85]. They decided to introduce an epitaxial Ge layer in to the contact, because of its low conduction band discontinuity with GaAs and its low barrier height with many metals. The goal was to produce ohmic contacts without the interfacial roughness of alloyed contacts (KU83), and without the stringent vacuum requirements of MBE. They developed a technique very similar to the silicide SPE described above, which had been applied to the Pd-Ge system by Majni, et al. (MJ77).

In this system, PdGe is used as the transport layer. One of the goals was to reduce the UHV requirements of $\mathrm{MBE}\left(10^{-10} \mathrm{Torr}\right)$, so all depositions were done by electron-beam evaporation in high vacuum $\left(10^{-6}\right.$ Torr). After deposition of $\sim 50 \mathrm{~nm}$ Pd, amorphous Ge was deposited without breaking vacuum. Sufficient Ge was deposited to completely react the $\mathrm{Pd}$ layer, with the remainder available to form the epitaxial Ge contact layer. During deposition of the Pd, the GaAs surface was prepared for epitaxial growth by a reaction which formed $\mathrm{Pd}_{\mathrm{x}} \mathrm{Ga}_{\mathrm{y}}$ As. After the annealing steps, the ternary phase was no longer present.

During the first annealing stage $\left(325^{\circ} \mathrm{C}, 30\right.$ minutes), the $\mathrm{Pd}$ reacted with the Ge to form PdGe. After the second annealing stage, the residual amorphous Ge layer dissolved in to the germanide, and diffused to the substrate, where it precipitated epitaxially at the PdGe/GaAs interface. The lattice mismatch between $\mathrm{GaAs}$ and $\mathrm{Ge}$ is $\sim 0.1 \%$. Electrical measurements showed that the conlacts were ohmic, with contact resistivities on the order of $10^{-6} \Omega \mathrm{cm}^{2}$. The authors concluded that the electrical behavior of the contacts was most likely due to tunneling. The contact characteristics degraded after annealing above $\sim 400^{\circ} \mathrm{C}$, however. 
The Ge/Pd contact has been applied to $\mathrm{Ir}_{53} \mathrm{Ga}_{47}$ As with some success [CH86]. Contact resistances of $2.3 \times 10^{-6} \Omega \mathrm{cm}^{2}$ to p-type material were measured, and $6 \times 10^{-7} \Omega \mathrm{cm}^{2}$ to $\mathrm{n}$-type. The contacts were also attractive from a processing standpoint $\left(325^{\circ} \mathrm{C}\right.$ anneal) and thermal stability ( 4 hours at 300 to $500^{\circ} \mathrm{C}$ ).

The Au-Ni-Ge contact described in section 2.3 actually utilizes the dissolution and regrowth techniques. During the annealing, the GaAs substrate is partially dissolved in the contact material, and then regrows epitaxially on the substrate, incorporating some of the contact elements into the new material. Unfortunately, the nterface is very rough and non-uniform, perhaps due to the presence of native oxides [SA88].

\subsection{Solid Phase Reaction Epitaxy}

\section{Elemental Substrates}

During Solid Phase Reaction Epitaxy, the products of a thin film reaction grow epitaxially on a substrate material. The growth of epitaxial silicides is an example of the simplest case of this technique. Several metals can be reacted with $\mathrm{Si}$ wafers to form epitaxial reaction products, with varying degrees of crystallinity (sce [TN82b] for review). Epitaxial silicides include $\mathrm{CoSi}_{2}, \mathrm{NiSi}_{2}, \mathrm{PdSi}_{2}, \mathrm{PtSi}, \mathrm{CaSi}_{2}$ (MO88), $\mathrm{ErSi}_{2}$ [AY89], and numerous refractory metal silicides [CL85].

The simplest method for producing epitaxial silicides, with the lowest vacuum requirements, involves the deposition of the metal followed by an annealing treatment to induce silicide formation. The silicide grows on the silicon substrate as an epitaxial layer. The annealing usually consists of a two stage heat treatment: a low temperature anneal $\left(300-400^{\circ} \mathrm{C}\right)$ to form the polycrystalline silicide, followed by a high temperature anneal $\left(800-900^{\circ} \mathrm{C}\right)$ to induce the preferential growth of epitaxial grains (e.g. (CJ82a]). In some cases, the epitaxial silicide can be formed in one stage. 
When epitaxial silicides are formed by reaction, the overlayer is of ten composed of two types of grains, each with a specific orientation relationship with the Si substrate, and related to each other by some symmetry operation [CK81, TN82b]. Typically, the films have been deposited on a chemically cleaned substrate by electron beam evaporation, although some groups have deposited the pure metal by MBE. The electronbeam evaporated films are of lower quality; during annealing of the chemically cleaned substrates, nucleation of epitaxial material can only occur through holes in the contamination (oxide) layer [GI82].

Epitaxial silicides have been grown on all low-index Si planes ((100), (110), (111)). High quality, monocrystalline layers have been produced by these techniques (TN82a, AV89]. On a local scale, the silicide-substrate interface is abrupt to within $2 \mathrm{~nm}$, but only on (111) $\mathrm{Si}$ is the interface flat [CK81, TN82b]. This is due to the greater stability of the (111) interface; other orientations result in faceting of these planes, with protrusions on the order of tens of nanometers (CJ82b).

\section{Compound Substrates}

Solid phase reactive epitaxy on compound substrates introduces an additional problem not encountered with elemental semiconductors. In addition to the issues of lattice mismatch and interfacial compatibility, there is the possibility of the formation of multiple reaction products, one of which could impede epitaxial growth. Binary semiconductors can react with elemental metal layers to form ternary (e.g. $M_{x} A B$ ) or binary $\left(\Lambda A_{x}, \Lambda B_{Y}\right)$ phases.

The formation of a single ternary compound is not unlike the silicide case; the metal diffuses into the substrate, and reacts to form an epitaxial ternary phase. Lahav, et al., have reported that the $\mathrm{Ni} / \mathrm{GaAs}$ system can undergo this behavior. In their experiment, $\mathrm{Ni}$ was deposited by electron-beam evaporation on chemically cleaned (111) and (100) GaAs. The two substrate orientations yielded different results. They reported that $\mathrm{Ni}_{2} \mathrm{GaAs}$ phase formed epitaxially on both substrates for anneals 
between 100 and $300^{\circ} \mathrm{C}$, although the product on (100) was microtwinned while the product on (111) was of higher crystalline quality. Above $350^{\circ} \mathrm{C}$, the ternary phase decomposed on the (100) substrates to epitaxial $\beta \mathrm{NiGa}$ and randomly oriented NiAs. Later experiments by Sands, et al. [SA86a], indicated that the ternary phase was actually $\mathrm{Ni}_{3} \mathrm{GaAs}$.

Similar studies have been done on the Pd/GaAs system. Oelhafen, et al. found that at lower annealing temperatures, a highly textured $\mathrm{Pd}: \mathrm{Ga}$ :As ternary phase (which they identified as $\mathrm{Pd}_{2} \mathrm{GaAs}$ ) formed, while at higher temperatures (above $350^{\circ} \mathrm{C}$ ), epitaxial islands of $\mathrm{PdGa}$ were reported. Later studies by Sands, et al. [SA86b] concluded that the actual ternary composition was $\mathrm{Pd}_{5}(\mathrm{GaAs})_{2}$.

The Co/GaAs illustrates two possible interfacial epitaxial reactions, depending on annealing temperature [PA87). At lower temperatures, a ternary $\mathrm{Co}_{2} \mathrm{Ga}_{2-\mathrm{y}} \mathrm{As}_{\mathrm{y}}$ (with y $\sim$ ) appears at the reacted layer/GaAs interface, and exhibits a strong orientation relationship with the substrate. At higher temperatures, the ternary phase decomposes in to two binaries, CoGa and CoAs, each aligned with the substrate (PA87, SA87b).

Alternatively, the product phases may segregate so that one binary phase grows with an orientation relationship with the substrate, while another grows on the surface. This has been shown in the case of $\mathrm{Pt} / \mathrm{GaAs}$, where $\mathrm{PtAs}_{2}$ forms with a strong orientation relationship on the GaAs, while $\mathrm{Pt}-\mathrm{Ga}$ phases form on the surface [SI73, KM75, FO83). To a lesser extent, the same situation develops in the $\mathrm{Pt} / \mathrm{InP}$ system, where $\mathrm{PtP}_{2}$ exhibits texturing with the InP substrate, although some intermixing of the $\mathrm{PtP}_{2}$ and Pt-In phases is evident [OL89].

In summary, these metal/ $\mathrm{A}^{\mathrm{III}}-\mathrm{B}^{\mathrm{V}}$ systems exhibit three different cases for the formation of epitaxial reaction products: a ternary textured phase (Ni/GaAs, Pd/GaAs, Co/GaAs), two binary textured phases (CoGa and CoAs on GaAs), and a single textured binary phase with vertical segregation $\left(\mathrm{PtAs}_{2}\right.$ and $\left.\mathrm{PtP} \mathrm{P}_{2}\right)$. These systems provide the potential for the formation of epitaxial contacts by SPRE. 


\subsection{Phase Separation}

In the $\mathrm{Pt} / \mathrm{In}_{\mathrm{x}} \mathrm{Ga}_{1-\mathrm{x}}$ As system, multiple reaction products are expected. Even if one of these phases has the inclination to form epitaxially on the semiconductor substrate, it may be impeded by the presence of other phases from forming a continuous layer. Therefore, it may be desirable to induce the segregation of the reaction products so that continuous layers can be formed. This occurs naturally in the Pt/GaAs system, although it is still unclear why the layering sequence occurs. In the next chapter, models for the occurrence of phase separation will be considered, as well as techniques for exploiting them to achieve desirable structures. 


\subsection{METALLURGY}

This study has been motivated by the desire to develop stable contact structures on compound semiconductors. Consequently, an understanding of the possible metal. lurgical reactions is of profound importance. As has been mentioned previously, elemental metals in contact with compound semiconductors will generally react with the substrate, modifying the electrical and morphological characteristics of the system. The reaction products can be beneficial; therefore, inducing a desirable phase to develop at the proper interface with the appropriate morphology is very important. Some issues to consider when examining the metallurgy will be discussed in this chapter: reaction products, phase segregation, diffusion, kinetics, and diffusion barriers.

\subsection{Product $\mathrm{Phases}$ in $\mathrm{Pt} / \mathrm{In}_{\mathrm{x}} \mathrm{Ga}_{1-\mathrm{x}} \mathrm{As}$}

Six biliary phase diagrams for the $\mathrm{Pt}: \mathrm{In}: \mathrm{Ga}$ :As quarternary system are shown in figure 4.1.a-f [MF87, HN58]. The Pt-In and Pt-Ga phase diagrams show that there are several intermetallic phases possible in these systems. However, previous studies of $\mathrm{Pt} / \mathrm{III} \mathrm{V}$ reactions $[\mathrm{SI73}, \mathrm{KM} / 75, \mathrm{SI} 78, \mathrm{FO} 83, \mathrm{OL} 89]$ indicate the likely product phases, which are discussed below.

\section{The Dipnictides}

In the $\mathrm{Pt}$-As system, there is only one viable product phase for these reactions, $\mathrm{PtAs}_{2}$. This belongs to a class of compounds, known as Pt-dipnictides, and which have the form $\mathrm{MB}_{2} \mathrm{~V}$, where $\mathrm{B}=\mathrm{P}, \mathrm{As}$, Sb [FU65, HL65, FU67, BB74]. These compounds have the cubic $\mathrm{FeS}_{2}$ (1)yrite) structure, with lattice parameters within the range of many ternary substrates, which makes them nearly ideal for the purposes of this study [VI8.5]. In addition, these three compounds contain the group V elements commonly used in $A_{a}^{I I I}-A_{b}^{I I I}-B^{V}$ ternary substrates- $P, A s$, and $S b$. 


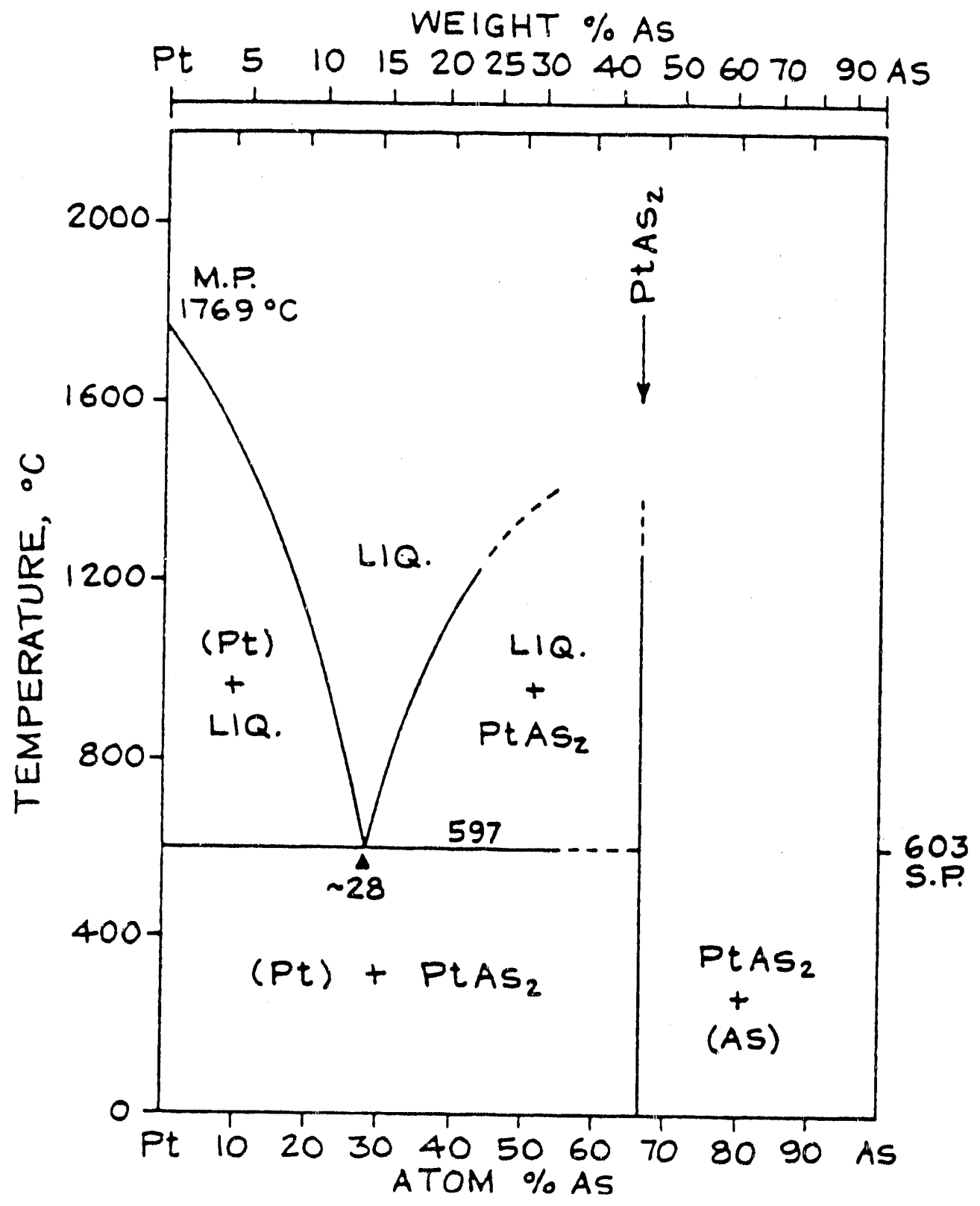

Figure 4.1.a: Phuse diagram of the As-Pt system, after Moffet, 1987 [MF87]. 


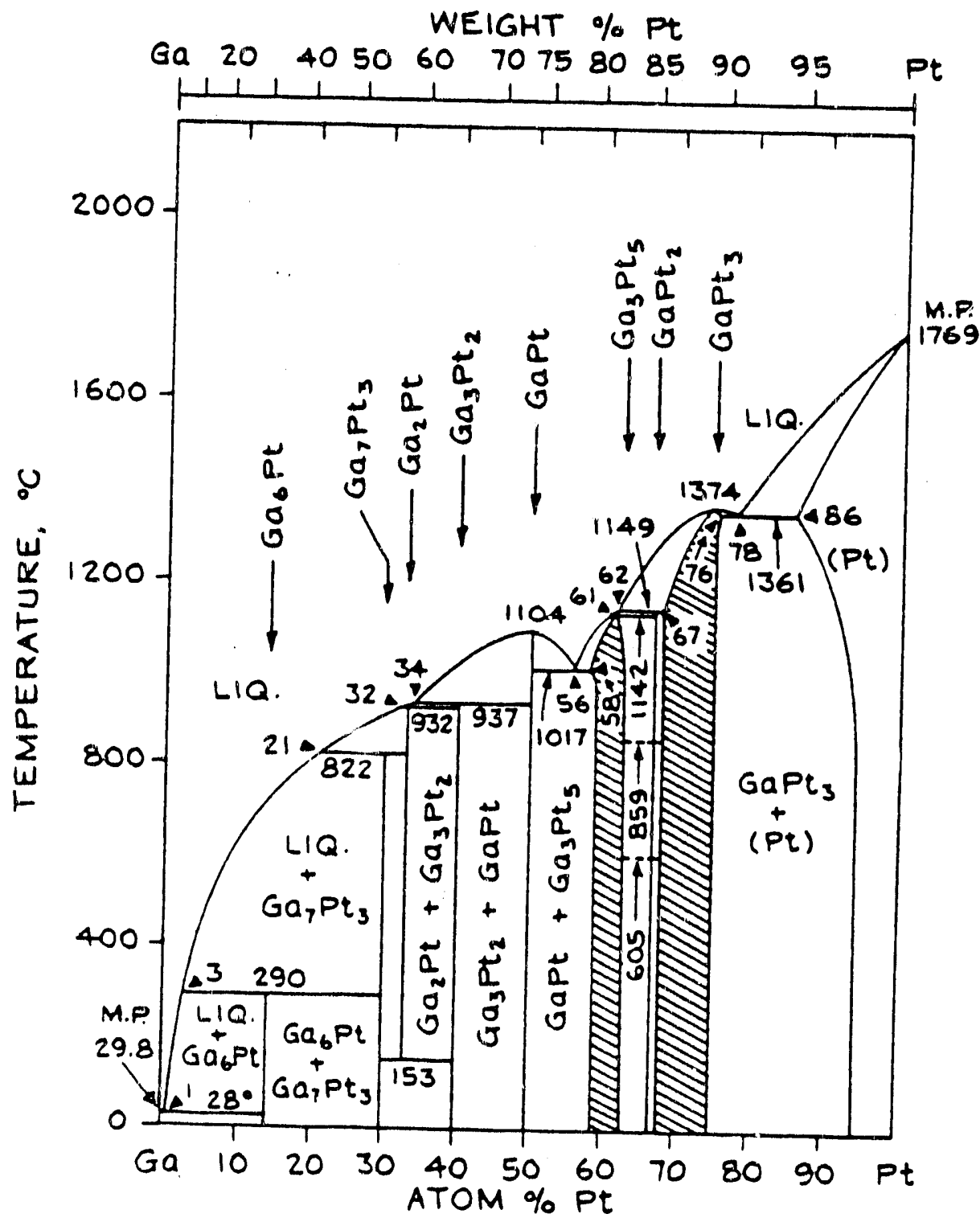

Figure 4.1.b: Phase diagram of the Ga-Pt system, after Moffet, 1987 [MF87]. 


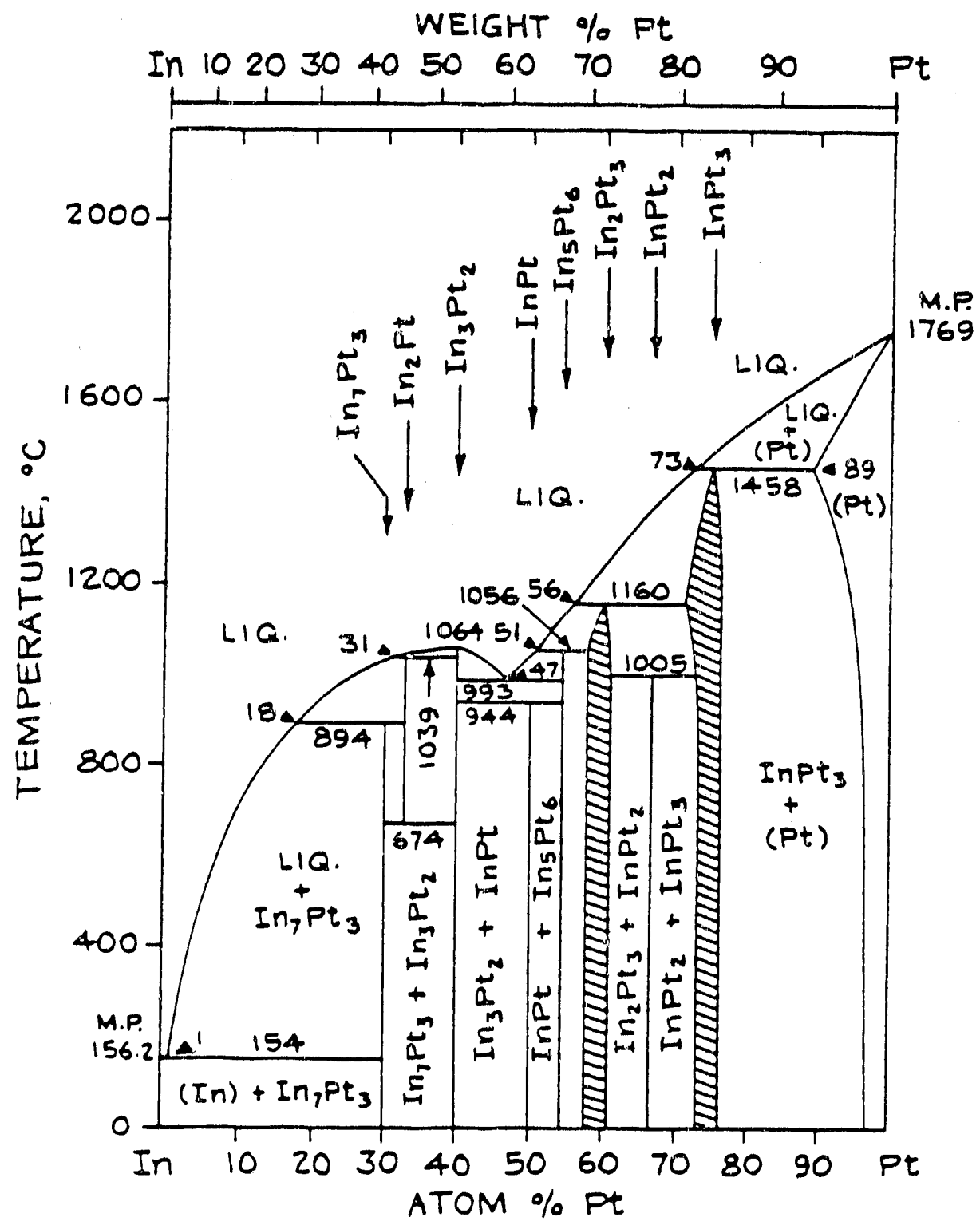

Figure 4.1.c: Phase diagram of the In-Pt system, after Moffet, 1987 [MF87]. 


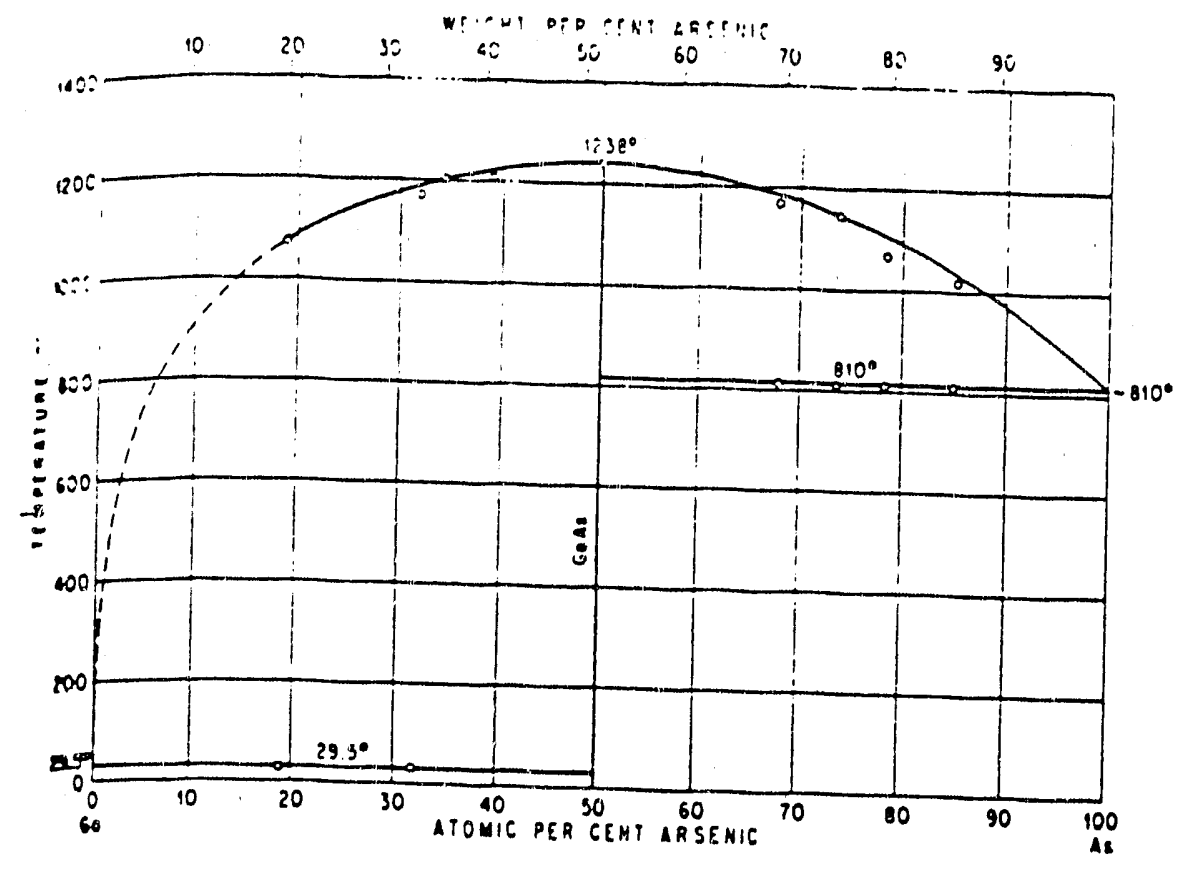

Figure 4.1.d: Phase diagram of the Ga.As system, after Hansen, 19.58, p. 165 [H. 58 . 


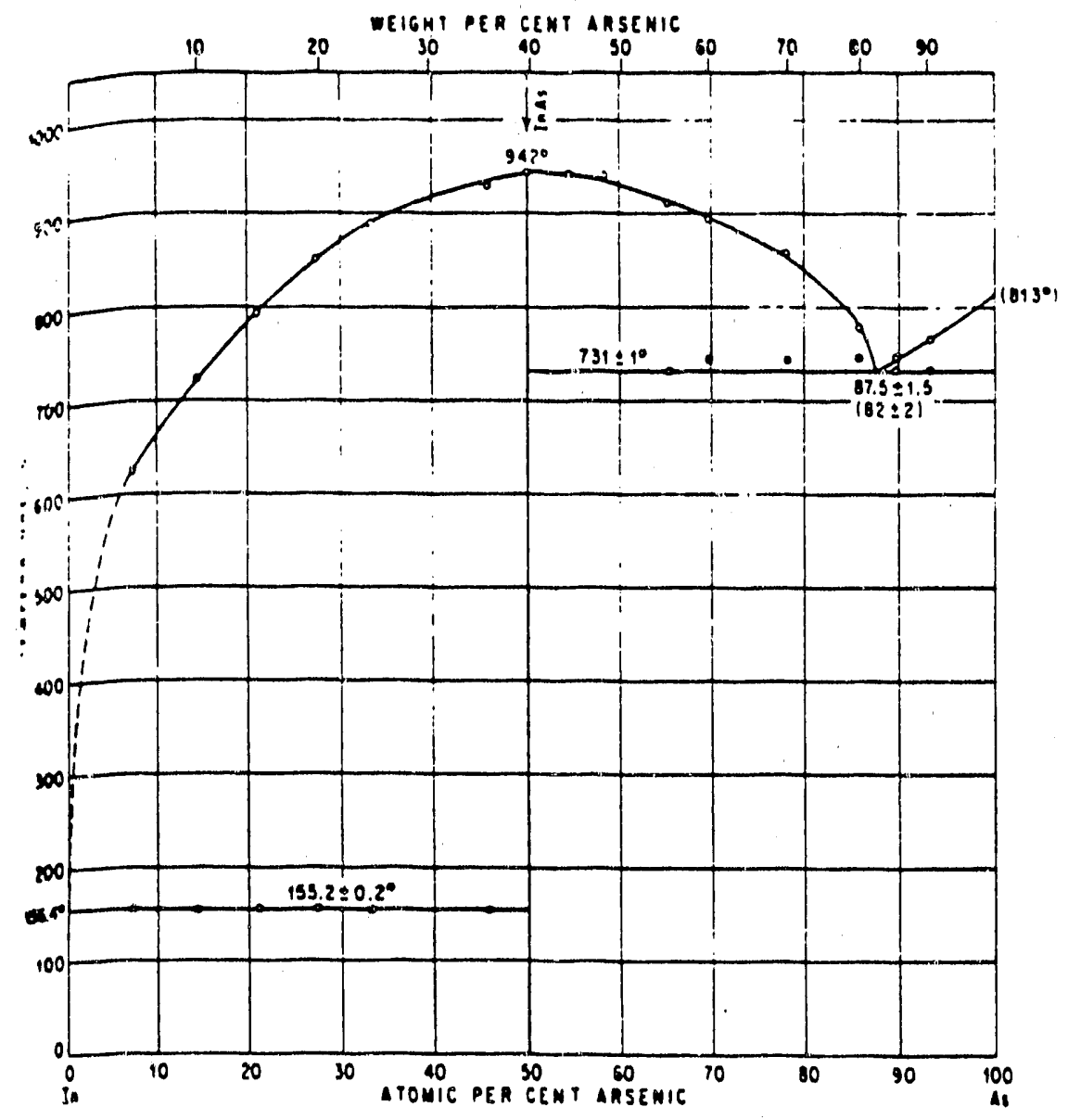

Figure 4.1.e: Phase diagram of the In-As system, after Hansen, 1958, p. 166 [HN58]. 


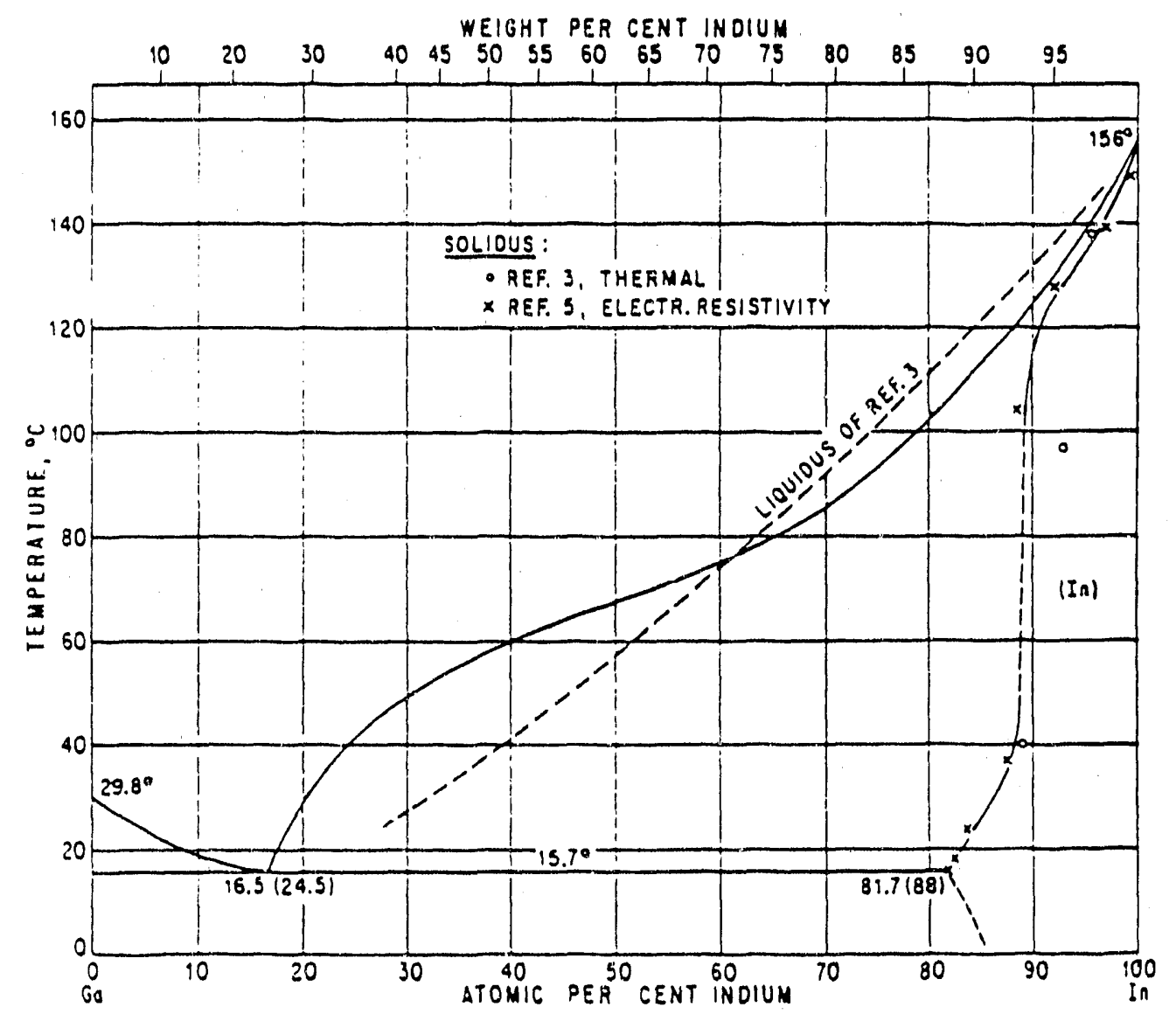

Figure 4.1.f: Phase diagram of the Ga-In system, after Hansen, 1958, p. 745 [HN58]. 
The substrate which is chosen for this study is $\operatorname{In}_{x} \mathrm{Ga}_{1-x} \mathrm{As}$. This material has two attributes which make it an attractive material for device applications. First, its high electron mobility allows it to be used for the design of high speed electronic dev. ices. Second, its bandgap energy encompasses the useful $1 \mu$ to $2 \mu$ range, which is desirable for low-loss optical waveguides.

The room temperature lattice parameter for $\operatorname{In}_{x} \mathrm{Ga}_{1-x}$ As varies linearly between $0.5653 \mathrm{~nm}(\mathrm{GaAs})$ and $0.6058 \mathrm{~nm}$ (InAs). The lattice parameter for $\mathrm{PtAs}_{2}$ is $0.5967 \mathrm{~nm}$, which corresponds to $\operatorname{In}_{.78} \mathrm{Ga}_{22}$ As. Unfortunately, growth of this composition is impossible without a heavily defected structure, because of the large lattice mismatch. $\operatorname{In}_{\mathrm{x}} \mathrm{Ga}_{1-\mathrm{x}} \mathrm{As}$ can be grown epitaxially on $\mathrm{InP}$ at a composition of $\operatorname{In}_{.53} \mathrm{Ga}_{47} \mathrm{As},\left(\mathrm{a}_{\mathrm{o}}=\right.$ $.587 \mathrm{~nm}, \mathrm{E}_{\mathrm{g}}=0.75 \mathrm{eV}$ ). At this composition, the lattice mismatch with $\mathrm{PtAs}_{2}$ is $1.7 \%$, which is low enough for epitaxial growth.

\section{Intermetallics}

Other compounds that are likely to form during $\mathrm{Pt} / \mathrm{In}_{\mathrm{x}} \mathrm{Ga}_{1-\mathrm{x}}$ As reactions are those that are encountered in $\mathrm{Pt} / \mathrm{GaAs}$ [KM75, CO74, CC75, Sl78, FO83, SA87a], $\mathrm{Pt} / \mathrm{GaP}$ [SI78], and $\mathrm{Pt} / \mathrm{InP}$ [BS83, OL89] reactions: $\mathrm{PtGa}$ and $\mathrm{PtIn}_{2}$. Both are cubic phases, with lattice parameters of $.491 \mathrm{~nm}$ and $.637 \mathrm{~nm}$, respectively [VI85]. The crystal structure of $\mathrm{PtGa}$ is the FeSi structure, while $\mathrm{PtIn}_{2}$ forms in the fluorite structure, which consists of a Pt FCC lattice with indium atoms filling all of the tetrahedral sites. Both lattice parameters are well outside the range of the $\operatorname{In}_{x} \mathrm{Ga}_{1-x}$ As substrate.

Ternary phases may be encountered between the expected reaction products. In the case of $\mathrm{PtGa}$, the corresponding In phase is PtIn. This phase is monoclinic, which makes extensive solid solutions between these phases unlikely. In the case of $\mathrm{PtIn}_{2}$, the corresponding Ga-based phase, $\mathrm{PtGa}_{2}$, has the identical fluorite crystal structure, with a lattice parameter of $.592 \mathrm{~nm}$, so some solubility of the two phases is expected. Introduction of $\mathrm{Ga}$ in $\mathrm{PtIn}_{2}$, for example, should reduce the lattice mismatch with 
$\operatorname{In}_{\mathrm{x}} \mathrm{Ga}_{1-\mathrm{x}}$ As.

\section{Morphology}

During $\mathrm{Pt} / \mathrm{GaAs}$ reactions, $\mathrm{PtAs}{ }_{2}$ forms with a strong orientation relationship on the CaAs substrate [SI73, KM75, FO83], although the cube axes of the two phases are not parallel. This also occurs in the $\mathrm{Pt} / \mathrm{InP}$ system, where $\mathrm{PtP}_{2}$ exhibits texturing with the InP substrate, $[\mathrm{OI}, 89]$. In both $\mathrm{Pt} / \mathrm{GaAs}$ and $\mathrm{Pt} / \mathrm{InP}$, the lattice mismatch between the substrate and $\mathrm{Pt}-\mathrm{B}^{\mathrm{V}}$ phase is rather high (5.4\% and $2.9 \%$, respectively), diminishing the likelihood of epitaxial growth.

The symmetry of the dipnictides is lower than that of $\mathrm{A}^{\mathrm{III}} \mathrm{B}^{\mathrm{V}}$ substrates. As a consequence, four different variants are expected when (100) $\mathrm{PtAs}_{2}$ is grown on (100) $\mathrm{In}_{\mathrm{x}} \mathrm{Ga}_{1-\mathrm{x}} \mathrm{As}$ surfaces. The crystal structure of the $\mathrm{Pt}$ dipnictide phases consists of an FCC Pt sublattice, with all the octahedral sites filled with pairs of $\mathrm{B}^{\mathrm{V}}$ atoms. While the FCC Pt sublattice is invariant under the symmetry operations of the substrate, the $\mathrm{B}^{\mathrm{V}}$ sublattices are not. The $\mathrm{Pt}$ atoms will form a continuous lattice across the domain boundaries when the dipnictide phase forms with a specific orientation relationship with the substrate (e.g. its cube axes parallel to the substrate cube axes). Thus, different domains arise from the four possible variations of $\mathrm{B}^{\mathrm{V}}$ orientations within this sublattice. The domain boundaries are likely to consist of $\mathrm{B}^{\mathrm{V}}$ point defects.

\subsection{Phase Separation}

Phase separation during metal/semiconductor interactions is critical for producing a desirable interface structure. The various product phases will likely have different electrical characteristics; if more than one are present at the contact interface, nonuniformity of the electrical properties will result. The product phases may have different crystal structures; if one has a tendency to form epitaxially on the substrate, another phase may intrude and disrupt the crystallinity. By understanding the reasons 
for layering, better control of interfacial uniformity is possible. Vertical segregation of phases can be affected by a number of factors, including variations in solubility limits, deposition thickness, and variations in diffusivities.

\section{Solubility}

The existence of multiple elements in the compound semiconductor substrate provides one possibility for vertical phase separation. If the substrate elements have different solubility limits in the metal overlayer, then an excess of the lower solubility element could develop at the substrate/reacted layer interface. In the case of $\mathrm{Pt} / \mathrm{GaAs}$, Kumar [KM75] has shown that the Ga saturates the $\mathrm{Pt}$, leaving an excess of As to react at the interface. Both of the group III elements in this study have substantially greater solubility in $\mathrm{Pt}$ than As (over the temperature range $400-800^{\circ} \mathrm{C}$ ): $\mathrm{Ga} \sim 6$ atomic $\%$, In $\sim 3$ atomic $\%$, As negligible (figure 4.1.a, b and c, (MF87]). Consequently, more $\mathrm{Ga}$ and In than $\mathrm{As}$ can dissolve in the Pt, leaving an excess of As at the interface to react and form $\mathrm{Pt} \ddot{A s}_{2}$, as in the case of GaAs substrates.

\section{Thickness}

The thickness of the initial metal derosition can have a profound effect on the reacted morphology $[\mathrm{SA} 87 \mathrm{~b}, \mathrm{YU} 8 \mathrm{z} \mathrm{a}\}$. If the grain size of the reaction products is greater than the layer thickness, then the vertical segregation cannot occur. In this case, the reaction products would be laterally separated, i.e. intermingled. Yu, et al. demonstrated this behavior in the $\mathrm{Rh} / \mathrm{GaAs}$ system by annealing thin $(15 \mathrm{~nm})$ and thick (60nm) films (YU87a). They found lateral segregation of the RhGa, RhAs, and $\mathrm{RhAs}_{2}$ reaction products in the thin film, and vertical segregation $\left(\mathrm{RhGa}_{\mathrm{RhAs}} / \mathrm{GaAs}\right)$ in the thick film. 


\section{Native Oxides}

Native uxide layers are present on the surface of all chemically-cleaned semiconductors (W185). In general, these are detrimental to interfacial reactions, but some metals (e.g. $\mathrm{Pt}$ and $\mathrm{Pd}[\mathrm{SA} 87 \mathrm{a}]$ ) have been shown to be effective in penetrating this layer. It is unclear what effect the presence of a native oxide layer will have on the phase segregation. There is evidence that the oxide layer acts as a diffusion filter; Auger studies of $\mathrm{Pt} / \mathrm{GaAs}$ indicate that residual oxide remains at the boundaries between the segregated phases in the reacted microstructure [CC75, SA87a]. If this is indeed the case, the presence of a native oxide layer may aid phase segregation during the $\mathrm{Pt} / \mathrm{In}_{\mathrm{x}} \mathrm{Ga}_{1-\mathrm{x}}$ As reaction.

\section{Sublimation}

One technique that could eliminate some of the reaction products is anneal uncapped specimens. This allows volatile As or As compounds to sublime, resulting in the formation of only metal-IIl phases. Selective desorption can be useful if the As compounds in the system give rise to unwanted microstructures, or have undesirable electrical properties. Studies of uncapped Co/GaAs [PA87] and Pd/GaAs [SA87b] have demonstrated the viability of this technique. Decomposition of the substrate is undesirable, however, so it must be protected by encapsulation of the backside of the wafer, or by keeping the annealing temperature low.

\section{Diffusivity}

Probably the most important reason for phase segregation in these systems is variation in the diffusion coefficients, or diffusivities, of the elements involved in the reactions (e.g. SA87b, PA87). The elements with the higher diffusivities will diffuse more rapidly down the chemical potential gradient, leaving an excess of the slower diffusing elements behind. This will give rise to local variations in the concentration, which will lead to variations in the phase formation. The diffusion of species in thin 
films is very important to this study, and is the subject of the next section.

\subsection{Diffusion [SW69, PT81, SM81]}

Diffusion is the fundamental process by which a systern transports material to lower its free energy. If the chemical potential of an element varies within a sample (as might occur for variations in concentration), the system is not in equilibrium. Natural processes will occur to diminish the chemical potential gradient to zero, and bring the system in to a stable, low-energy configuration.

The natural process is known as diffusion. Atomistically, diffusion can be modelled by considering the local oscillations of an atom around its lattice site. When the amplitude of the vibration is sufficient, the atom can jump into an adjacent vacant site. The jump frequency, $\Gamma$, can be described by:

$$
\Gamma=z \omega \exp \frac{-\Delta G_{m}}{k T}
$$

where $z$ is the number of available vacant sites, $\omega$ is the vibrational frequency of the atom, and $\Delta G_{m}$ is the activation energy for the migration of the atom. From equation 4.1 , it is evident that an increase in temperature will cause an increase in the jump frequency.

Diffusion occurs when these jumps give rise to a net flux of atoms. For the case of a one-dimensional system, the magnitude of the flux of $B$ atoms in a medium $\alpha$ is given by Fick's first law:

$$
\mathrm{J}_{\mathrm{B}}\left(\text { atoms } \mathrm{m}^{-2} \mathrm{~s}^{-1)}=\cdots \mathrm{D}_{\mathrm{B}}^{\alpha} \frac{\partial \mathrm{C}_{\mathrm{B}}}{\partial \mathrm{x}}\right.
$$

The quantity $D$ is defined as the diffusivity, and is given by $\Gamma$ multiplied by several factors:

$$
D=D_{0} \exp \frac{-\Delta H_{m}}{k T}
$$


The entropy component of the activation energy, $\Delta S_{m}$ is brought out as a preexponential factor which does not depend on temperature:

$$
\mathrm{D}_{\circ} \equiv \lambda z \omega \exp \frac{\Delta \mathrm{S}_{\mathrm{m}}}{\mathrm{k}}
$$

$\lambda$ represents geometric factors which are determined by the lattice and the diffusion mode. The diffusivity is an important measure of how easily an atom can diffuse through the matrix. Note that this quantity decreases as $\Delta H_{m}$ increases, thereby reducing the flux. However, $D$ increases exponentially with temperature, at a rate which is proportional to $\Delta H_{\mathrm{m}}$.

The mechanism by which diffusion occurs can be divided in to three regimes: bulk, grain boundary, and dislocation. In the bulk, the diffusing specie moves through the crystal lattice primarily by either exchanging with vacancies, or via interstitial sites. The activation energy is rather high for this diffusion mode, hence bulk diffusion predominates at higher temperatures, where the activation energy is available. The looser atomic configuration of grain boundaries results in a lower activation energy if atoms diffuse along this path. At intermediate temperatures (below $\sim 0.75$ of the melting temperature of the medium), grain boundary diffusion can dol.inate. At lower temperatures (below $\sim 0.5 \mathrm{~T}_{\mathrm{M}}$ ), diffusion along dislocation pipes can become the domin ant mode.

The density of high-diffusivity paths (grain boundaries and dislocation pipes) must be considered when comparing the predominance of these three modes. Even if the activation energy for diffusion is very low, there must be a sufficient number of diffusion paths available for the mode to be significant. The total area through which diffusion can occur must be taken into account when evaluating the amount of diffusion that occurs by a given mode. For a polycrystalline sample, the cross-sectional area available in a grain for lattice diffusion is $d$, the grain size, while the crosssectional area available for boundary diffusion is $\delta$, the width of the grain boundary $(\sim 0.5 \mathrm{~nm})$. In order to compare the relative contributions by these two mechanisms, 
the diffusion coefficients must be scaled by the area available for diffusion:

$$
\mathrm{D}_{\mathrm{T}}=\mathrm{D}_{\mathrm{i}}+\frac{\delta}{\mathrm{d}} \mathrm{D}_{\mathrm{g} \cdot \mathrm{b}}
$$

As the temperature decreases the lattice diffusivity, $D_{l}$, decreases more rapidly than $\mathrm{D}_{\mathrm{g}, \mathrm{b}, ;}$ therefore, diffusion via grain boundaries will make a more significant contribution to the total flux. Similar analysis results in an expression for diffusion along dislocations, with a cross-sectional area per unit bulk area of g:

$$
\mathrm{D}_{\mathrm{T}}=\mathrm{D}_{\mathrm{l}}+\mathrm{gD}_{\mathrm{d}}
$$

It should be noted that all three types of diffusion will be occurring at all temperatures, but with varying prevalence, depending on their activation enthalpy, $\Delta \mathrm{H}_{\mathrm{m}}$, and the density of the appropriate diffusion paths. Estimates of relative contributions for lattice and grain boundary diffusion for possible product phases in the $\mathrm{Pt} / \operatorname{In}_{\mathrm{x}} \mathrm{Ga}_{1-\mathrm{x}} \mathrm{As}$ system are provided in Table I. These calculations are based on approximations for lattice vs. grain boundary diffusivities by Gupta [GP85] for pure metals.

As the complexity of a system increases, multiple species and mechanisms can contribute to the total flux. The concept of an effective diffusion constant, $D_{\text {eff }}$, which reflects a combination of all the active diffusivities must be introduced. The active modes may include diffusion through different media, or of different species, or by different mechanisms. 


\begin{tabular}{|c|c|c|c|c|}
\hline Phase & $T_{m}(K)$ & $D_{l}\left(\mathrm{~cm}^{2} \mathbf{s}^{-1}\right)$ & $D_{\mathbf{g} . \mathbf{b}}\left(\mathrm{cm}^{2} \mathbf{s}^{-1}\right)$ & $R$ \\
\hline $\mathrm{Pt}$ & 2042 & $2 \times 10^{-23}$ & $9 \times 10^{-17}$ & $2 \times 10^{-5}$ \\
\hline $\mathrm{PtAs}_{2}$ & $1795^{*}$ & $8 \times 10^{-21}$ & $9 \times 10^{-15}$ & $9 \times 10^{-5}$ \\
\hline $\mathrm{PtIn}_{2}$ & 1312 & $2 \times 10^{-15}$ & $7 \times 10^{-11}$ & $2 \times 10^{-3}$ \\
\hline $\mathrm{PtGa}_{2}$ & 1205 & $3 \times 10^{-14}$ & $5 \times 10^{-10}$ & $5 \times 10^{-3}$ \\
\hline $\mathrm{PtGa}_{\mathrm{P}}$ & 1377 & $3 \times 10^{-16}$ & $2 \times 10^{-11}$ & $2 \times 10^{-5}$ \\
\hline
\end{tabular}

* estimated.

\section{Table I}

Estimates of the relative contribution of lattice and grain boundary diffusivities at $400^{\circ} \mathrm{C}$. Calculated using equation 4.3 , and the approximations for diffusion parameters by Gupta [GP85] for pure metals: $\Delta \mathrm{H}_{\mathrm{m}}^{1}(\mathrm{cal} / \mathrm{mole})=34 \mathrm{~T}_{\mathrm{M}}(\mathrm{K}), \Delta \mathrm{H}_{\mathrm{m}}^{\mathrm{g}} \mathrm{b}=25 \mathrm{~T}_{\mathrm{M}}$, $\mathrm{D}_{0}^{!}=0.5\left(\mathrm{~cm}^{2} \mathrm{~s}^{-1}\right), \mathrm{D}_{0}^{\mathrm{g}} \mathrm{b} .=3.1, \delta=0.5 \mathrm{~nm}$, and $\mathrm{d}=50 \mathrm{~nm}$. $R$ refers to the ratio:

$$
R=\frac{D_{1}}{\frac{\delta}{d} D_{g} b}
$$




\section{The Diffusion Couple}

The simplest case for the development of layering during reaction is that of the diffusion couple. In this experiment, samples of two different materials, $A$ and $B$, are welded together, and allowed to interdiffuse. After a suitable amount of time, interdiffusion will give rise to a concentration gradieat in the system as shown in Figure 4.2. If intermediate $A: B$ compounds are possible in the system, they will develop in the appropriate concentration range. A layering sequence, which is a consequence of the starting geometry of the system, will re It.

In a multiphase system, the reaction interface can be defined as the interface where the $A$ and $B$ elements meet and react to form intermediate compounds. the position of the interface is determined by the diffusivities of $A$ and $B$ atoms in the appropriate medium. If $\mathrm{D}_{\mathrm{B}}^{\alpha}<<\mathrm{D}_{\mathrm{A}}^{\alpha}$, for example, then the reaction will occur at the B-rich interface, and vice versa. Reactions can occur simultaneously at more than one in terface.

\section{Segregation in $\mathrm{Pt} / \mathrm{In}_{\mathrm{x}} \mathrm{Ga}_{1-\mathrm{x}}$ As}

$\mathrm{Pt} / \mathrm{GaAs}$ and $\mathrm{Pt} / \mathrm{In} \mathrm{P}$ have very similar reaction behavior. Both react to form layered structures with a $\mathrm{Pt}-\mathrm{B}_{2} \mathrm{~V}$ phase at the substrate/reacted layer interface, and a $\mathrm{Pt}-\mathrm{A}^{\mathrm{III}}$ phase at the surface. In the $\mathrm{Pt} / \mathrm{GaAs}$ case, this structure is evident even at low annealing temperatures, while the $\mathrm{Pt}, \mathrm{In}$, and $\mathrm{P}$ are completely intermixed for $\mathrm{Pt} / \mathrm{InP}$ until higher temperature anneals. The differences between the $\mathrm{Pt} / \mathrm{GaAs}$ and $\mathrm{Pt} / \mathrm{In} \mathrm{P}$ cases may be attributed to the different diffusivities of the elements involved. In the case of $\mathrm{Pt} / \mathrm{GaAs}$, the Ga diffuses out from the substrate at fairly low temperature $[\mathrm{SI} 73, \mathrm{CC} 75]$, with the remaining As reacting with the $\mathrm{Pt}$ overlayer to form $\mathrm{PtAs} \mathrm{s}_{2}$. In the case of $\mathrm{Pt} / \mathrm{InP}$, the diffusion of $\mathrm{In}$ in to the overlayer does not dominate, allowing the formation of intermixed phases until high temperature anneals [OL89]. 


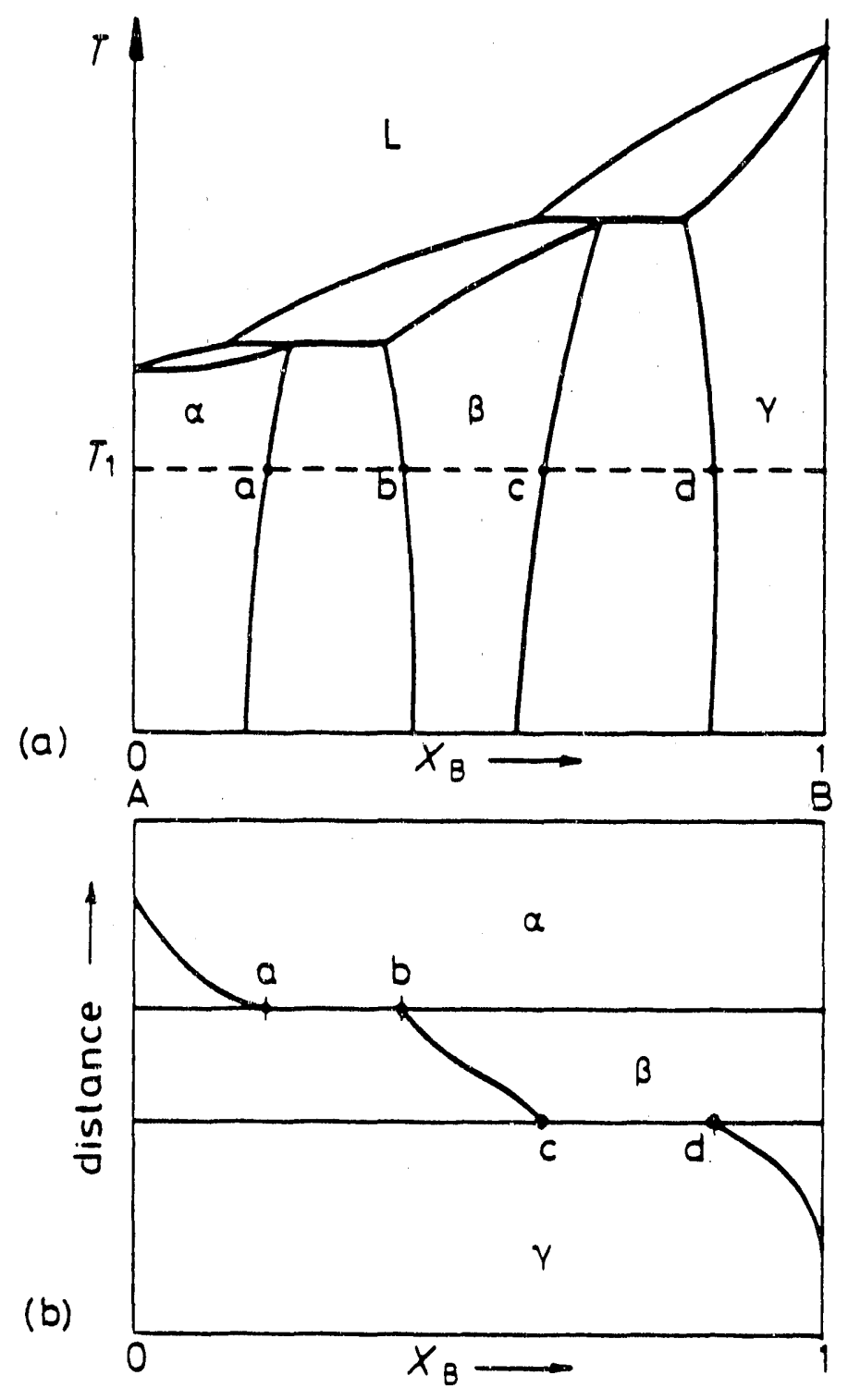

Figure 4.2: Sequence of phase formation that results from a diffusion couple (after reference $[\mathrm{PT} 81\}$, page 104$)$. 
In the case of $\mathrm{Pt} / \mathrm{In}_{\mathrm{x}} \mathrm{Ga}_{1-\mathrm{x}} \mathrm{As}$, the relative diffusivities of the components becomes very important because of the number of elements involved. If a continuous $\mathrm{PtAs}_{2}$ layer is to be formed at the substrate/reacted layer interface, both $\mathrm{Ga}$ and In must diffuse in to the overlayer. Based on previous studies [SI73, OL89], the ratio of the diffusivities of $\mathrm{Ga}$ to $\mathrm{Pt}$ should be greater than the ratio of In to $\mathrm{Pt}$. This indicates that the interface should be free of $\mathrm{Pt}-\mathrm{Ga}$ phases, but may contain $\mathrm{Pt}$-In phases. As the In concentration of the substrate increases, the lattice compatibility of $\mathrm{PtAs}_{2}$ and $\mathrm{In}_{\mathrm{x}} \mathrm{Ga}_{1-\mathrm{x}}$ As will improve, but the potential for intrusion of $\mathrm{Pt}_{\mathrm{t}-\mathrm{In}}$ phases will increase. There are several experimental parameters which should contribute to the segregation of the $\mathrm{Pt}$-In phases, which rely on selecting reaction conditions that enhance $\mathrm{Pt}, \mathrm{Ga}$, and In diffusion, and inhibit As diffusion.

The first parameter which may induce segregation by unequal diffusivities is the annealing temperature. It may be possible to select a high enough temperature which will allow for significant $\mathrm{Ga}$, In, and $\mathrm{Pt}$ diffusion, but minimal As outdiffusion. There is experimental evidence which supports this approach. Even when $\mathrm{Pt} / \mathrm{GaAs}$ thin films are annealed over a range of temperatures $\left(300-600^{\circ} \mathrm{C}\right)$, the layered $\mathrm{Pt}$ $\mathrm{Ga}^{\prime} \mathrm{PtAs} \mathrm{S}_{2} / \mathrm{GaAs}$ structure is maintained [KM75, SA87b]. This suggests that the impetus for $\mathrm{PtAs}_{2}$ segregation at the interface is somewhat insensitive to temperature. In the $\mathrm{Pt} / \mathrm{InP}$ system, phase segregation has been observed as low as $500^{\circ} \mathrm{C}$, and becomes much more pronounced as the annealing temperature is increased to $600^{\circ} \mathrm{C}$ [OL8y]. By annealing $\mathrm{Pt} / \mathrm{In}_{\mathrm{x}} \mathrm{Ga}_{1-\mathrm{x}} \mathrm{As}$ at higher temperatures, it is possible that suitable phase segregation will be obtained.

Diffusion rates are affected by other iactors than temperature. The mechanism (e.g. grain boundary vs. bulk diffusion) will also determine the rate of diffusion. The dominant diffusion mechanism may vary for the four elements involved. For example, changing the ratio $\delta / \mathrm{d}$ by changing the average grain size of the polycrystalline $\mathrm{Pt}$ layer may alter the relative diffusion rates of the components. The grain size can be changed by varying the substrate temperature during deposition (e.g. [CP69]). The 
disadvantage of relying on grain boundary diffusion is that the interface will not be smooth; the reaction will proceed preferentially along the grain boundaries.

\subsection{Kinetics}

The kinetics of the thin film reaction is important, as the contact structure will always be thermodynamically unfavorable. This is because of the concentration gradients necessary to obtain the desired electrical properties. Consequently, a "stable" contact is really one in which the interdiffusion and interactions are much slower than the processing time and projected lifetime of the device. By slowing the reaction kinetics, the lifetime of the device can be extended.

According to the analysis done by Kidson [KD61], the growth of a $\beta$ product layer of thickness $x$ from $\mathrm{A}$ and $\mathrm{B}$ phases can be described by the following equation:

$$
\mathrm{dx} / \mathrm{dt}=\frac{\mathrm{G} \Delta \mathrm{C} \kappa}{\left(1+\mathrm{x} \kappa / \mathrm{D}_{\mathrm{eff}}\right)}
$$

where $G$ is a constant dependent on the composition of the reactant and product phases, $\Delta \mathrm{C}$ is the difference in composition between the $\mathrm{A} \beta$ and $\beta \mathrm{B}$ interfaces, and $\kappa$ is the effective interfacial reaction barrier, which depends on the individual reaction constants at the two interfaces.

Equation 4.7 can be divided into two regimes by the parameter $\mathrm{x}^{*}=\mathrm{D}_{\mathrm{eff}} / \kappa$ :

$$
\mathrm{dx} / \mathrm{dt} \sim \mathrm{G} \Delta \mathrm{C} \kappa, \text { for } \mathrm{x}<<\mathrm{x}^{*}
$$

and

$$
\mathrm{dx} / \mathrm{dt} \sim \mathrm{G} \Delta \mathrm{C} \kappa / \mathrm{x}, \text { for } \mathrm{x}>>\mathrm{x}^{*}
$$

These equations can be integrated to give the dependence of the layer thickness on time:

$$
x \sim t
$$

and 


$$
x^{2} \sim t
$$

This result shows that for sufficiently small values of $x$, any system will be dominated by interface reactions, until a changeover thickness of $x^{*}$ (which depends on the ratio between the diffusivity and reaction rate) is reached, after which diffusion effects will dominate.

\subsubsection{Interface Controlled}

The significance of the two regimes in equations $4.9 \mathrm{a}$ and $\mathrm{b}$ can be explained as follows. When a reaction involves the growth of a phase which the reactant must diffuse through, there are two components of "resistance" that the moving species will experience. When atoms arrive at a phase boundary, they experience a resistance to movement across the interface. When diffusing through the growing medium, they also experience resistance. When the resistance to crossing the boundary dominates (as in the early stages of a reaction), the kinetics are interface controlled, and linear growth may be observed, i.e. $x=C t$, where $x$ is the reaction variable (i.e. some measure of the progress of the reaction, such as $x=1-h$, where $h$ is the thickness of unreacted material).

\subsubsection{Diffusion Controlled}

When the diffusion resistance dominates, the kinetics of the metal/semiconductor reaction are parabolic, i.e. $x^{2} \sim D_{\text {eff }}$. This is the behavior exhibited by many metal/semiconductor reactions (e.g. [OT86, YU87b|, including Pt/GaAs [CO74]). Plots of $x^{2}$ vs. $t$ will appear as straight lines under these conditions, with the slope $~$ $\mathrm{D}_{\mathrm{eff}}$.

There are complications of this simple model which must be considered, such as the development of intermediate layers, or change in the diffusion path during the reaction. 


\section{Intermediate Layers}

Sequential grow'th of intermediate layers could give rise to deviations from simple parabolic growth, even when the kinetics are diffusion controlled. If the reactant $A$ is initially diffusing through the phase $\alpha$, the diffusivity is $D_{A}^{\alpha}$. If an intermediate layer of phase $\beta$ develops and becomes continuous, then the diffusion should be described by $D_{A}^{\beta}$ as well. If $D_{A}^{\alpha}<<D_{A}^{\beta}$, then a plot of the reaction rate would exhibit two different slopes in the two regimes. If the two diffusivities are similar, the change in slope of $x^{2}$ vs. $t$ will be less distinct, and $D_{\text {ell }}$ may involve a combination of $D_{A}^{\alpha}$ and $D_{A}^{\beta}$ 
Stage 1

\begin{tabular}{|c|c|c|}
\hline$A B$ & ${ }^{\mathrm{B}}$ & \multirow[t]{2}{*}{$\bar{C}$} \\
\hline & B & \\
\hline
\end{tabular}

$A+C \rightarrow \gamma$

Stage II

\begin{tabular}{l|l|l|l}
\hline$A B$ & $B$ & $\gamma$ & $C$ \\
& & & \\
& $A$ & $A$ \\
\hline
\end{tabular}

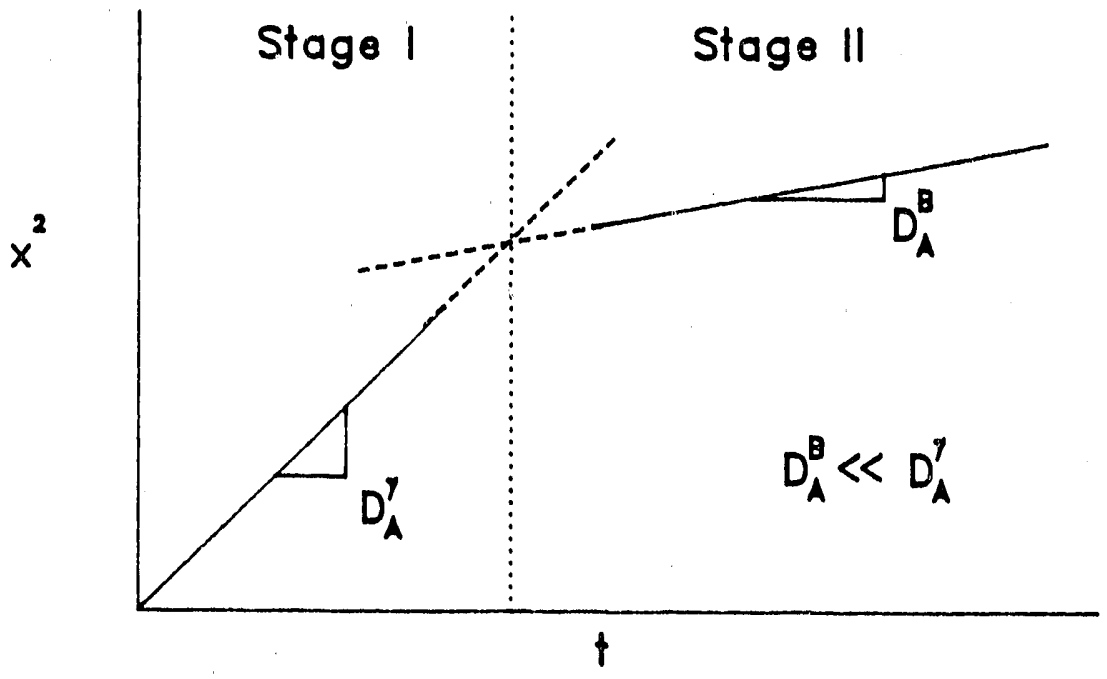

Figure 4.3: Schematic of the effect of the formation of a new phase on the diffusivity in a system. A reacts with $\mathrm{C}$ to form the $\gamma$ phase, leaving $\mathrm{B}$ behind which eventually forms a continuous layer. Diffusion through the $\gamma$ phase dominates the kinetics in the initial stage of the reaction. If $D_{A}^{B}<<D_{A}^{\gamma}$, diffusion through the $B$ layer will dominate at later stages. 


\section{Grain Growth}

The annealing temperature of these experiments is kept at a level where bulk diffusion is unlikely to be the dominant mode (see Table I). The low temperature is necessary to avoid decomposition of the compound semiconductor substrates. Consequently, grain boundary diffusion is likely to be significant, which requires that grain growth be considered. If the dominant mode of diffusion is through grain boundaries, and the grains are growing during diffusion, the density of grain boundaries and hence the ratio $\delta / d$ will decrease. This will cause the diffusion rate to fall below $x^{2} \sim D t$.

Studies on the growth of superconducting A-15 compounds have shown a less than parabolic growth rate $[\mathrm{FH} 74]$. In the case of $\mathrm{Nb}_{3} \mathrm{Sn}$, the compound is grown by solid-phase reaction of pure $\mathrm{Nb}$ with $\mathrm{Cu}-\mathrm{Sn}$ alloys. The process relies on grain boundary diffusion through the polycrystalline $\mathrm{Nb}_{3} \mathrm{Sn}$ product layer. Farrell, et al., suggested that the deviation from parabolic growth could be attributed to coarsening of this product layer. As the $\mathrm{Nb}_{3} \mathrm{Sn}$ grains grow, the density of diffusion paths diminishes. In a subsequent paper, Farrell, et al. (FH75), derived an expression for the reaction kinetics, which takes into account the competition between grain growth and layer growth. Assuming the following time dependence of the grain size, L, on time:

$$
\overline{\mathrm{L}^{2}}=\lambda \mathrm{t}^{\mathrm{m}}
$$

where

$$
\lambda=\lambda_{0} \exp \left(-Q_{\mathrm{L}} / \mathrm{kT}\right)
$$

Farrell, et al. derived the following to describe the layer thickness as a function of time:

$$
\mathrm{x} \sim\left(\frac{\mathrm{D}_{\mathrm{eff}}}{\lambda}\right)^{0.5} \mathrm{t}^{(1-\mathrm{m}) / 2}
$$

That is, the growth rate of the layer of $x \sim t^{k}$ can be reduced by an amount corresponding to the rate of grain growth. Evidence of this type of time dependence has been found in metal/semiconductor systems, for titanium silicide growth [CR91]. 


\subsection{Diffusion Barriers}

Many contact structures are thermodynamically unstable (NI81). Different materials are brought into contact, each of which satisfy some requirement of the whole structure. The two materials are not generally inert with respect to each other, and can interact to degrade the contact characteristics. An intermediate layer can be introduced to the system to inhibit interactions, but because of the inherent instability of the structure, a diffusion barrier can only slow down undesirable interactions. Diffusion barriers can be introduced in to the system to inhibit undesirable interactions and to extend the lifetime of the device.

There are several requirements that a material must satisfy in order to function as a diffusion barrier (see (NI81, NI78) for review): a) atomic transport across the layer should be very low. Because the thickness of contact structures is measured in tenths of microns, defect (rather than bulk) diffusion dominates the material transport. Therefore, control of the extended defects (e.g. grain boundaries) present in the contact layers can greatly reduce the diffusion through the barrier; b) the barrier should be thermodynamically stable with respect to the adjacent compounds, with low mutual solubilities; c) the barrier should adhere well to the adjacent compounds; d) the barrier should have electrical and mechanical properties which do not reduce the behavior of the sy'stem below that which necessary for proper operation. Satisfying all of these requirements simultaneously is practically impossible, so any diffusion barrier will have to be a compromise.

All of the phases which are likely to form in the $\mathrm{Pt} / \mathrm{In}_{\mathrm{x}} \mathrm{Ga}_{1-\mathrm{x}}$ As system have absolute melting temperatures above $1000 \mathrm{~K}$. In order to be inside the grain boundary dominated diffusion regime, the annealing temperature must be $<.75 \mathrm{~T}_{\mathrm{M}}[\mathrm{PT} 81]$. The temperatures corresponding to this boundary are shown in Table II. The data indicates that for all of the likely product phases, grain boundary diffusion should dominate up to $\sim 600^{\circ} \mathrm{C}$. Since the reaction products are stable on $\mathrm{In}_{\mathrm{x}} \mathrm{Ga}_{1-\mathrm{x}} \mathrm{As}$, they already satisfy one of the most important requirements for a diffusion barrier. As grain 


\begin{tabular}{|c|c|c|}
\hline Phase & $\mathbf{T}_{\mathbf{m}}(\mathbf{K})$ & $0.75 \mathbf{T}_{\mathbf{M}}\left({ }^{\circ} \mathbf{C}\right)$ \\
\hline $\mathrm{Pt}$ & 2042 & 1259 \\
\hline $\mathrm{PtAs}_{2}$ & $1795^{*}$ & 1073 \\
\hline $\mathrm{PtIn}_{2}$ & 1312 & 711 \\
\hline $\mathrm{PtGa}$ & 1205 & 631 \\
\hline $\mathrm{PtGa}$ & 1377 & 760 \\
\hline
\end{tabular}

* estimated.

\section{Table II}

Comparison of melting temperatures of product phases in the $\mathrm{Pt} / \mathrm{In}_{\mathrm{x}} \mathrm{Ga}_{1-\mathrm{x}}$. As system, and the temperature below which grain boundary diffusion is expected to dominate the flux. 


\subsection{EXPERIMENT}

\subsection{The Contact Metallurgy Experiment}

The metallurgical behavior of a given metal/semiconductor couple can be examined with a simple experiment: the metal is deposited on to the substrate, the sample is annealed, and the metal/ semiconductor interactions are evaluated. Despite its simplicity, there are some important issues which must be considered when designing the contact metallurgy experiment.

Metal contacts on semiconductors are inherently non-equilibrium structures. Large concentration gradients are necessary for two reasons. First, the properties of the structure must change quickly from a conductor to a semiconductor. Second, the presence of the contact elements in the substrate are generally undesirable. Large interfacial area to volume ratios exist within the microstructure, because of the thickness of the films (hundreds of nanometers) and the fine-grained microstructures (tens of nanometers) often encountered. Coupled with these large thermodynamic driving forces in the system are kinetically favorable reaction conditions; short diffusion distances necessary to saturate the film, and high diffusivity paths in the form of grain boundaries.

The problems associated with the non-equilibrium nature of the contact can be diminished by controlling the thermal history of the device. A thermal budget can be defined as the maximum time at temperature which a device structure can withstand without degradation of its properties below given values. Once the thermal budget of the device is set to some reasonable value, the conditions for a viable contact structure can be engineered.

When determining the conditions for a contact metallurgy experiment, the parameters must reflect the non-equilibrium nature of the contact; the stable or end phases are those which remain unchanged after exposure to typical fabrication conditions (i.e. 
the thermal budget). Thermodynamic phase diagrams can be used as a guideline for predicting the stable phases, but the elemental composition of the system is artificially imposed by geometry and kinetics, and will change with time, although ideally not within the projected lifetime of the device.

Another consideration is the condition of the substrate prior to deposition. All air-exposed $A^{I I I-} B^{V}$ substrates will have $1-2 n m$ of native oxide on the surface. The native oxides can be removed, but will quickly regrow during handling, and can be expected to be present on all semiconductor surfaces. This oxide can inhibit interactions of some metals with some semiconductors, but there are several potential contact metals which can penetrate the thin oxide layer. Alternately, the contact metallurgy experiment can be carried out entirely in vacuum, preparing the surface either by cleaving the substrate or by desorbing the native oxide, and depositing the metal without breaking vacuum. The cleaving experiment is particularly suited for studies of the electrical and chemical behavior of the interface, especially for very thin (monolayer) coverages. The experiment in this study was designed for thicker metal layers (tens of nanometers), with metal overlayers that are not impeded by native oxide.

The thickness of the deposition must be held constant when comparing specimens from different annealing conditions; very thick layers will take a long time to react, ard may experience intermediate states that are not achieved with thin depositions. From a practical standpoint, the deposition thickness should be thick enough to allow a suitable range of annealing times without completely consuming the pure metal layer, but not so thick that steady state conditions are not achieved. In addition, the analytical techniques (especially plan-view TEM) put an upper limit on the deposition thickness. For this experiment, a thickness of $70 \mathrm{~nm}$ has been selected.

When dealing with $\mathrm{A}^{\mathrm{III}}-\mathrm{B}^{\mathrm{V}}$ compound semiconductors, care must be taken to ensure that the system is closed during annealing. The group $\mathrm{V}$ element in these materials is quite volatile, and can be expected to evolve as a gas during high temperature annealing. For GaAs, preferential evaporation of the group $\mathrm{V}$ element can be 
expected above $657^{\circ} \mathrm{C}$, for InP, above $362^{\circ} \mathrm{C}$ [OB83]. In order to prevent decomposition of the substrate during annealing, either directly from the surface or through the grain boundaries of the deposited metal film, the samples can be encapsulated in $\mathrm{SiO}_{2}$.

\section{$5.2 \mathrm{In}_{\mathrm{x}} \mathrm{Ga}_{1-\mathrm{x}}$ As substrates}

The InAs-GaAs system was chosen for this experiment, among other things, because the substrate lattice parameter can be varied by varying the composition. Unfortunately, this makes the substrate material difficult to produce in high quality for most values $x$. Growth of a single crystal must be initiated by either a seed crystal (for Czochralski growth) or a substrate (for deposition techniques) with a lattice parameter very close to that of the desired $\operatorname{In}_{\mathrm{x}} \mathrm{Ga}_{1-\mathrm{x}}$ As crystal. When the lattice parameter of the seed deviates from that of the growing material, dislocations will be introduced to accommodate the strain. Due to a lack of seed crystals and substrates with suitable lattice parameters, $\operatorname{In}_{\mathrm{x}} \mathrm{Ga}_{1-\mathrm{x}} \mathrm{As}$ is difficult to obtain for most of the composition range.

Recent developments in crystal growth by Dr. William Bonner at Bellcore, Inc. indicate that $\operatorname{In}_{\mathrm{x}} \mathrm{Ga}_{1-\mathrm{x}}$ As will eventually be produced in bulk crystalline form, but for the purposes of this experiment, $\operatorname{In}_{\mathrm{x}} \mathrm{Ga}_{1-\mathrm{x}}$ As substrates were prepared by Molecular Beam Epitaxy (MBE) on GaAs and InP substrates. In this procedure, the appropriate substrate material is loaded in to a vacuum chamber equipped with sources of $\mathrm{As}, \mathrm{Ga}$, and In. The sources are known as effusion cells, and consist of a crucible containing the desired element, which can be heated to achieved a substantial vapor pressure. In the vacuum chamber $\left(10^{-10}\right.$ Torr), the vapor produce proceeds on a direct line-of-sight to the substrate, where it adsorbs on to the surface. Prior to the deposition procedure, the specimen is heated to a suitable temperature (above $-500^{\circ} \mathrm{C}$ ) to desorb any native oxides on the substrate surface. An overpressure of As is maintained to inhibit decomposition of the substrate during the surface preparation procedure. 
For this experiment, three compositions were used, all with (100) orientations: GaAs, In ${ }_{.15} \mathrm{Ga}_{.85}$ As (grown on GaAs), and $\mathrm{In}_{.53} \mathrm{Ga}_{{ }_{47}} \mathrm{As}$ (grown on InP). The GaAs was provided by Dr. Zïn-Man Yu of Lawrence Berkeley Laboratory (Berkeley, CA 94720). The $\operatorname{In}_{x} \mathrm{Ga}_{1-x}$ As was provided by Dr. Tim Sands and Dr. James Harbison of Bellcore, Inc (R zad Bank, NJ 07701). The $\mathrm{In}_{\mathrm{x}} \mathrm{Ga}_{1-\mathrm{x}} \mathrm{As}$ was grown on a Varian Gen II MBE system, operating at a base pressure of $5 \times 10^{-11}$ Torr. The substrates were heated to $580^{\circ} \mathrm{C}$ in an As overpressure to desorb surface oxides prior to deposition.

\subsection{Pt deposition}

Metal layers can be deposited on semiconductor substrates by a variety of means. The $\mathrm{Pt}$ metallizations in this experiment were deposited by plasma-enhanced sputtering, using a Perkin-Elmer Model 2400 radio-frequency plasma generator. An argon gas plasma was used to sputter the target material. The base pressure was $10^{-5} \mathrm{Torr}$, and the deposition pressure was $10^{-2}$ Torr.

Prior to deposition, the substrates were etched by the following procedure to remove native oxide: 2 minutes in boiling trichloroethane, 2 minutes in boiling acetone, methanol rinse, blow dry in $\mathrm{N}_{2}, 5$ minutes in de-ionized $\mathrm{H}_{2} \mathrm{O}$ :buffered HF solution (1:1), blow dry in $N_{2}$. Although 1-2nm of native oxide will regrow while the specimens are loaded in to the sputtering chamber, the etching procedure will remove previous oxides, and provide the same starting surface for all specimens. On order to ensure good cooling of the substrate during the deposition procedure, the specimens were attached to a water-cooled plate with a dental wax. The maximum temperature attained by the substrate during deposition was estimated to be less than $100^{\circ} \mathrm{C}$.

The $\mathrm{Pt}$ was deposited using a forward power of 300 watts, and a target bias of 1350 volts; which resulted in a deposition rate of $\sim 35 \mathrm{~nm} /$ minute. Following the $\mathrm{Pt}$ deposition, $\mathrm{SiO}_{2}$ was deposited using a forward power of 300 watts, and a target bias of 1100 volts; the deposition rate was $-10 \mathrm{~nm} /$ minute. The final thicknesses of the 
films were $70 \mathrm{~nm}$ of $\mathrm{Pt}, 150 \mathrm{~nm}$ of $\mathrm{SiO}_{2}$.

\subsection{Annealing}

The $\mathrm{Pt}$ and the $\mathrm{In}_{\mathrm{x}} \mathrm{Ga}_{1-\mathrm{x}}$ As substrates were annealed in flowing forming gas $\left(\mathrm{N}_{2}: \mathrm{H}_{2}, 95: 5\right)$ in a Lindburg Hevi-duty furnace, with a Eurotherm controller and an Omega type-K thermocuuple. Temperatures within the furnace were controlled to within $1^{\circ} \mathrm{C}$. Once the furnace and quartz holder reached the desired temperature, the specimen was placed on the holder and inserted in to the furnace tube. After the designated annealing time, the speciren was air-quenched. For the kinetic studies, the samples were annealed at $400^{\circ} \mathrm{C}$ for times ranging from 10 minutes to 3 hours.

\subsection{Analytical Techniques}

In order to characterize these systems, three main features were examined, including: the progression of chemical reaction as a function of the annealing schedule, the crystal structures of the reaction products, and the morphology of the reacted layer. To determine this information, four analytical techniques were used: X-Ray Diffraction (ARD), Rutherford Backscattering (RBS), Scanning Auger Microscopy (SAM), and Transmission Electron Microscopy (TEM).

\section{X-Ray Diffraction}

The X-ray diffraction was performed as a quick, non-destructive way to examine the extent of the chemical reactions which occurred during the various annealing stages. In addition, the $x$-ray spectra helped identify the phases which developed by identifying the lattice spacings present in the system. Preferred orientations in the deposited and reacted material could be observed by the intensity ratios of the peaks; deviation from predicted ratios indicates an enhancement of grains with particular orientations. XRD was also very important for determining if new phases appeared for different annealing conditions. If new phases develop, the kinetic data would be 
compromised, as different reactions would be occurring. This test was performed by comparing spectra from different times and temperatures to see if new d-spacings were present.

In this technique, a Siemens Kristalloflex X-Ray Diffractometer was used. The accelerating voltage was $40 \mathrm{KeV}$, with a tube current of $30 \mathrm{~mA}$ and a $\mathrm{Cu}$ target. A graphite crystal monochromator was used so that only peaks arising from diffraction of $\mathrm{Cu}$ $\mathrm{K} \alpha_{1,2}$ incident radiation were recorded. The $\mathrm{x}$-rays were detected with a Tl-doped $\mathrm{NaI}$ scintillation counter.

Continuous scans were taken over $2 \theta=15^{\circ}$ to $95^{\circ}$, with a step size of $0.1^{\circ}$, and a recording time of 2 seconds per step. The scans encompassed peaks down to $0.1 \mathrm{~nm}$ d-spacings. The $(100)$ oriented substrate material contributed two peaks in this range, corresponding to the $(200)$ and $(400)$ planes (GaAs: $31.6^{\circ}$ and $66.1^{\circ}$ and In ${ }_{53} \mathrm{Ga}_{47} \mathrm{As}: 30.4^{\circ}$ and $63.3^{\circ}$ ). Based on structure factor calculations, the (200) peak will be of much lower intensity than the (400), and occasionally is not visible above the signal of the reaction products. The Pt depositions show preferred (111) or (100) orientations, which was evident by the enhancement of those peaks coirpared to the standard $\mathrm{Pt}$ powder spectrum. No specimen preparation was required for the $\mathrm{x}$-ray diffraction.

\section{Rutherford Backscattering}

In order to determine the extent of the $\mathrm{Pt} / \mathrm{In}_{\mathrm{x}} \mathrm{Ga}_{1-\mathrm{x}}$ As interaction, RBS was performed. This is a non-destructive means for determining the depth distribution of the elements through the microstructure. Because of the complexity of the system, and the overlap of the signals from elements with similar atomic number ( $\mathrm{Ga}$ and As), detailed information on the distribution of elements was impossible. However, RBS was effective in giving absolute thicknesses of the remaining unreacted $\mathrm{Pt}$ and $\operatorname{In}_{\mathrm{x}} \mathrm{Ga}_{1-\mathrm{x}} \mathrm{As}$ layers. 
The thickness of the unreacted material was used to determine the reaction behavior of the system. The thickness of the reacted material is plotted versus the annealing time; for simple diffusion limited growth, the reaction rate should be parabolic: $x \sim \sqrt{ }$ Dt. In principle, these plots can also be used to determine the activation energy of the reaction. However, in this experiment, the reaction is too complex to expect a single value.

RBS spectra were obtained by $\mathrm{Dr}$. Kin Man Yu of the Lawrence Berkeley Laboratory. A $2 \mathrm{MeV}$ Van de Graaff accelerator was used to produce a $1.95 \mathrm{MeV}^{4} \mathrm{He}^{+}$beam. The backscattered protons were collected with a Si surface barrier detector located at an angle of $165^{\circ}$ with respect to the incident beam. The apparatus gave a maximum depth resolution of $\pm 5 \mathrm{~nm}$. No specimen preparation was required for RBS.

\section{Scanning Auger Microscopy}

Auger depth profiling is a destructive technique for determining the elemental distribution (and thereby the phase distribution) in the reacted structures. Auger spectra were obtained by bombarding the exposed specimen surface with an electron beam (10KeV), and recording the resultant Auger electron energies. Depth profiles were obtained by sputtering the specimen for a set time with an Ar ion beam (6 seconds at $5 \mathrm{keV}, 1 \mathrm{~mm}^{2}$ probe size), and taking a spectrum of the newly exposed surface. This procedure was repeated until the entire reacted layer was milled through (on the order of 20 minutes).

Absolute thicknesses are very difficult to determine with this technique, because of the variation in sputtering rates with changes in composition and morphology of the phases in the reacted layer. Depth profiles of elements will tend to blur the abruptness of an ideal interface, and extend the tails of the profile deeper in to the specimen. The strength of the Auger signal from each of the elements cannot be easily correlated with its concentration in the layer, as the intensity depends on the element as well as the concentration. However, the sequence of elements in the microstructure can be 
determined quite accurately. No specimen preparation was required for the Auger depth profiles.

\section{Transmission Electron Microscopy}

When several phases are present in the system, the XRD spectra are not effective in determining the phases present. For this reason, both conventional TEM and microdiffaction were used to uniquely identify the crystal structures of the product phases. TEM was also used to determine the morphology of the reaction products. Both cross-sectional and plan-view specimens were used in the TEM studies. In this study, a Philips EM 400, operating at $100 \mathrm{KeV}$ accelerating voltage was used. In order to resolve the microstructural features in this system, magnifications of 100,000 to $200,000 x$ were used.

Specimen preparation is critical for obtaining good results in TEM. In order to be transparent to the electron beam, the specimen thickness must be reduced to $<50 \mathrm{~nm}$, without introducing changes in the microstructure. Two orientations of the specimen were used to determine microstructural information. In plan-view specimens, the electron beam is normal to the original substrate surface. This orientation is useful for determining features in the plane of the reacted layer, grain size, and orientation relationships which may develop between the reacted layer and the substrate. In crosssection specimens, the electron beam is parallel to the original substrate surface. This orientation is useful for determining the depth distribution of the reaction products, and their morphology.

It should be noted that these materials are extremely fragile, so great care was taken to minimize the stress on the specimens at all stages of specimen preparation. This was especially important when handling the finished specimen.

The procedure for producing plan-view specimens in this experiment was fairly simple (figure 5.1). First the $\mathrm{SiO}_{2}$ encapsulation was removed by etching for two 

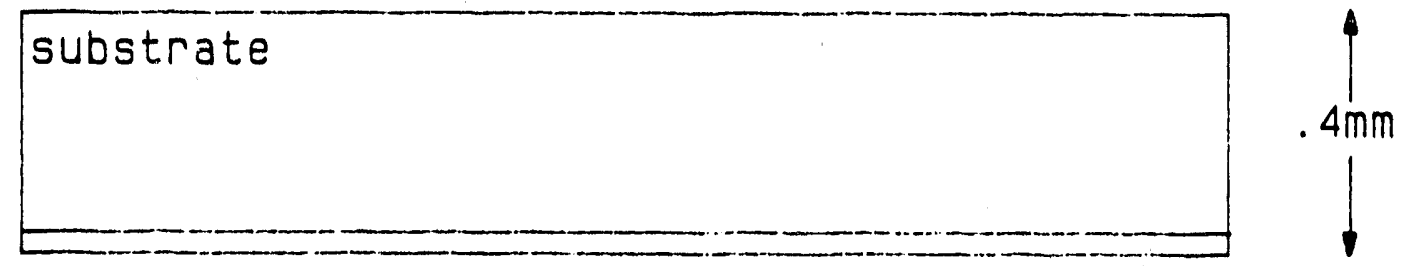

deposition

$2 \mathrm{~mm}$

a

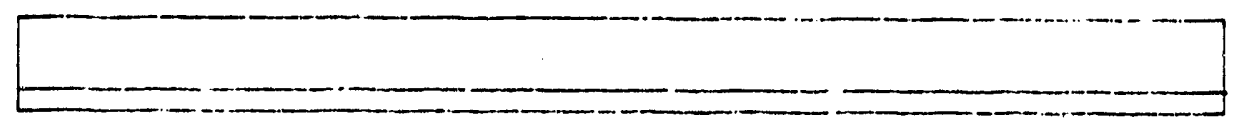

$b$
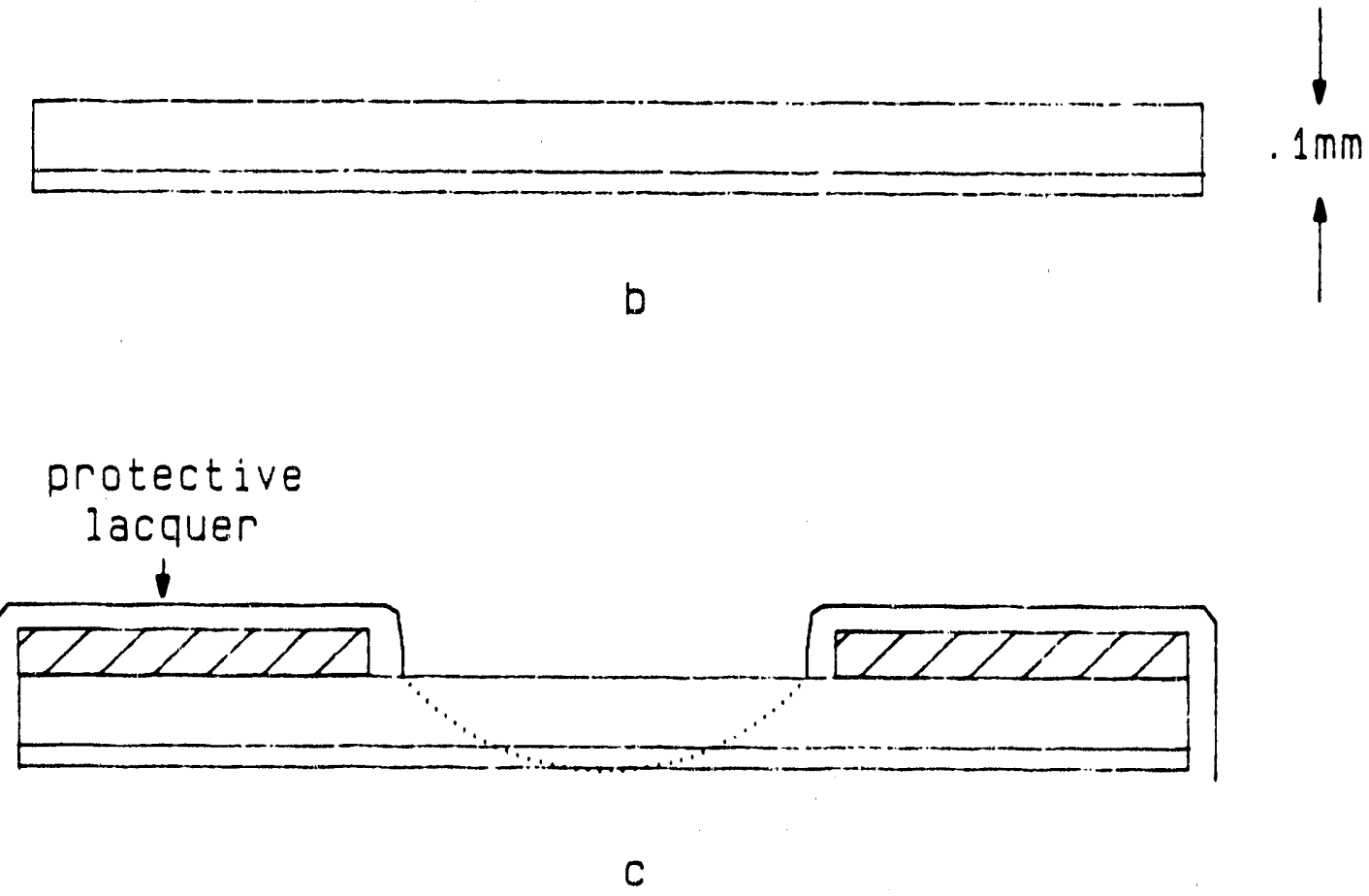

Figure 5.1: Procedure for preparation of plan-view specimens for the TEM. a. The sample is cleaved into $2 \mathrm{~mm}$ squares. b. The specimen is ground down to $1 \mathrm{~mm}$ in thickness. c. A Cu grid is epoxied to the specimen to provide structural support, then a protective lacquer is applied, and the specimen is etched. 
minutes in a solution of $\mathrm{HF}$ :de-ionized $\mathrm{H}_{2} \mathrm{O}(1: 1)$. The sample was then cut by cleaving in to $2 \mathrm{~mm}$ square specimens, which were 300 to 400 microns thick, with the deposition on one side, and the semiconductor substrate exposed on the other. The squares were then mechanically thinned down to 100 microns in thickness by removing the substrate material on a grinding wheel, with 600 grit paper. Support grids (Gilder $3 \mathrm{~mm}$ diameter, $1 \times 2 \mathrm{~mm}$ slotted $\mathrm{Cu}$ grids) were then attached to the substrate side using Devcon 2Ton Clear epoxy. During the grinding procedure, the specimens were fixed to a polishing stud with wax; this required that the specimens be exposed briefly to approximately $150^{\circ} \mathrm{C}$.

The specimens were then prepared for etching. The $\mathrm{Cu}$ support grids were protected by covering them with Tolber Miccroshield Stop-Off Lacquer. The substrate material was removed using a chlorine/methanol solution, which was prepared by bubbling chlorine through methanol until saturation. The specimens were suspended in a flow of the etching solution until the substrate was removed to perforation. At this point, most of the specimens were ready for the electron microscope. Occasionally, the etching solution did not remove enough of the reacted material; in these situations, ion milling was used to achieve the proper thickness.

The procedure for producing cross-sections was more complex (figures 5.2 and 5.3). First, the sample was cleaved into pairs of $2 \mathrm{~mm}$ strips, which were epoxied together with the reacted layers face-to-face in the center. In order to ensure good bonding between the halves, the epoxied specimens were cured in an oven at $100^{\circ} \mathrm{C}$ for 60 minutes. The specimen was then ground and polished on one side, using the following sequence of Buehler Carbimet silicon carbide grinding paper (approximate particle size in parentheses) 600 (30 micron), 1200 (18 micron), 2400 (8 micron), and 4000 (6 micron). A final polish was obtained by using a Gatan dimpler, with a felt polishing wheel and 0.05 micron $\mathrm{Al}_{2} \mathrm{O}_{3}$ slurry ( 3 minutes, medium speed, weight 20 grams). 


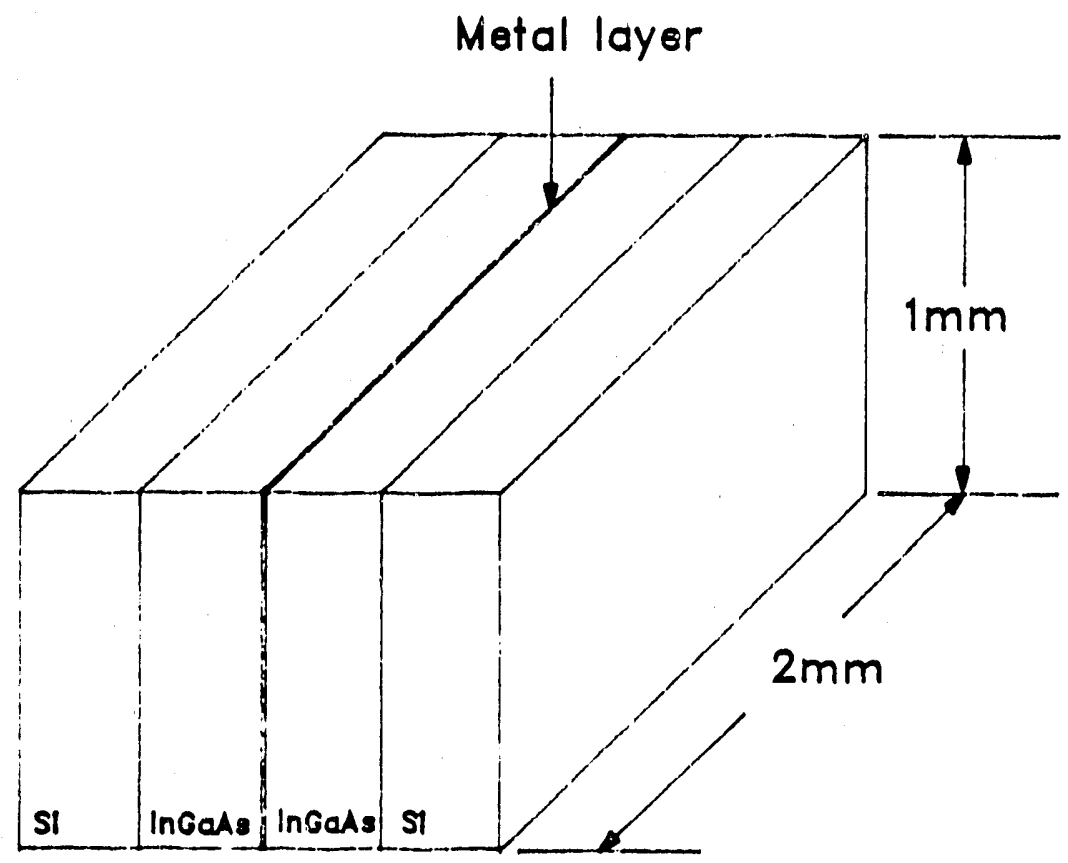

Figure 5.2: Procedure for preparation of cross-section specimens for the TEM. $1 \mathrm{~mm} \times 2 \mathrm{~mm}$ strips of the sample are cleaved, and epoxied with the deposited layers face-to-face. Support strips of Si are epoxied on either side to provide mechanical strength. 


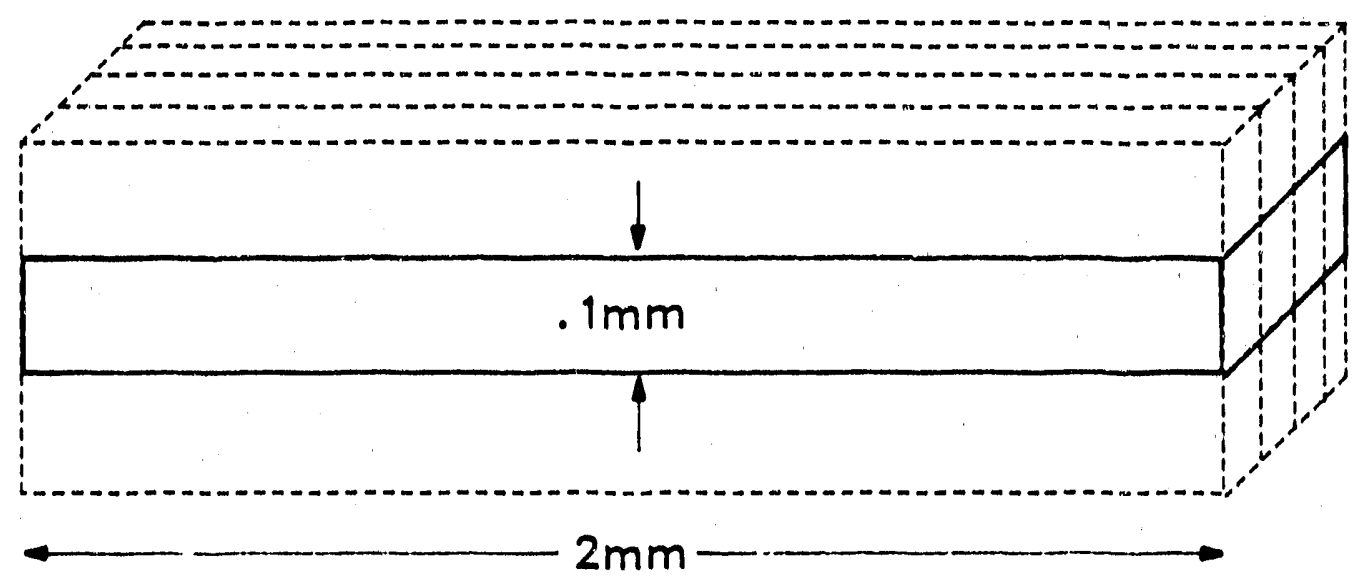

a

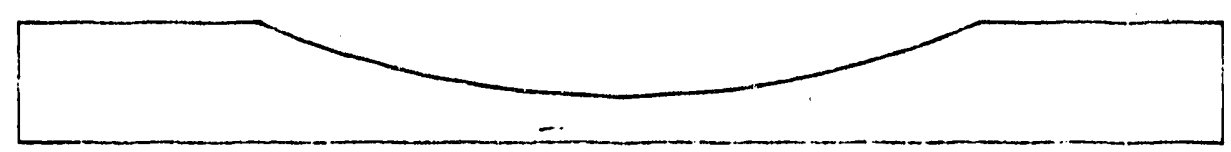

b

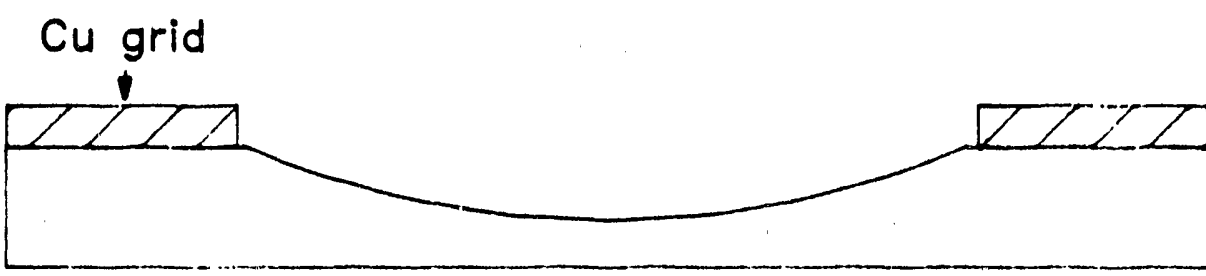

c

Figure 5.3: a) The epoxied sandwich is ground down to $0.1 \mathrm{~mm}$ in thickness. b) a shallow depression is ground in the specimen using a dimpler; the deepest part of the dimple is centered at the deposited layer interface. c) Cu support grid is epoxied to the specimen, which is then ion-milled reduce the thickness to perforation. 
At this point, the specimen was prepared for dimpling. The specimen was turned over, and thinned down to 75 microns on 600 grit paper. A shallow depression, or dimple, centered on the two reacted layer interfaces, was formed in the specimen, using a brass wheel and $2-4$ micron diamond paste ( 10 minutes, medium speed, weight 20 grams), followed by a final polish with 0.05 micron $\mathrm{Al}_{2} \mathrm{O}_{3}$ slurry ( 3 minutes, medium speed, weight $20 \mathrm{grams}$ ). The thickness of the specimen at the bottom of the dimple at this point was 20 to 30 microns. A $3 \mathrm{~mm}$ slotted $\mathrm{Cu}$ grid was epoxied to the specimen to provide strength. During the grinding, polishing, and dimpling procedure, the specimen was exposed to a maximum of $150^{\circ} \mathrm{C}$ when attaching it to the polishing stud. Specimens in this experiment were dimpled on a Gatan model 656 Dimple Grinder.

The dimpled specimen was then thinned to the point of perforation at the bottom of the dimple. This was achieved by removing material in an ion mill, which functions by bombarding the specimen with energetic argon ions. The InP substrates used in this experiment posed a special problem for ion milling. The $\mathrm{P}$ atoms are much more easily removed from the substrate than are the In. Consequently, the In atoms tend to accumulate on the surface during the milling procedure, and can diffuse along the surface to agglomerate in to droplets, which are detrimental to imaging in the TEM.

Indium droplet formation can be impeded by keeping the specimen surface temperature low enough to prevent diffusion of the In atoms in to agglomerates. There are two measures which should be used to reduce the surface temperature: cooling the specimen with liquid nitrogen during milling, and reducing the total incident energy of the ion beam. Specimen cooling was achieved by mounting the specimen on a cold stage during milling, which was in thermal contact with a liquid nitrogen bath during milling. The total incident energy was reduced by keeping the energy of the ions low (below $3 \mathrm{KeV}$ ), and the ion beam current low (below $0.5 \mathrm{~mA}$ ). Specimens in this experiment were milled on a Gatan model 600TMP Ducmill, using guns designed for lowenergy applications (Gatan model 600-37). 


\subsection{Summary}

The analytical procedure can be summarized as follows: 1. After annealing, the specimens were examined by XRD to determine the extent of the metal/semiconductor reaction, and to identify the phases which have formed in the system (non-destructive). 2. RBS was performed to determine the thicknesses of unreacted $P t$ and $\operatorname{In}_{x} G a_{1-x}$ As (non-destructive). 3. SAM depth profiling was performed to determine the depth distribution of the elements in the contact structure (this technique uses $-2 \mathrm{~mm}^{2}$ of material). 4. TEN was performed to determine the morphology of the reacted phases, and their orientation with respect to the substrate (this technique uses several $\mathrm{mm}^{2}$ of material). The amount of material each technique requires is important because $\operatorname{In}_{\mathrm{x}} \mathrm{Ga}_{1-\mathrm{x}} \mathrm{As}$ is difficult to obtain in large quantities. 


\subsection{RESULTS}

\subsection{Pt/GaAs}

In order to relate this study to the work of previous investigators (section $4.3, \mathrm{p}$. 49), annealing experiments were done on the $\mathrm{Pt} / \mathrm{GaAs}$ system. The sarne conditions were maintained for the $\mathrm{Pt} / \mathrm{GaAs}$ analysis as for the $\mathrm{Pt} / \mathrm{In}_{53} \mathrm{Ga}_{{ }_{47}} \mathrm{As}$ system.

\subsubsection{X-Ray Diffraction}

X-ray diffraction spectra for several annealing times at $400^{\circ} \mathrm{C}$ are shown in $\mathrm{Fi}$, ures 6.1 through 6.4 ; as deposited, 10 minutes, 15 minutes, and 40 minutes. In the asdeposited sample (Figure 6.1), $\mathrm{Pt}$, diffraction peaks are evident at the $2 \Theta$ angles of $39.7^{\circ}, 46.0^{\circ}, 81.3^{\circ}$ and $85.6^{\circ}$, in addition to the GaAs (200) and (400) peaks at $31.7^{\circ}$ and $66.1^{\circ}$, "spectively. No peaks indicative of reaction between the substrate and the $\mathrm{Pt}$ were observed in the as-deposited case. The intensity of the $\mathrm{Pt}$ peak at $39.7^{\circ}$ peak is much higher than the $\mathrm{Pt}$ peak at $46.0^{\circ}$.

In Figure 6.2, the diffraction spectrum from the 10 minute anneal is shown. In addition to the GaAs and $P t$ peaks found in the as-deposited spectrum, several new peaks have appeared: $23.0^{\circ}, 25.9^{\circ}, 30.0^{\circ}, 41.3^{\circ}, 45.4^{\circ}, 50.7^{\circ}$, and $72.3^{\circ}$. The Pt peaks have considerably lower intensity (e.g. the maximum counts for the peak near $40^{\circ}$ are down by $\sim 83 \%$ ). In addition, the $\mathrm{Pt}$ peaks have shifted to higher angles (i.e lower d-spacings). There is no change in the substrate peaks.

In Figure 6.3, the spectrum from the 15 minute anneal is shown. In addition to the reaction profuct peaks present following the 10 minute anneal, peaks have appeared at $33.7^{\circ}, 36.8^{\circ}, 43.1^{\circ}, 62.9^{\circ}$, and $72.2^{\circ}$. The $\mathrm{Pt}$ peaks have decreased slightly in intensity, but have not shifted from their positions in the previous spectrum. The substrate peaks have not changed substantially, although the intensity of the (200) peak is much lower than previously. 


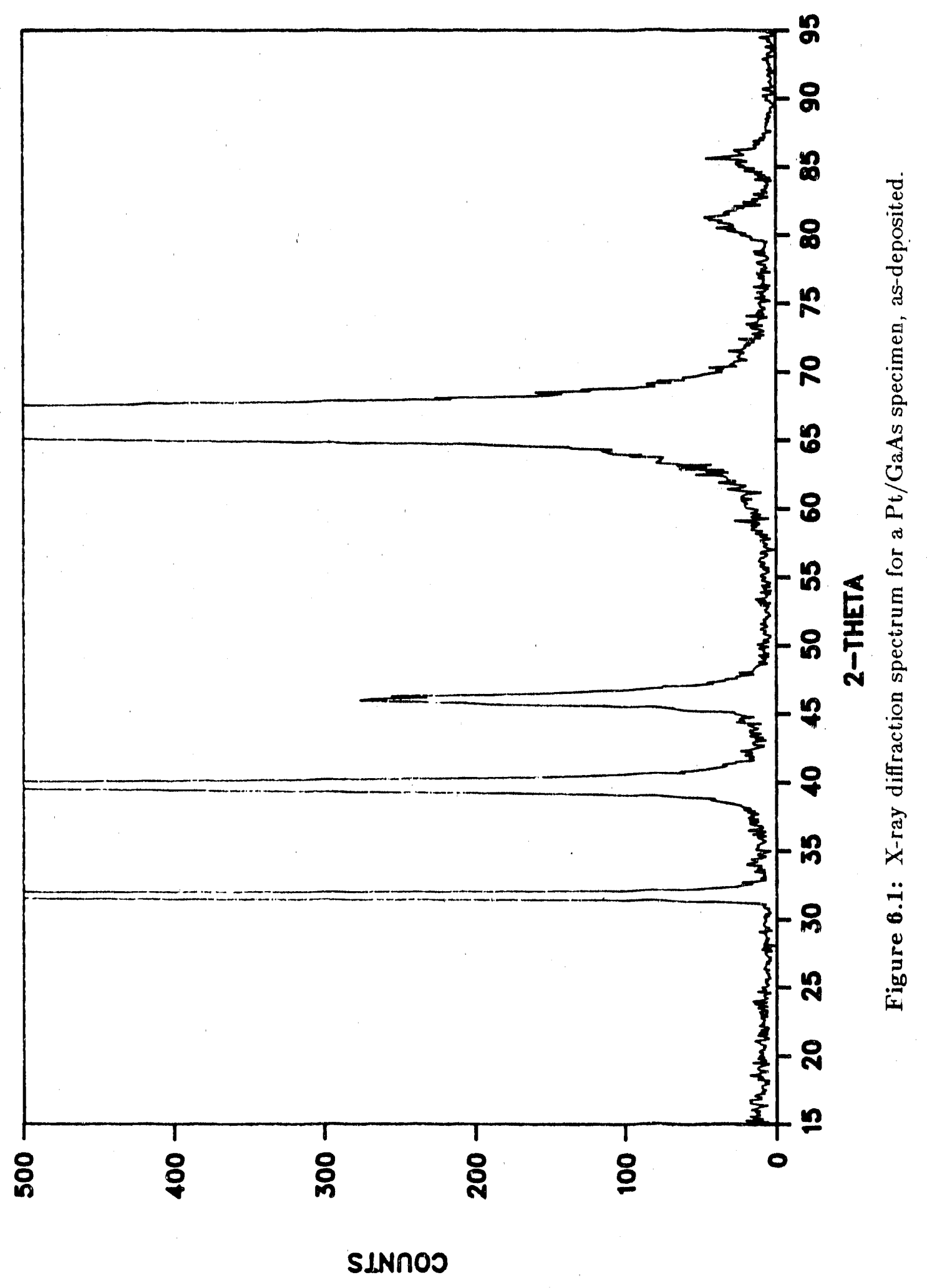




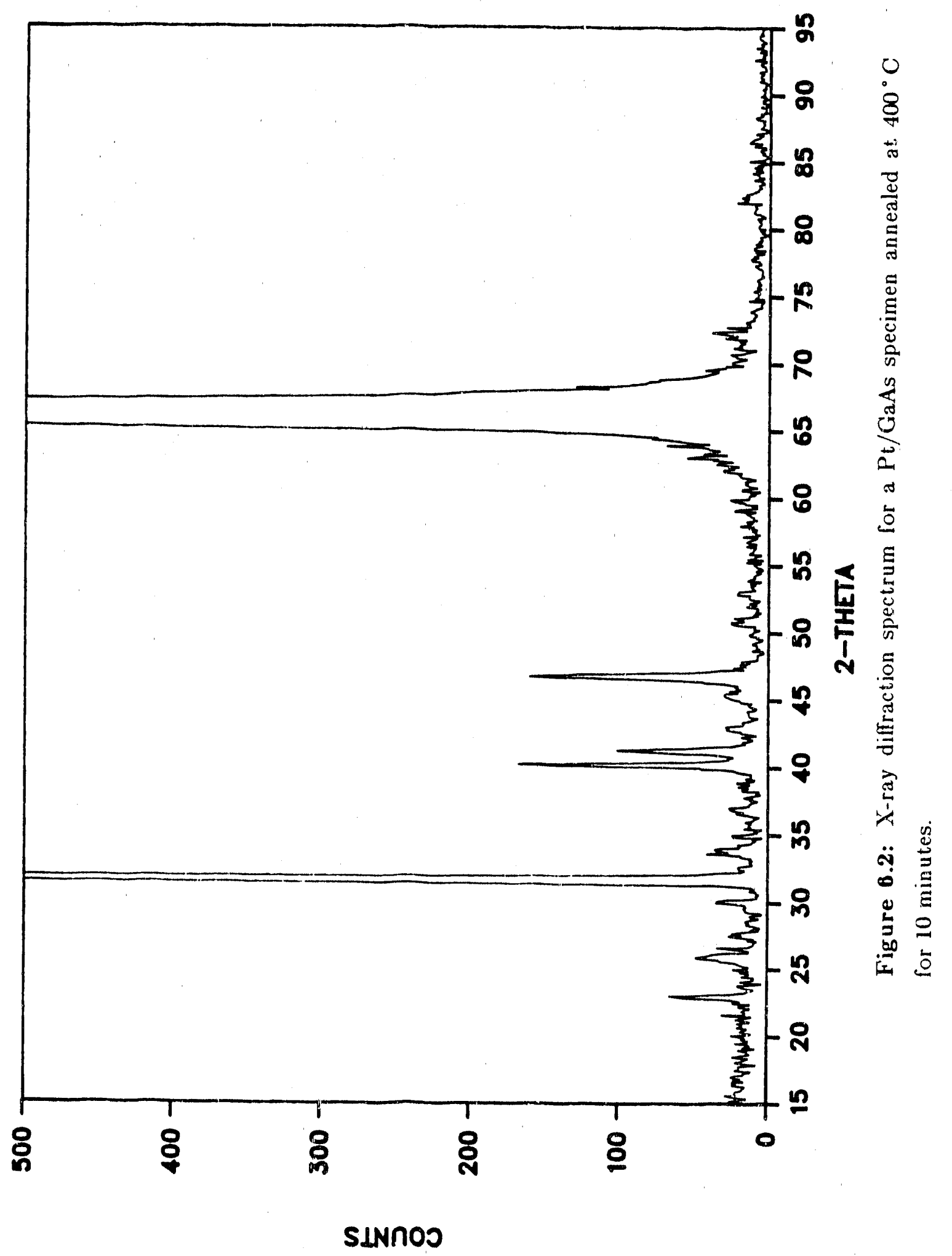




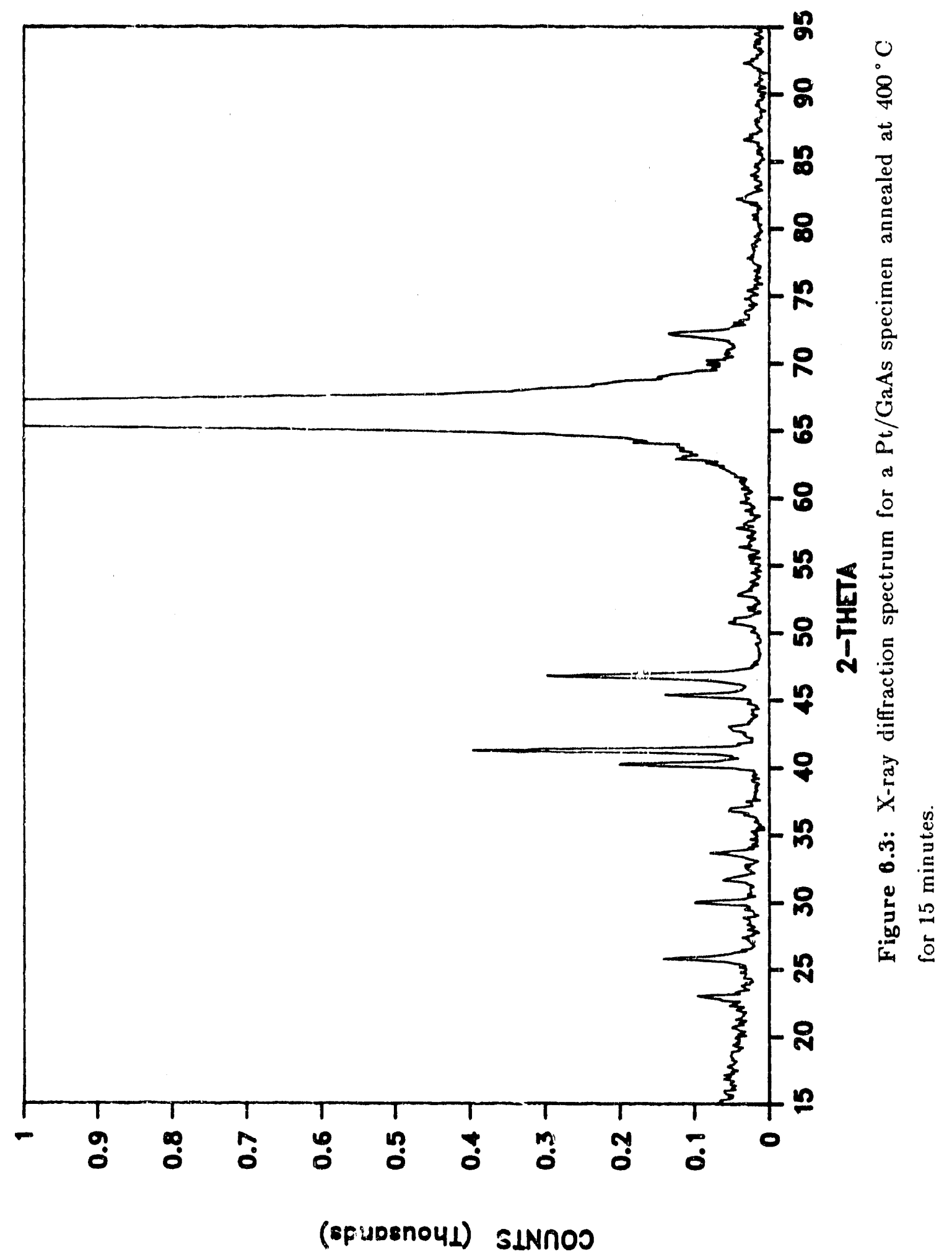




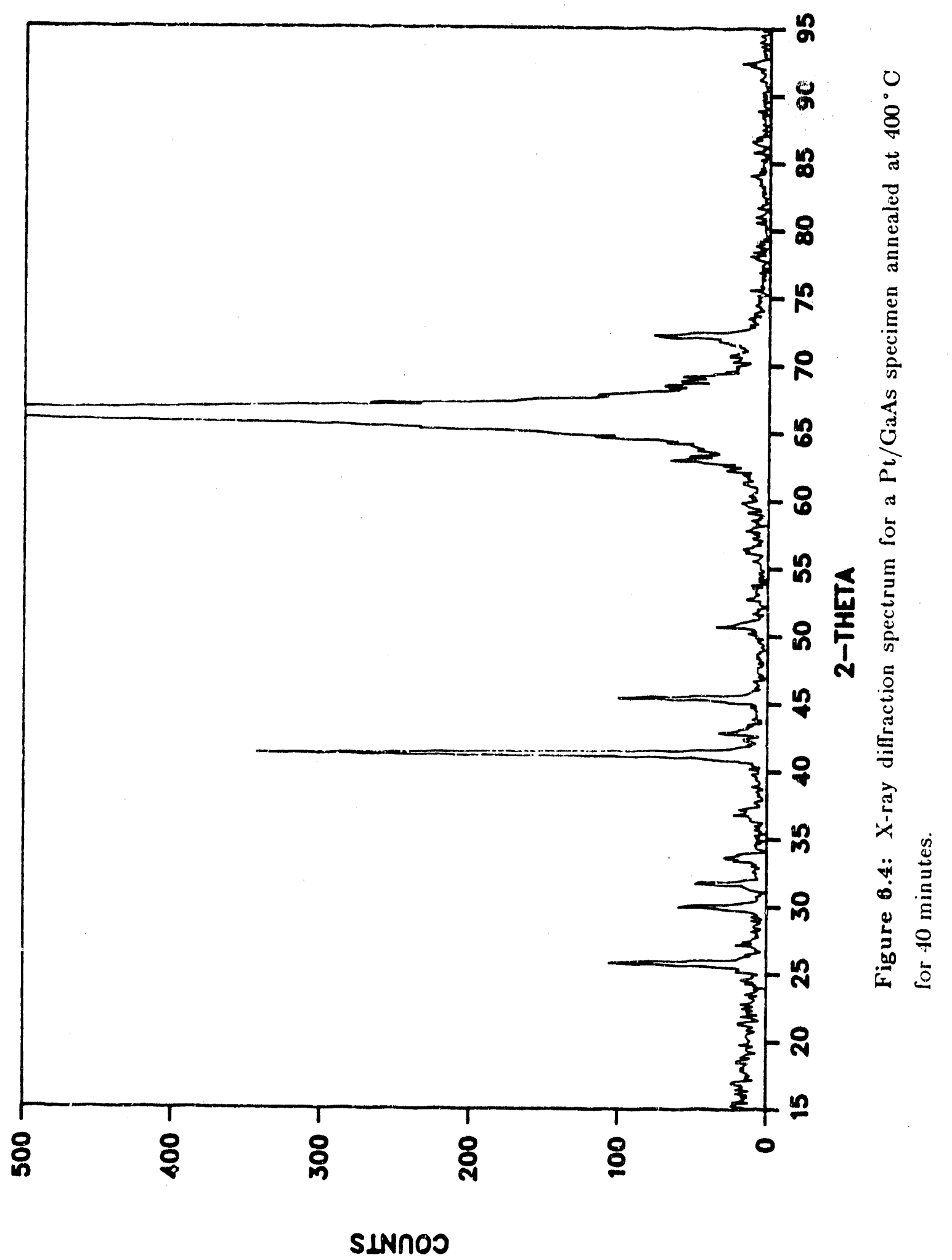


Additional spectra were obtained for anneals of 20 and 30 minutes, but are not included here as they show no change from Figure 6.3. No new peaks developed, and no previous peaks disappeared.

In Figure 6.4, the spectrum from the $\mathbf{4 0}$ minute anneal is shown. At this stage in the annealing, the $\mathrm{Pt}$ signals have disappeared from the spectrum. The reaction product peaks are present at $25.8^{\circ}, 30.0^{\circ}, 33.7^{\circ}, 36.8^{\circ}, 41.3^{\circ}, 43.0^{\circ}, 45.4^{\circ}, 50.7^{\circ}$, $52.7^{\circ}, 56.5^{\circ}, 63.2^{\circ}$, and $72.2^{\circ}$. All are of much lower intensity than that of the initial $\mathrm{Pt}$ deposition. The reaction product peak at $23.0^{\circ}$, which was present in all but the as-deposited spectrum, has disappeared. The GaAs substrate paaks are still present, with the (400) of much higher intensity than the (200).

\subsubsection{Rutherford Backscattering}

RBS spectra for various $\mathrm{Pt} / \mathrm{GaAs}$ anneals are shown in Figure 6.5. The spectrum for the as-deposited specimen shows shows that the onset of the Pt signal occurs at at the channel corresponding to surface $\mathrm{Pt}$. The $\mathrm{Pt}$ signal increases to a broad peak, and drops off sharply at the low-energy end. There is a gap in the spectrum between the trailing edge of the $\mathrm{Pt}$ and the onset of the substrate $\mathrm{Ga}$ and As. The substrate signal increases fairly sharply, and exhibits no steps in its intensity at lower energies.

The spectrum following 10 minutes of annealing at $400^{\circ} \mathrm{C}$ shows a decrease in the intensity of the $P t$ signal, although the onset still occurs at the surface value. A step has appeared in the low-energy end of the $\mathrm{Pt}$ signal. The onset of the substrate signal has moved out into the gap between the $\mathrm{Pt}$ and $\mathrm{GaAs}$, and a step has developed at the high-energies.

The intensity of the Pt signal has decreased further following the 30 minute anneal. The peak has broadened considerably, and exhibits two intensity levels. The GaAs signals have merged with the low-energy tail of the $\mathrm{Pt}$ peak. 


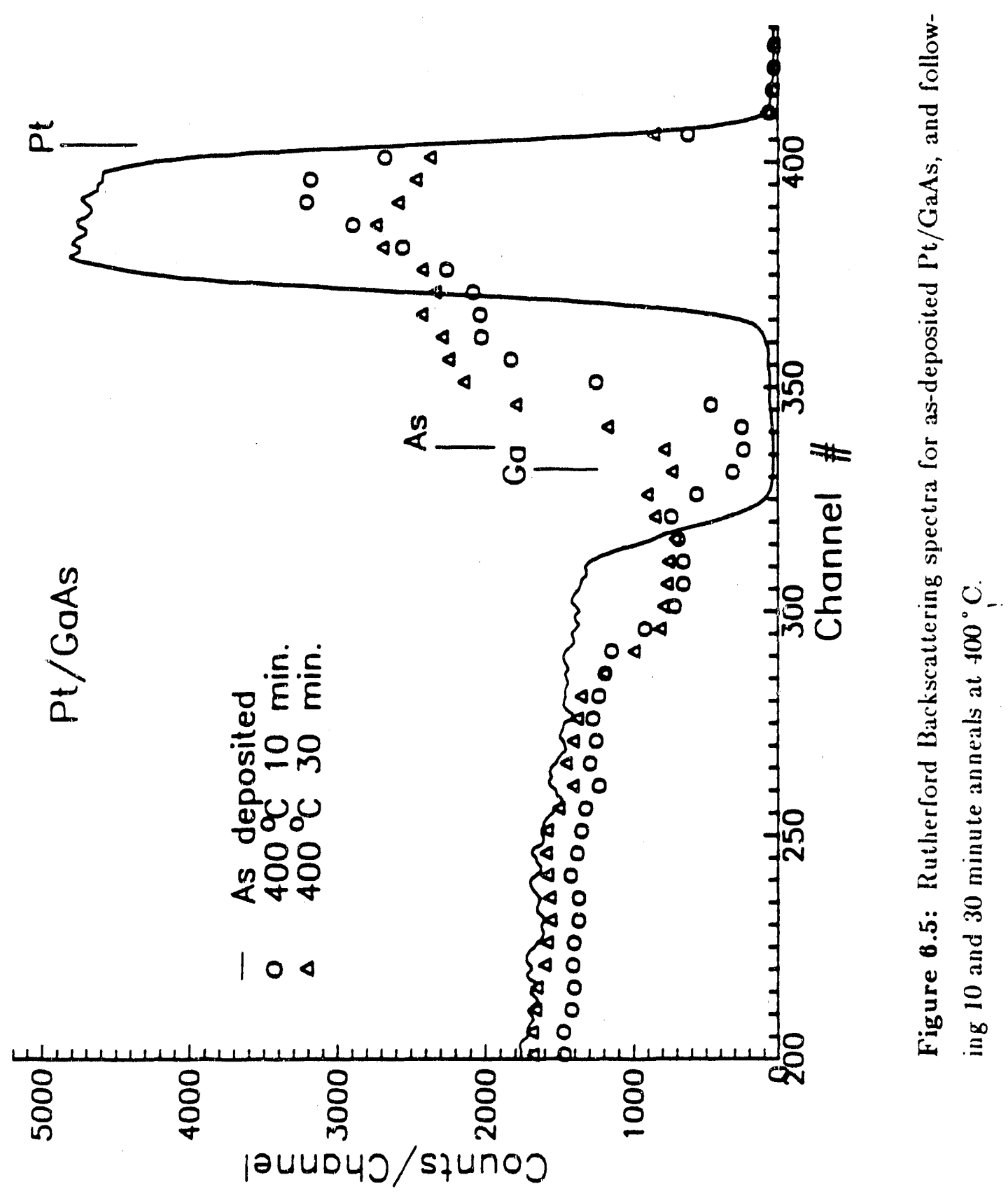




\subsubsection{Auger Depth Profile}

A depth profile of selected Auger transitions is shown in Figure 6.6, for a sample of $\mathrm{Pt} / \mathrm{GaAs}$ annealed for 60 minutes at $400^{\circ} \mathrm{C}$. In this profile, the following Auger transition energies were monitored as a function of ion milling time: As $1228 \mathrm{eV}, \mathrm{Ga}$ $1070 \mathrm{eV}$, and Pt $168 \mathrm{eV}$. The Auger computer was set to monitor the peak-to-peak height within an $\sim 30 \mathrm{eV}$ window. Because of the large number of possible Auger transitions for $\mathrm{Pt}$, it was found that 12 sweeps of the energy window were necessary to get a good signal-to-noise ratio, as opposed to 6 each for $\mathrm{As}$ and $\mathrm{Ga}$. It should be noted that the $\mathrm{Pt}$ signal is much lower than that for the other elements. While this may be indicative in part of low $\mathrm{Pt}$ concentrations, it results primarily from the larger number of Auger transitions available in the $\mathrm{Pt}$ atom. Consequently, each $\mathrm{Pt}$ Auger transition tends to have a lower intensity for a given incident radiation than do the transitions in smaller atoms.

The depth profiles in this study were taken on encapsulated specimens; this allowed for alignment of the device while sputtering the $\mathrm{SiO}_{2}$ without affecting data collection of the reaction products.

The profile shows a very sharp increase in the Ga signal after $\sim 5$ minutes of milling. The Pt signal begins to increase soon afterwards, while the As signal remains flat until much later in the profile. After reaching a local maximum at $\sim 10$ minutes, the Ga signal begins to decrease gradually. The As signal begins to increase gradually $\sim 2.5$ minutes later, and levels off near 20 minutes. At the same time, the Ga signal reaches a local minimum and begins increasing, although at a lower rate than for the onset of the $\mathrm{Ga}$ signal. The $\mathrm{Pt}$ signal is fairly level between 7.5 minutes and 25 minutes, which is when the most $\mathrm{Ga}$ and As changes are occurring. Before 7.5 minutes, the $\mathrm{Pt}$ signal is near zero, as are the $\mathrm{Ga}$ and As. After $\mathbf{2 5}$ minutes, the $\mathrm{P}_{\mathrm{t}}$ signal again goes to zero, while the $\mathrm{Ga}$ and $\mathrm{As}$ level off at a much higher value. 


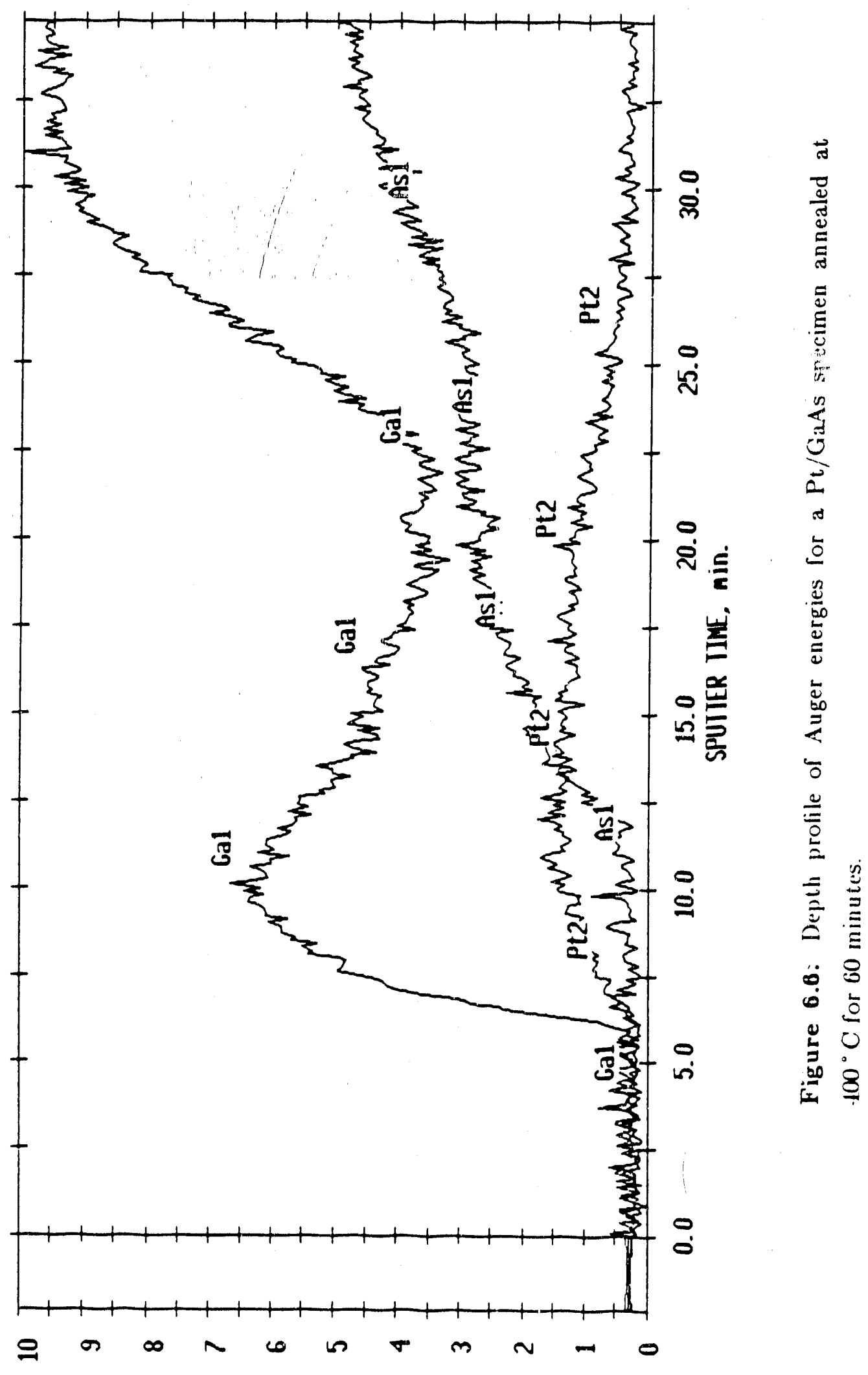

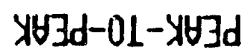


Features to note: First, there is no sharp transition between the various features in the As, Ga, and Pt signals. Second, the Ga signal never decreases to zero after the encapsulation is milled away. Third, the Pt signal does not vary substantially after the the $\mathrm{Ga}$ signal first decreases, until the $\mathrm{Ga}$ and As level off. Fourth, the As signal does not increase until well after $\mathrm{Ga}$ is first encountered. 


\section{$6.2 \mathrm{Pt} / \mathrm{In}_{.53} \mathrm{Ga}{ }_{.47} \mathrm{As}$}

\subsubsection{X-Ray Diffaction}

Spectra of $\mathrm{Pt} / \mathrm{In}_{53} \mathrm{Ga}_{47}$ As samples annealed at several different times and temperatures are shown in Figures 6.7 through 6.13. They can be divided in to two subgroups: 1. Samples annealed at $400^{\circ} \mathrm{C}$ for 10 minutes through 180 minutes, and 2 . Samples annealed at $350^{\circ} \mathrm{C}$ to $600^{\circ} \mathrm{C}$, for long times.

\section{as-deposited}

The $x$-ray diffraction spectra following the deposition of $\mathrm{Pt}$ on $\mathrm{In}{ }_{53} \mathrm{Ga}_{47} \mathrm{As}$ is shown in Figure 6.7. The substrate peaks are present at $30.6^{\circ}$ and $63.4^{\circ}$, while the $\mathrm{Pt}$ deposition peaks appear at $39.7^{\circ}, 45.9^{\circ}, 80.8^{\circ}$, and $85.4^{\circ}$. The $\mathrm{Pt}$ peak at $397^{\circ}$ has a much higher intensity than the other Pt peaks. No peaks are present that would indicate the interaction of the substrate and the $\mathrm{Pt}$ during deposition.

\section{0 minutes}

Several new peaks have appeared following this anneal (Figure 6.8), although most are of low intensity, e.g. $22.6^{\circ}$ and $25.9^{\circ}$. Two of the new peaks have significant intensity; at $30.3^{\circ}$ and $58.2^{\circ}$. The $P t$ peaks are all still present, and have shifted to larger angles (smaller d-spacings). The substrate peaks are essentially unchanged, although the intensity of the (200) is lower than was recorded in the previous spectra.

\section{0 minutes}

The spectrum obtained following the 60 minute anneal (Figure 6.9) is quite similar to that of the previous spectrum. Two peaks, at $31.5^{\circ}$ and $41.2^{\circ}$, have become evident on the high angle shoulders of larger peaks. There are indications of the presence of these peaks after 20 and 30 minute anneals, but they are of too low intensity to be 
convincing in those cases. Substantial reaction product peaks are present at $25.9^{\circ}$, $28.2^{\circ}, 33.6^{\circ}, 42.4^{\circ}, 46.4$, and $50.7^{\circ}$. Very high intensity peaks are present at $39.9^{\circ}$ and $58.1^{\circ}$. 


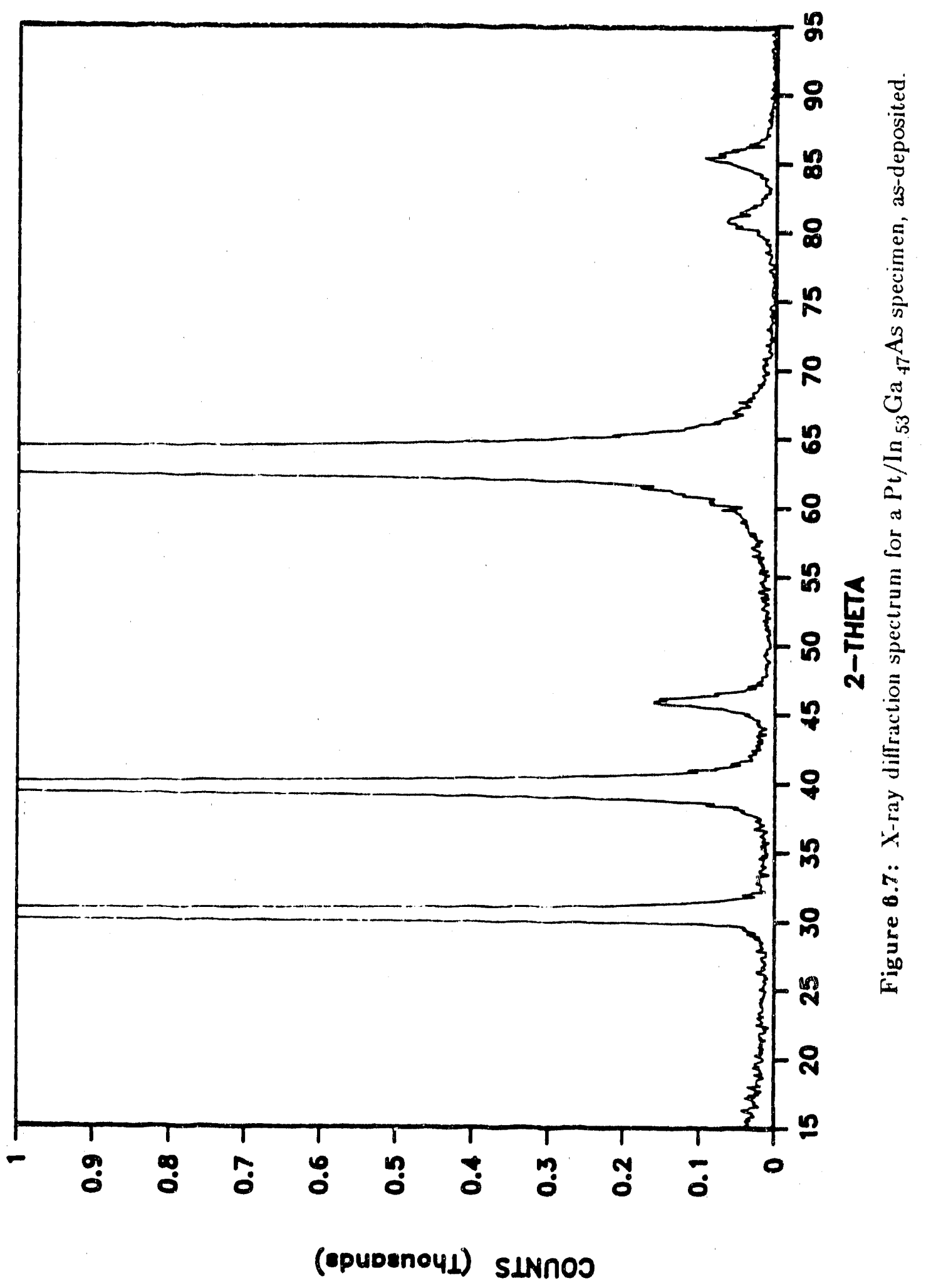




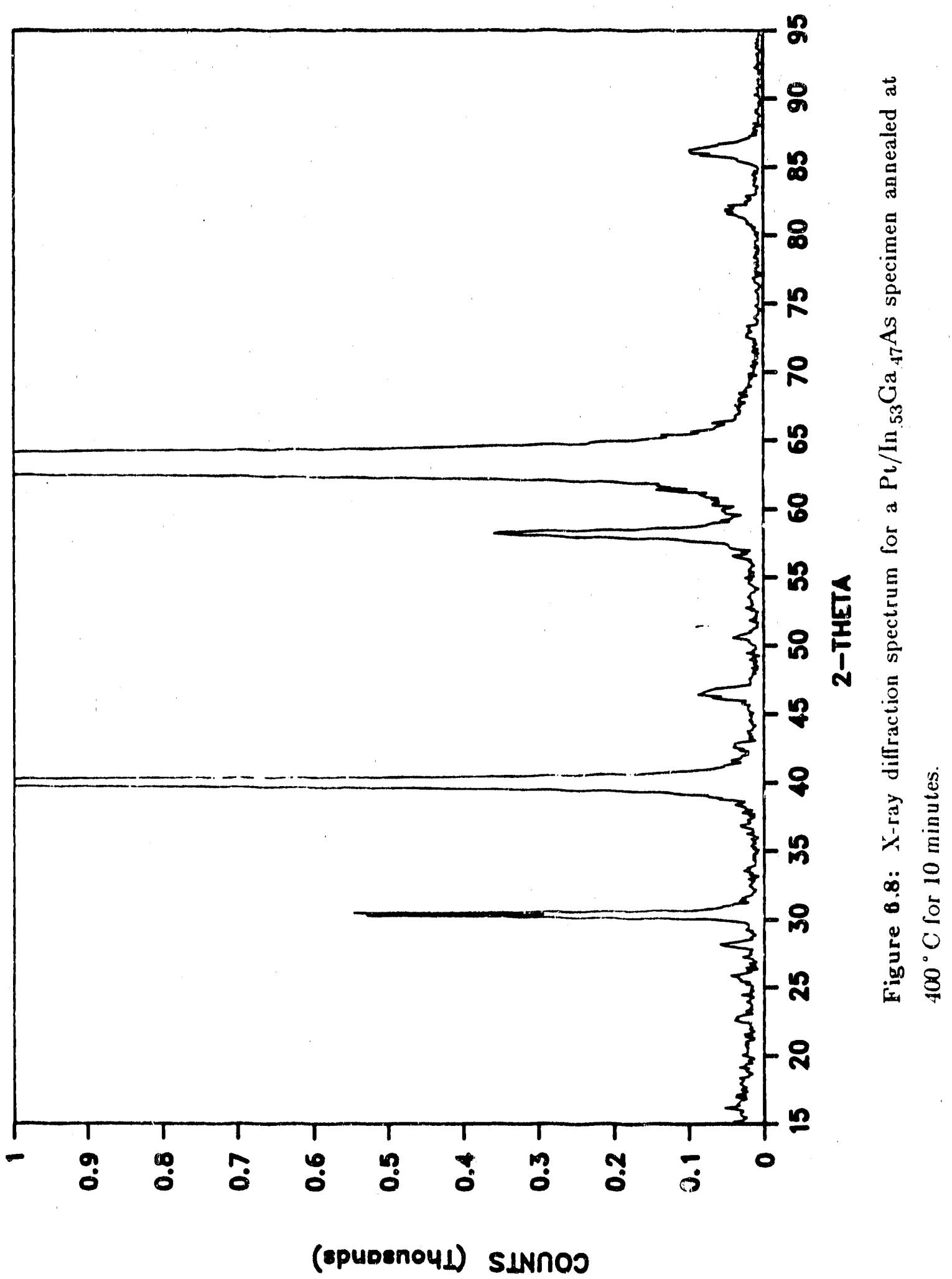




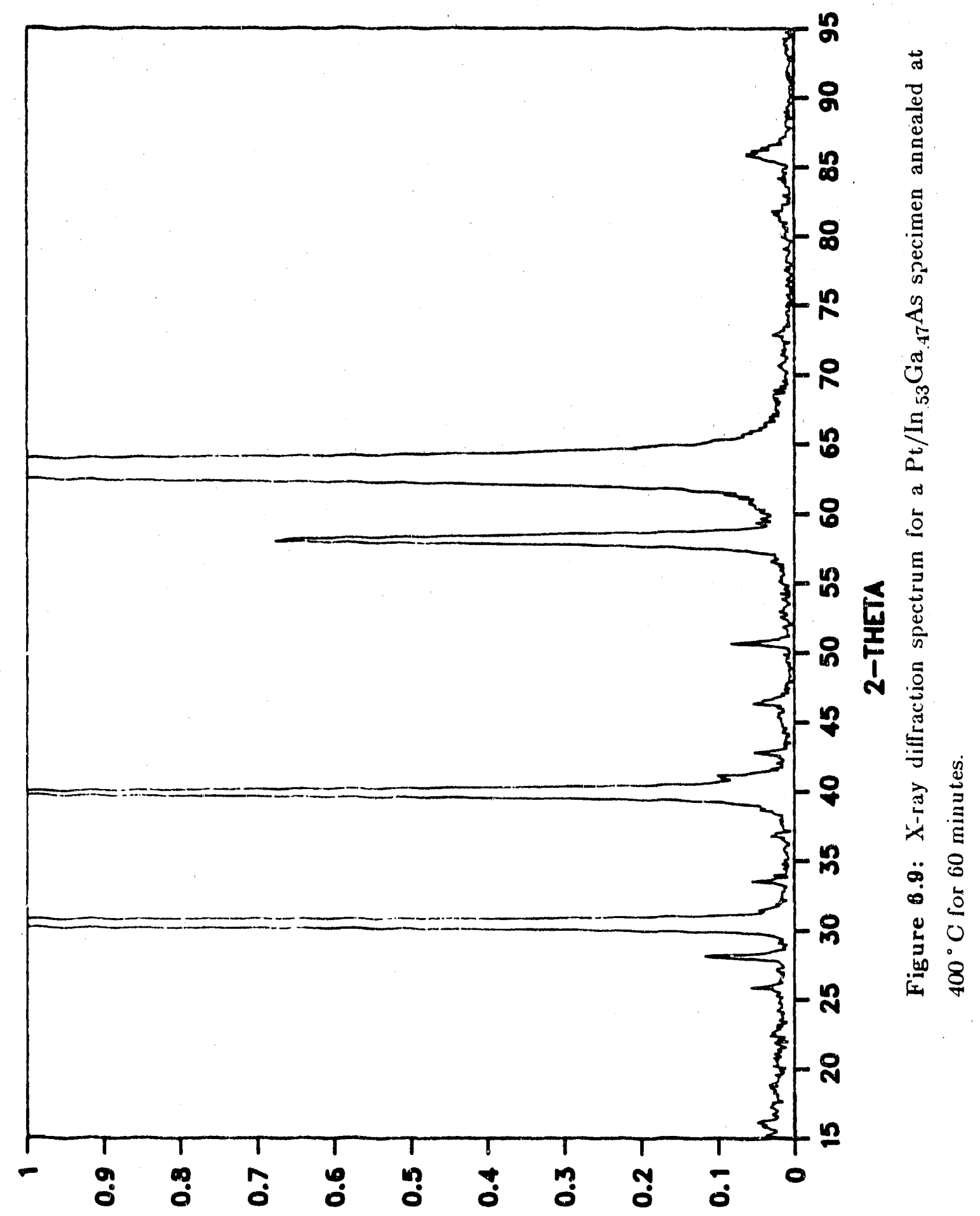

(spudeno41) SLNnOS 


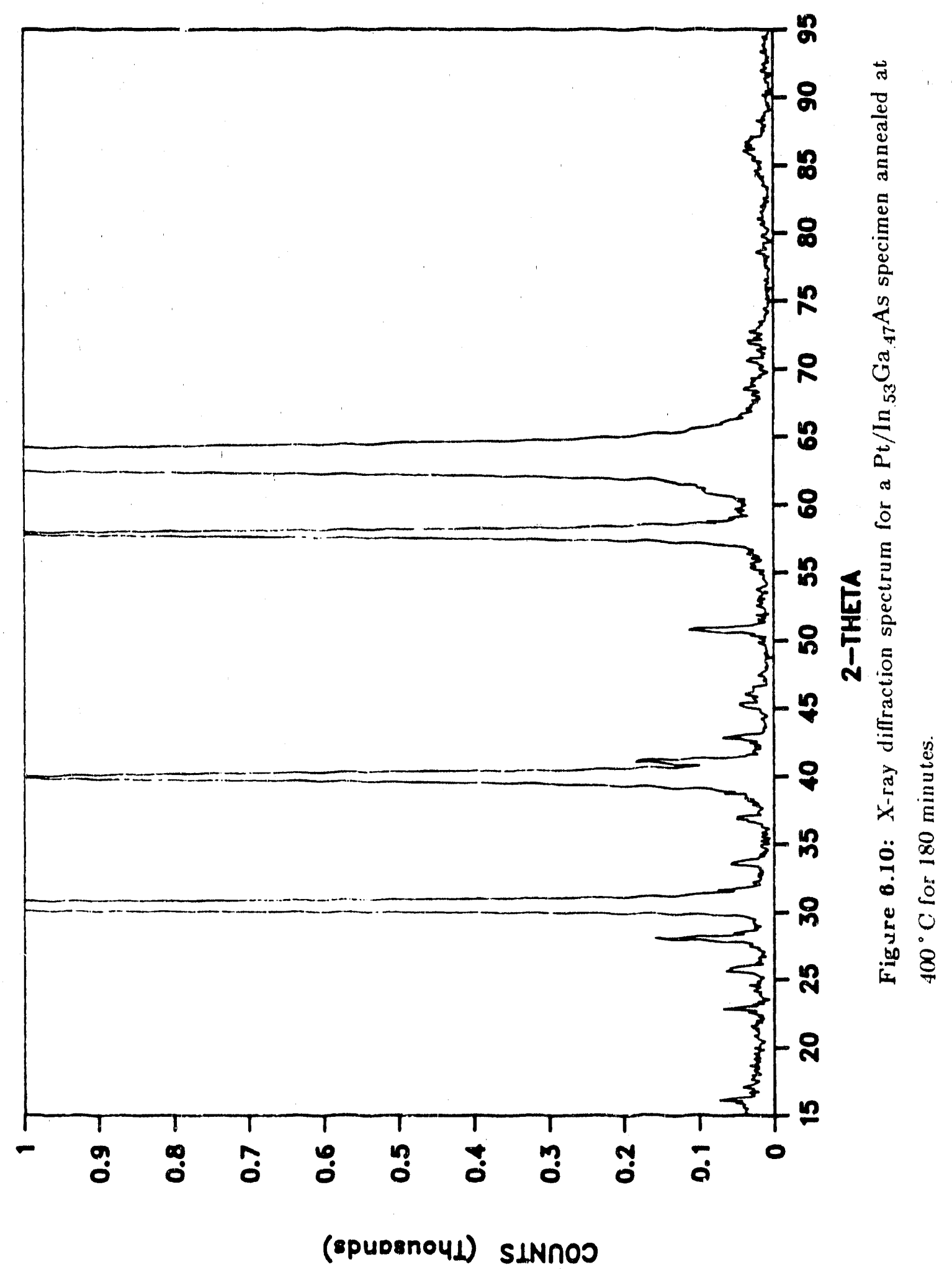




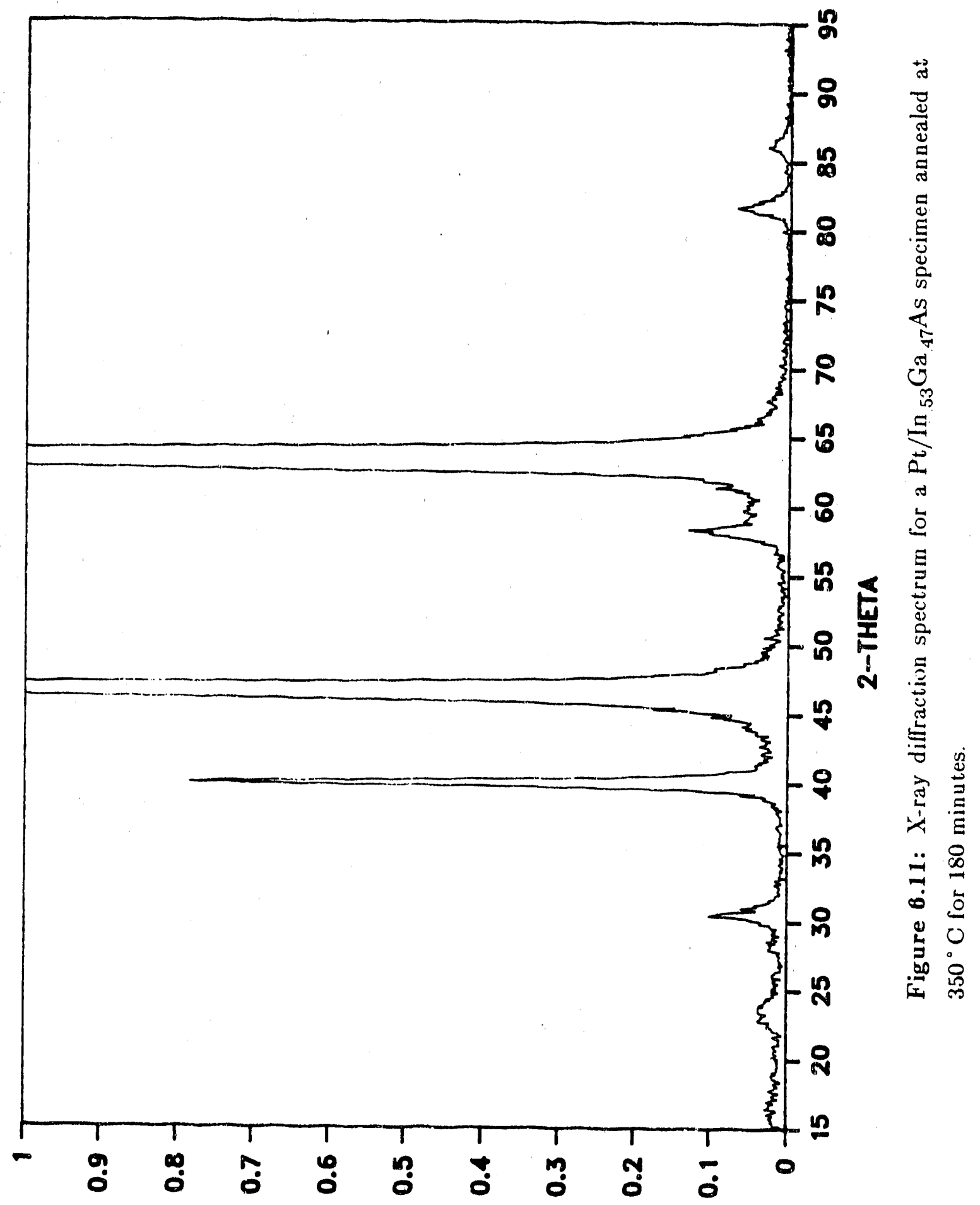

(spudsno4L) SINnOS 


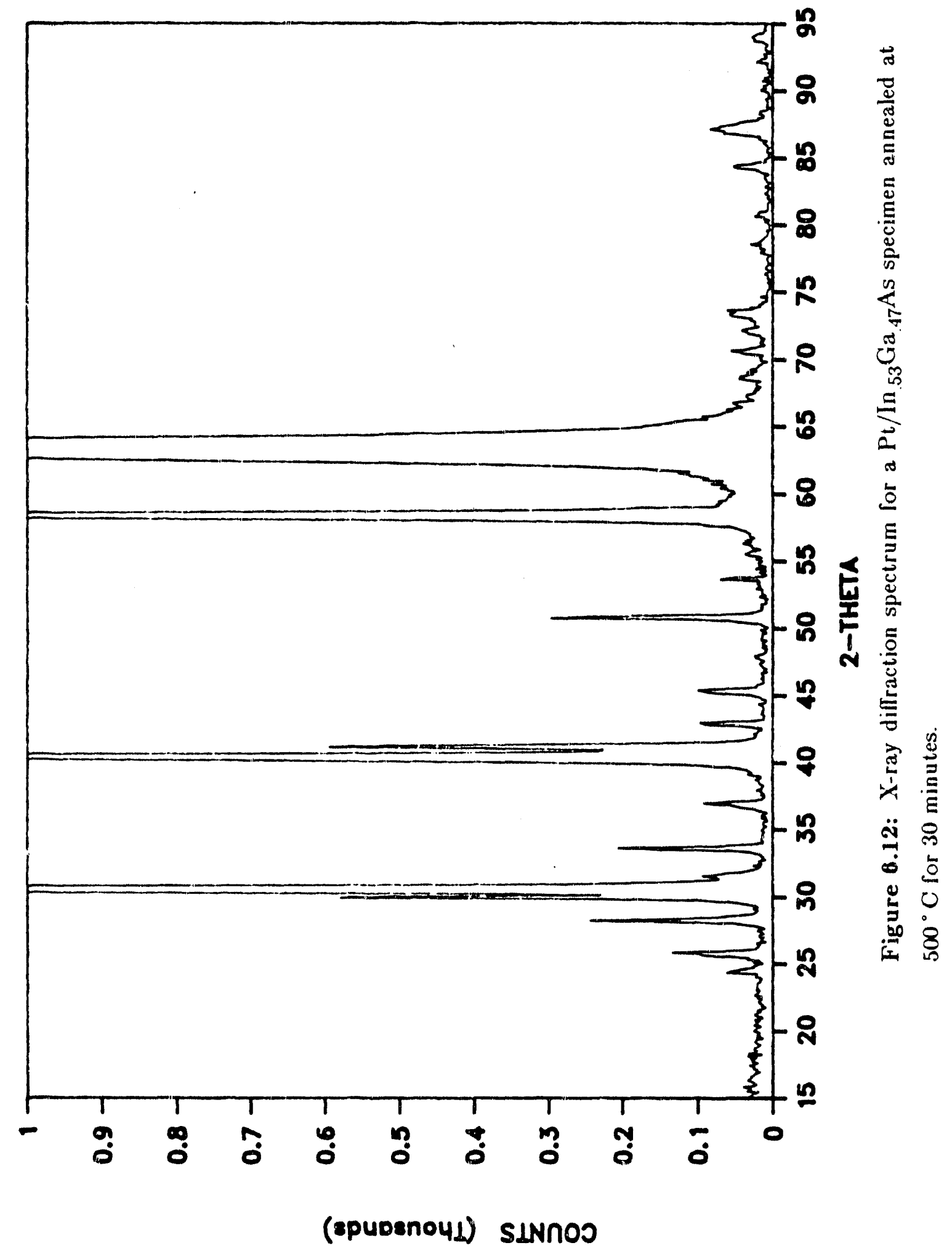




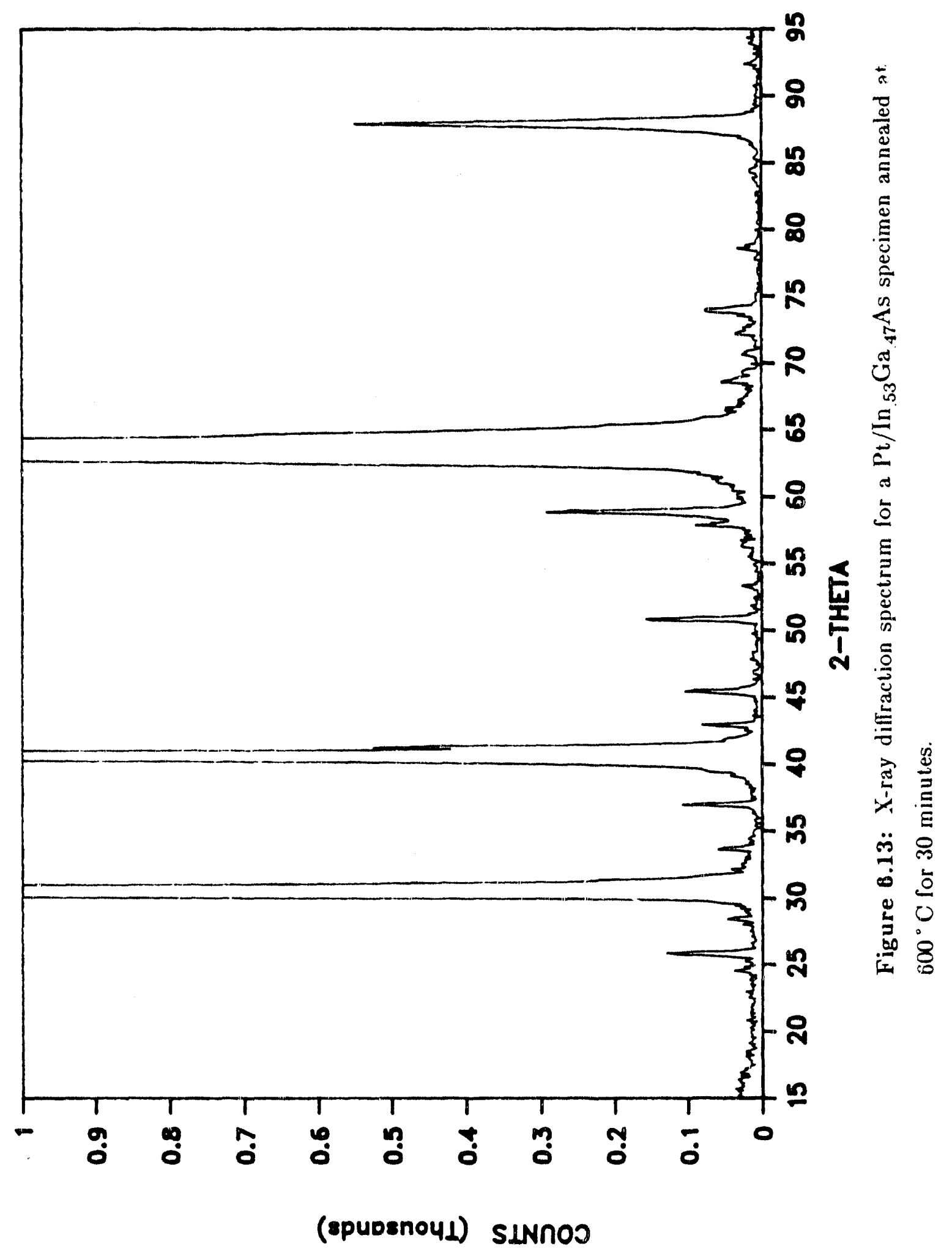




\section{0 minutes to 180 minutes}

X-ray diffraction spectra were obtained following anneals for $90,120,150$, and 180 minutes. The spectra differ only in the intensity of the diffraction peaks, so only the final spectrum (180 minutes) is provided here in Figure 6.10. All of the reaction product peaks are pronounced and well-defined for the longer anneals. No new peaks have appeared as compared to shorter anneals, although the peak near $41.2^{\circ}$ mentioned previously has become much larger. There are also indications of a double peak at $25.7^{\circ}$.

\section{long-term anneals}

$\mathrm{X}$-ray diffaction spectra were obtained for long-term anneals to determine the effect of temperature on the final reaction products. The annealing conditions for this set of data were: $350^{\circ} \mathrm{C}: 180$ minutes, $400^{\circ} \mathrm{C}: 180$ minutes, $500^{\circ} \mathrm{C}: 30$ minutes, and $600^{\circ} \mathrm{C}: 30$ minutes. The large variation in annealing time was necessary as the $\mathrm{Pt} / \mathrm{In}_{53} \mathrm{Ga}_{47} \mathrm{As}$ reacts slowly at the lower temperatures. The spectrum for the $400^{\circ} \mathrm{C}: 180$ minutes anneal has been previously described.

\section{$350^{\circ} \mathrm{C}: 180$ minutes}

Despite the long annealing time, little reaction has occurred following this anneal (Figure 6.11). The Pt peaks are still quite strong, although they have shifted from their as-deposited positions to higher angles: $40.0^{\circ}, 46.7^{\circ}, 81.7^{\circ}$, and $86.1^{\circ}$. One substantial reaction product peak is visible at $58.4^{\circ}$. In addition, a very broad signal is visible between $22^{\circ}$ and $25^{\circ}$, and a narrower signal near $28^{\circ}$.

\section{$500^{\circ} \mathrm{C}: 30$ minutes}

The $\mathrm{Pt} / \mathrm{In}_{53} \mathrm{Ga}_{47} \mathrm{As}$ system has completely reacted following this anneal (Figure 6.12). All the reaction product peaks are quite pronounced, and of larger intensity than those of the lower temperature anneal. Most of the higher temperature peaks are 
within $0.1^{\circ}$ (the step size of the diffractometer) of the $400^{\circ} \mathrm{C}: 180$ minute anneal peaks, with a few exceptions. For example, the peak at $28.1^{\circ}$ has shifted to $28.3^{\circ}, 39.9^{\circ}$ to $40.4^{\circ}$ and $57.9^{\circ}$ to $58.4^{\circ}$. In addition, a significant peak has appeared at $30.0^{\circ}$, on the low-angle shoulder of the substrate (200) peak at $30.6^{\circ}$.

Other features to note in this spectrum are the appearance of some small peaks, at $24.4^{\circ}, 53.7^{\circ}$, and several between $66^{\circ}$ and $90^{\circ}$. These peaks probably do not represent the appearance of new phases, as they correlate with regions of high noise in the 400 " C: 180 minutes anneal. In addition, a low, broad peak at the position of the $\mathrm{Pt}(200)$ has disappeared in going from the $400^{\circ} \mathrm{C}$ to the $500^{\circ} \mathrm{C}$ anneals.

\section{$600^{\circ} \mathrm{C}: 30$ minutes}

This is the highest temperature anneal used in this study (Figure 6.13). This spectrum is very similar to the $500^{\circ} \mathrm{C}: 30$ minutes case, with the same exception noted before: some of the peaks have shifted to higher angles, the same that shifted when going from $400^{\circ} \mathrm{C}$ to $500^{\circ} \mathrm{C}$. With respect to $500^{\circ} \mathrm{C}$ anneals, the peaks have shifted: from $24.4^{\circ}$ to $24.6^{\circ}$, from $28.3^{\circ}$ to $28.5^{\circ}$, from $40.4^{\circ}$ to $40.7^{\circ}$, from $58.4^{\circ}$ to $58.9^{\circ}$, and from $87.2^{\circ}$ to $87.9^{\circ}$. The highest- and lowest-angle peaks in this set were too broad to be measured accurately in the $400^{\circ} \mathrm{C}: 180$ minutes spectrum.

The behavior of three of the peaks in the spectra these long-term anneals is of special note: those near $40^{\circ}, 51^{\circ}$, and $58^{\circ}$. At $40^{\circ}$, two peaks nearly overlap, but by an amount that decreases as the annealing temperature increases: $1.2^{\circ}, 0.8^{\circ}$, and $0.6^{\circ}$. Most of the decrease is taken up by the lower angle peak. At $58^{\circ}$, the peak goes through two changes as the temperature increases: it shifts to higher angles, and it develops a peak on th low angle shoulder. The peak at $51^{\circ}$ is interesting because nothing appreciable changes about the peak as the annealing temperature increases, as will be discussed in section 7 . 


\subsubsection{Rutherford Backscattering}

Two RBS spectra are shown in Figures 6.14 and 6.15. Figure 6.14 shows the spectrum of $\mathrm{Pt} / \mathrm{In}_{.53} \mathrm{Ga}_{{ }_{47}} \mathrm{As}$ after deposition. The $\mathrm{Pt}$ on the surface of the specimen is evident from the large signal at channel 485. This signal shows a square profile, with no tail in the low-energy end of the signal. The counts decrease to zero between the end of the Pt signal, and the onset of the In signal. As in the case of the Pt, the In signal increases abruptly, without a high-energy tail. The In signal is level in intensity until the onset of the $\mathrm{Ga}$ and As, which increase smoothly to the continuous substrate in tensity.

Figure 6.15 shows spectrum of a sample annealed for 30 minutes at $500^{\circ} \mathrm{C}$. The $\mathrm{Pt}$ signal in this case shows much lower intensity, and no clear dip between the $\mathrm{Pt}$ and the substrate $\mathrm{Ga}, \mathrm{As}$, and In signals. Both the $\mathrm{Pt}$ and the substrate signals have become irregular, exhibiting several broad peaks. The gap between the substrate and deposition signals no longer exists.

\subsubsection{Auger Depth Profiles}

Auger depth profiles have been obtained following anneals for several different annealing times at $400^{\circ} \mathrm{C}$. In addition, one profile was obtained for a sample annealed at $500^{\circ} \mathrm{C}$ for 30 minutes, to examine the distribution of elements in a fully reacted sample.

Depth profiles of Auger electron energies are shown in Figures 6.16 through 6.19 . The data collection conditions were the same as for those presented in Section 6.1 (page 81). In addition to the Auger energies sampled for $\mathrm{Ga}, \mathrm{As}$, and $\mathrm{Pt}$ mentioned previously, the In signal at $404 \mathrm{eV}$ was monitored. As in the case of $\mathrm{Ga}$ and As, 6 sweeps of the In window were taken. 


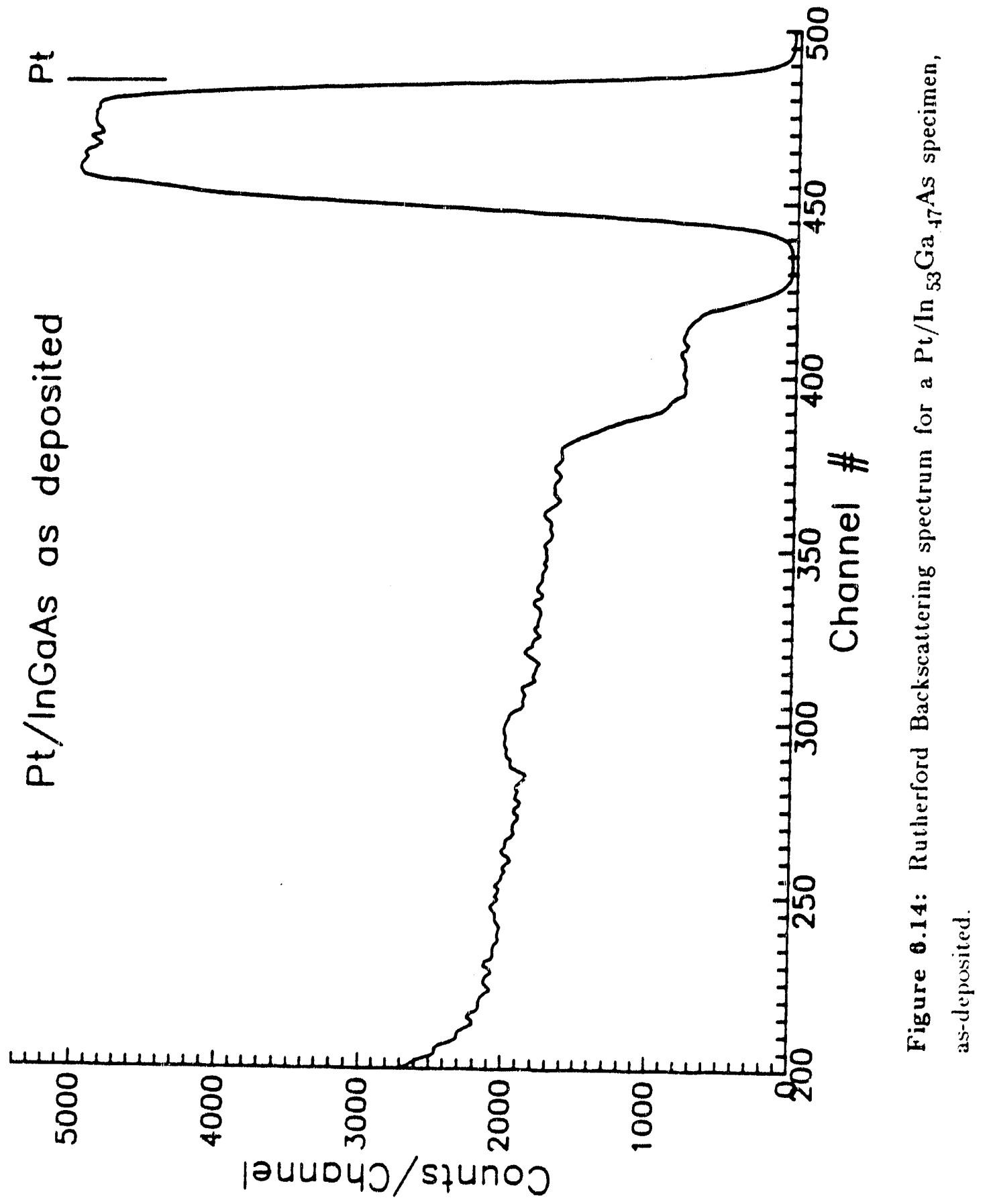


- 97 -
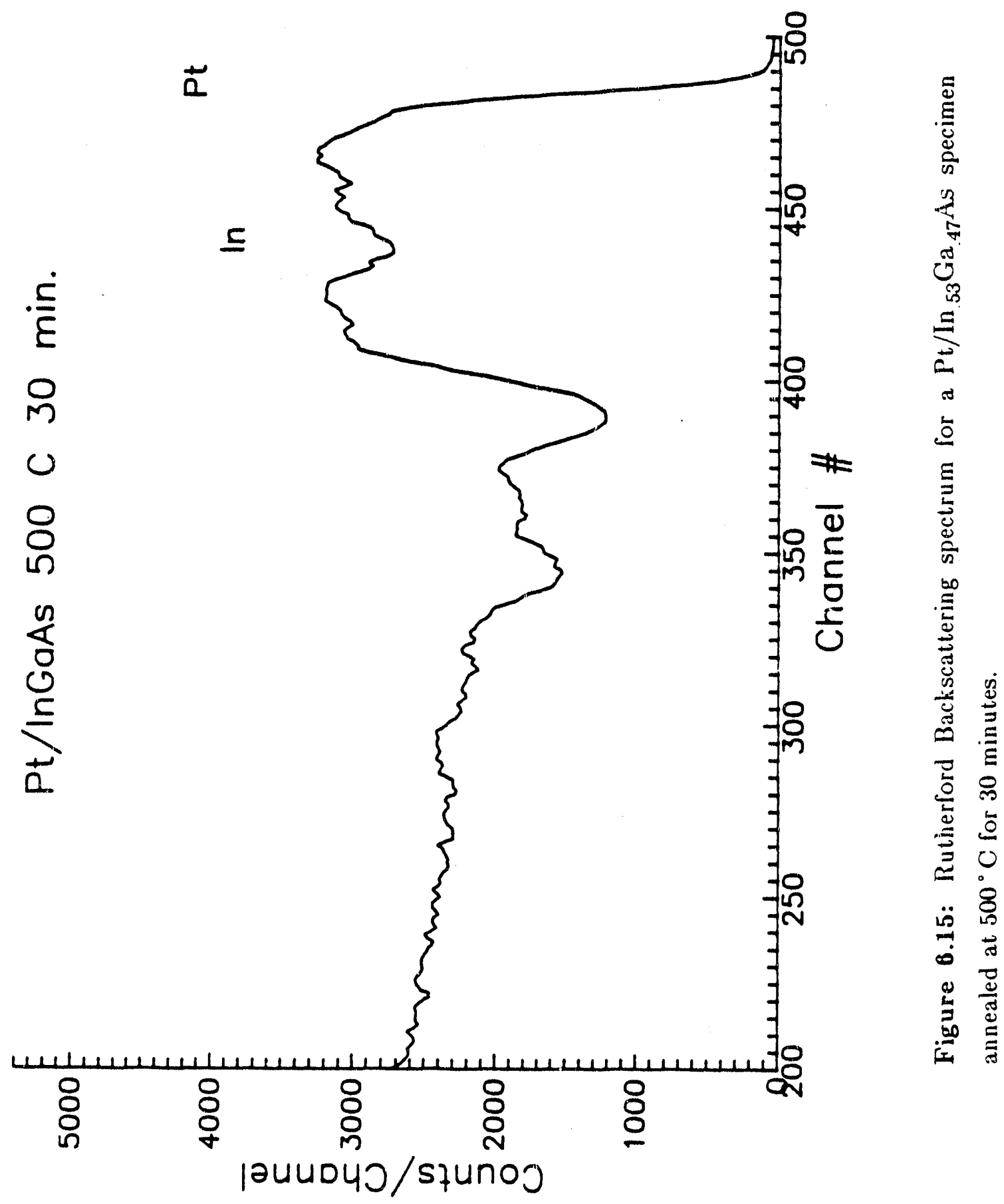


\section{as-deposited}

The Auger depth profile for the as-deposited specimen (not encapsulated) is shown in Figure 6.16. In this spectrum, the $\mathrm{Pt}$ signal is high from the start of the experiment. The signal remains constant until $\sim 3$ minutes, then decreases slowly until leveling off with a relative peak-to-peak height of $\sim 0.5$. Also near 3 minutes, the $\mathrm{Ga}, \mathrm{As}$, and In signals increase quite rapidly. The In signal rises first, followed simultaneously by the $\mathrm{Ga}$ and $\mathrm{As}$. The $\mathrm{Ga}, \mathrm{As}$, and In signals all become roughly level after their initial increase.

Features to note: First, the Pt signal does not decrease abruptly when the Ga, As, and In signals appear. Second, the relative peak-to-peak values of $\mathrm{Ga}$, As, and In change during subsequent milling. The In signal shows a slight local maximum while the $\mathrm{Ga}$ and $\mathrm{As}$ are still rising, then decreases, and gradually increases until leveling off to the substrate value. Third, the $\mathrm{Ga}$ signal follows a similar profile, although later in the spectrum, and the maximum intensity is not as pronounced as in the In case. The As is the slowest to reach its substrate level; not until after both the $G a$ and In have reached their maximum and diminished.

\section{$500^{\circ} \mathrm{C}: 30$ minutes}

The depth profile following the anneal at $500^{\circ} \mathrm{C}$ is shown in Figure 6.17. Several new features are present in this sample. The first element to shown an increase in its Auger signal is In, which develops very rapidly after $\sim 1.5$ minutes. After reaching a maximum $\sim 0 . \overline{5}$ minutes layer, the In signal drops off at a similar rate. As the In signal decreases, the $\mathrm{Ga}$ increases very rapidly, reaching a maximum near the same milling point as the In local minimum, i.e. $\sim 2.7$ minutes. As in the case of the initial In signal, the $\mathrm{Ga}$ drops off rapidly after peaking. The In signal rises inversely with the $\mathrm{Ga}$ decrease. Simultaneous with the In increase, the As signal begins to rise, though at a slower rate. The As reaches a plateau, and then drops down to a local minimum. While $A$ s is rising to its plateau, the In signal reaches a maximum much sooner, then 
begins a gradual decrease. When the As reaches its local minimum, the In has again jumped rapidly, peaked, and diminished to a constant value. Both the $\mathrm{Ga}$ and As reach a constant value after the In peak, in a manner similar to the as-deposited sample. 


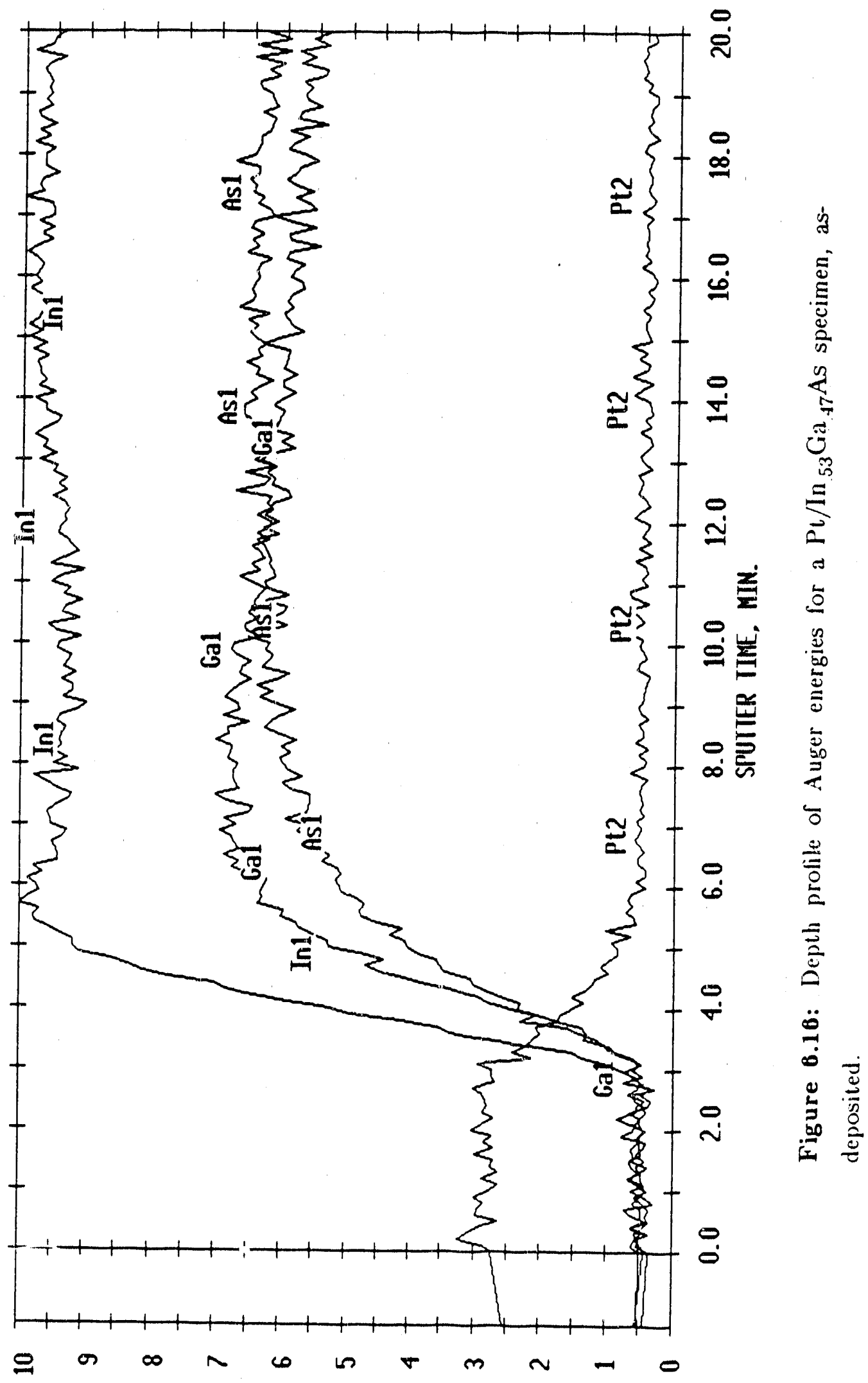

XXY $3 d-01-X \forall \exists d$ 


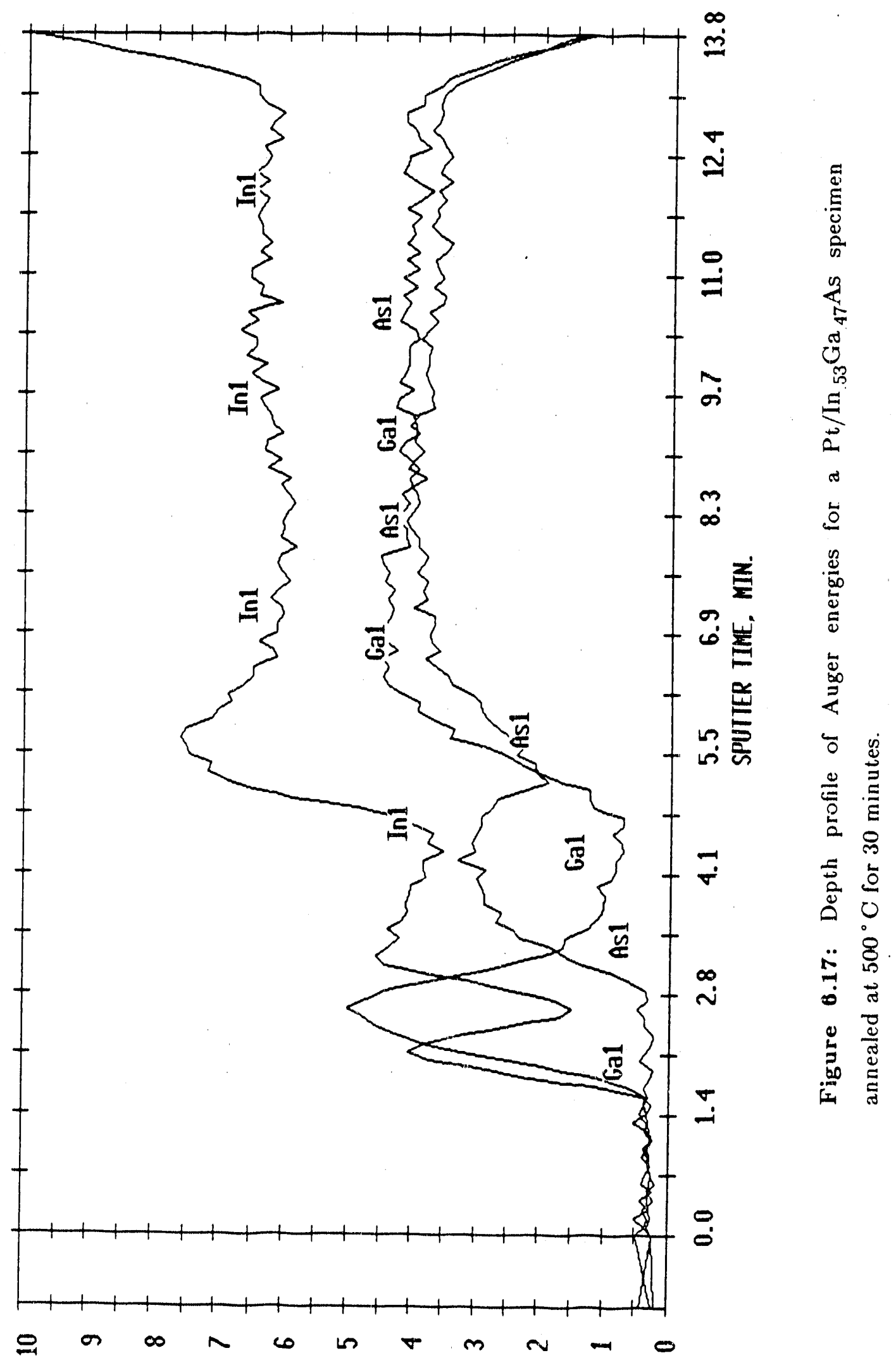

$2 \pi, 79-01-2 \pi, 39$ 
Features to note: First, both In and $\mathrm{Ga}$ begin the profile with peaks that develop sequentially, first In and then Ga. Second, the As profile begins with a much broader peak, that exists simultaneously with a significant In signal. Third, this In signal reaches a maximum quickly, and then decreases continuously throughout the range of the broad As peak. Fourth, at the onset of the substrate profile, the In signal peak is much more pronounced than it was in the as-deposited case. Fifth, the As signal reaches a local minimum when this In peak occurs.

\section{$400^{\circ} \mathrm{C}: 30$ minute}

The Auger depth profile taken following this anneal is shown in Figure 6.18. In contrast to the fully reacted sample in Figure 6.17, the Pt signal is the first to increase in this profile. The $\mathrm{Ga}$ and In signals begin to rise simultaneously $\sim 1$ mirute later. While the $\mathrm{Ga}$ signal reaches its maximum at a peak-to-peak value of $\sim 3.5$, the In continues to increase to the maximum of 10 . Following its maximum, the $\mathrm{Ga}$ signal dips to a local minimum before rising to its substrate level. Coincident with the Ga peak at $\sim 3.4$ minutes, the As begins to rise. Coincident with the $G_{a}$ dip, the As reaches a broad local maxinum, before increasing to its substrate level.

Features to note: First, the $P t$ signal begins to rise $\sim 1$ minute before any of the other elements. Second, the In signal rises slowly, to a very high peak-to-peak value. Third, the Ga signal rises to a local maximum within the range of the In signal. Fourth, the $G_{a}$ has a dip coincident with an As peak at $\sim 4.2$ ininutes. Fifth, the pronounced In peak occurs just after the Pt signal disappears, and before the Ga and As have reached the substrate levels. Sixth, the $\mathrm{Pt}$ signal reaches its peak after its onset, then decreases continuously until it disappears at the substrate. 


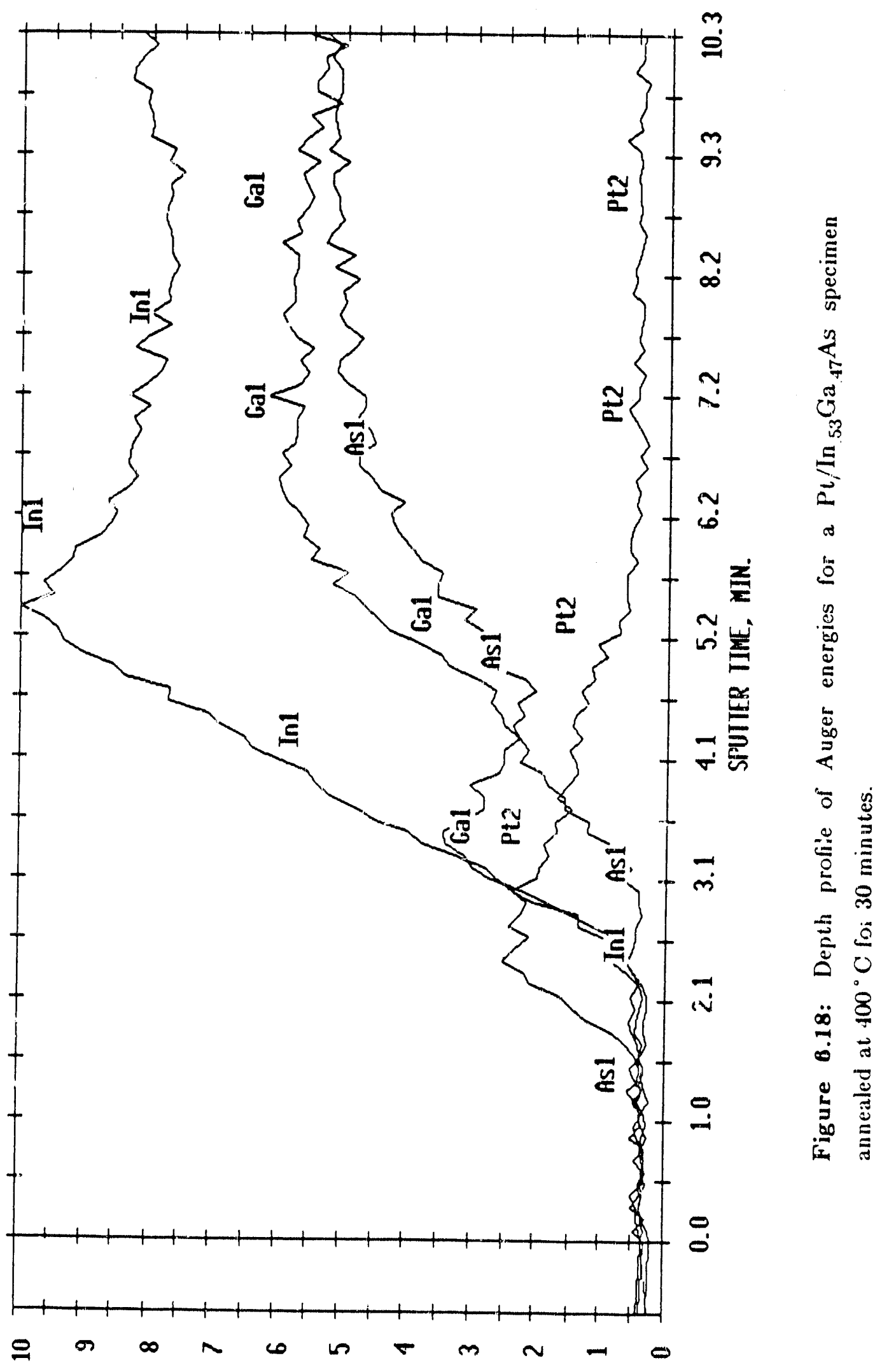

$X \forall \exists d-01-X \forall J c^{\prime}$ 


\section{$400^{\circ} \mathrm{C}: 120$ minute}

In Figure 6.19, the Auger depth profile following the $400^{\circ} \mathrm{C}: 120$ minute anneal is shown. As in the previous sample, the Pt signal begins to rise before the other elements. In this case, the delay before the onset of other elements is much shorter. In is the first element to appear, $\sim 0.2$ minutes after the Pt. The In signal rises quickly to a short plateau within $\sim 0.5$ minutes, at a peak-to-peak value of $\sim 3.0$. The In signal rise quickly from this plateau, decreases in slope briefly, and continues on to a very high peak. The $\mathrm{Ga}$ signal develops later than the $\mathrm{In}$, and increases very rapidly once it appears. The $\mathrm{Ga}$ reaches a local maximum, then drops very quickly to another minimum. At this point, it rises rapidly to the substrate value. The As signal begins to rise as the Ga signal drops. The As rises to a broad peak, diminishes slightly, and then increases to its substrate levels.

Features to ncte: First, the $\mathrm{Pt}_{\mathrm{t}}$ appears before any of the other elements, although the milling time before the onset of the In is very short. Second, In is the second element to appear, which reaches two plateaus as it increases to a very high maximum just before the substrate. Third, the $\mathrm{Ga}$ is the third element to appear, and reaches a peak at the end of the first In plateau. Fourth, the Ga signal nearly disappears after the initial peak, and then rises to its substrate values. Fifth, the onset of the As signal coincides with the dip in the Ga signal, and the As reaches a broad peak at the bottom of the $\mathrm{Ga}$ dip. Sixth, the $\mathrm{Pt}$ signal peaks before the onset of the other elements, the decreases continuously until it disappears at the substrate. 


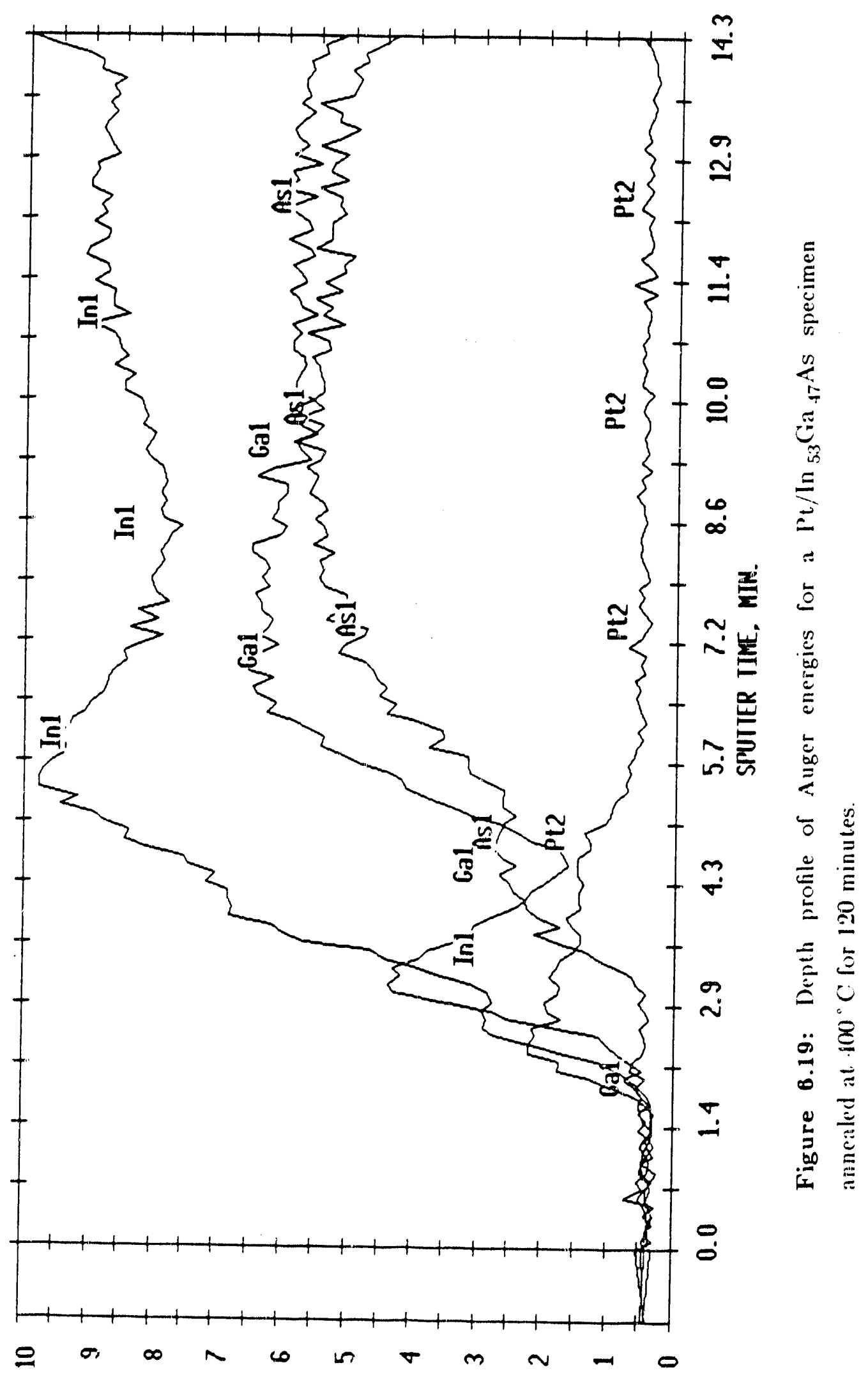

$Y X \exists]-01-x \in \exists]$ 


\subsubsection{Transmission Electron Microscopy}

Figure 6.20 shows a Selected Area Diffraction pattern from a cross-section of a specimen annealed for 120 minutes at $400^{\circ} \mathrm{C}$. The micrograph shows $\operatorname{In}_{53} \mathrm{Ga}_{47} \mathrm{As}$

(001) pattern, superimposed with a highly textured polycrystalline pattern from the reaction products.

An SAD pattern from a plan-view specimen annealed at $400^{\circ} \mathrm{C}$ for 120 minutes is shown in Figure 6.21. The SAD shows the diffraction spots from the substrate in the (011) orientation, as indicated by arrows in the figure. Well-defined diffraction spots from at least one of the reaction products are also visible. 

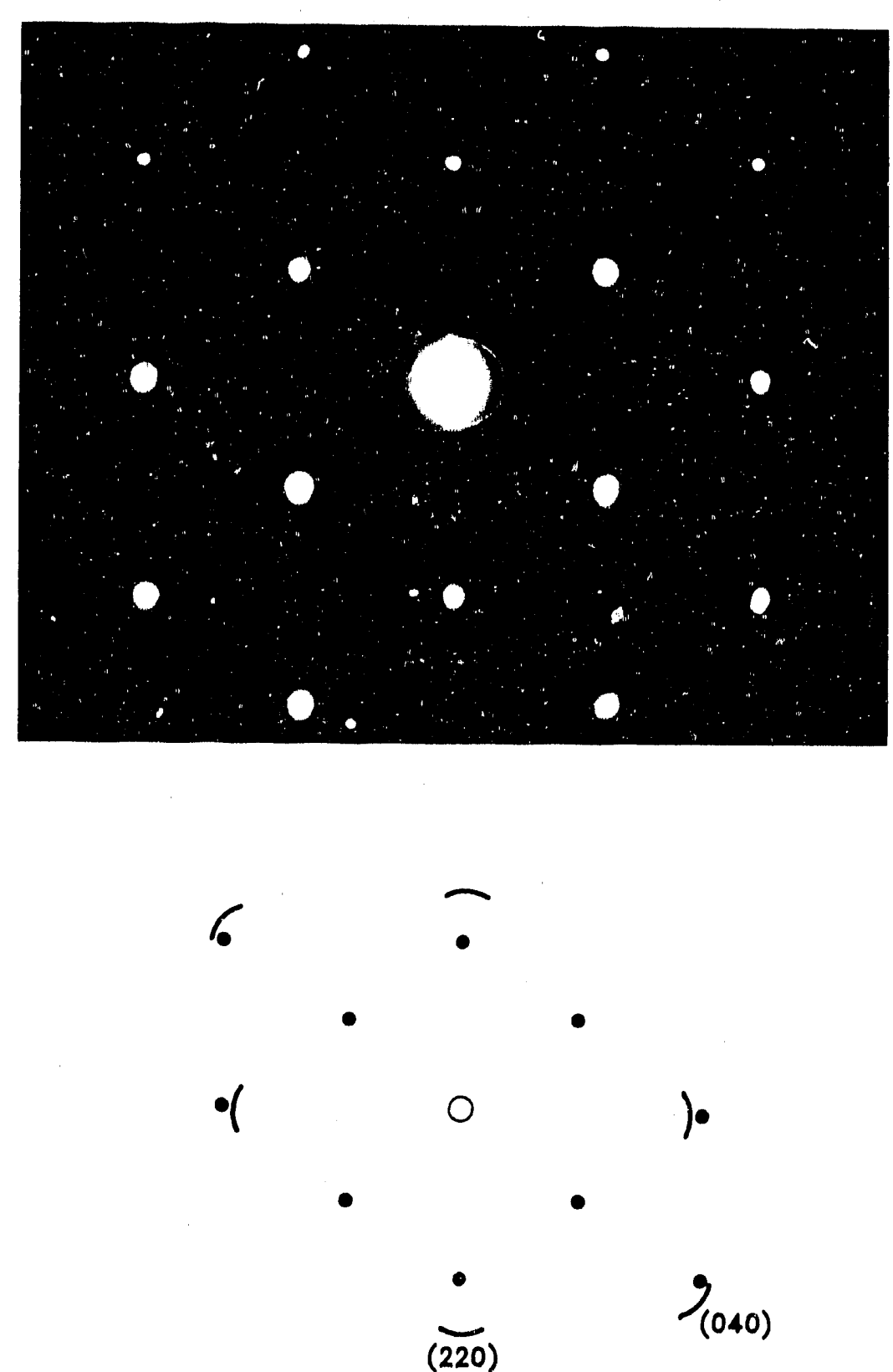

XBB 900-9365

Figure 6.20: Selected area diffraction pattern, taken from a cross-section specimen annealed at $400^{\circ} \mathrm{C}$ for 120 minutes. The substrate (011) pattern is present, with a textured polycrystalline pattern overlayed which can be indexed as a $\mathrm{Pt}\left(\operatorname{In}: \mathrm{Ga}_{2}\right)_{2}(001)$. 


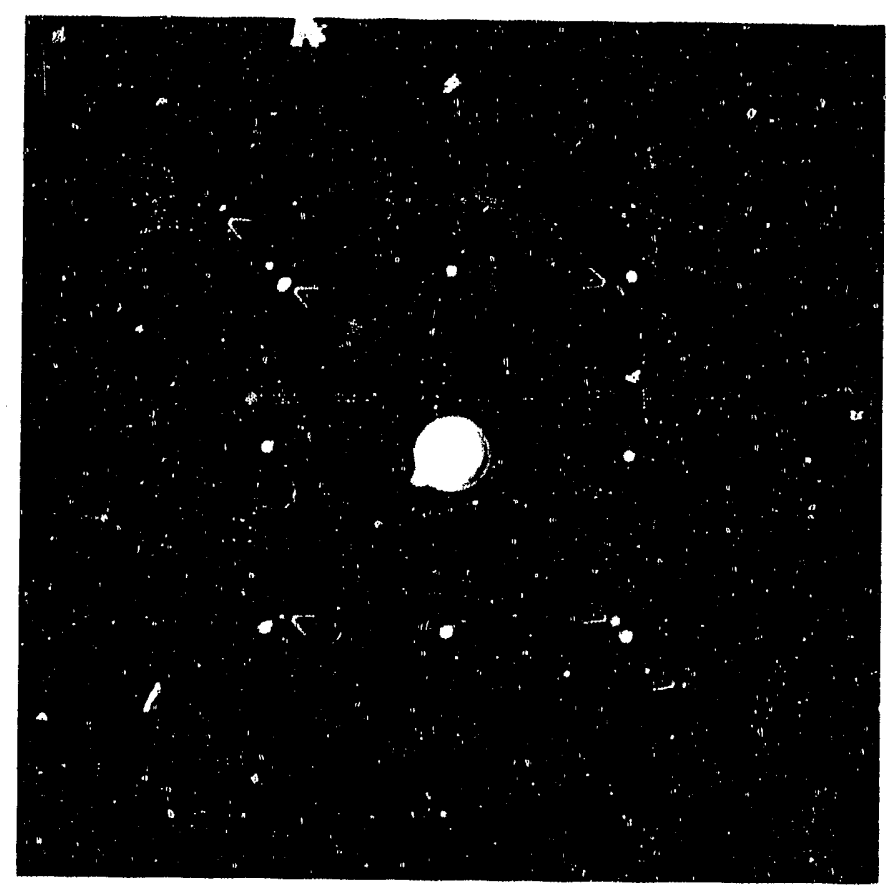

$\Delta$
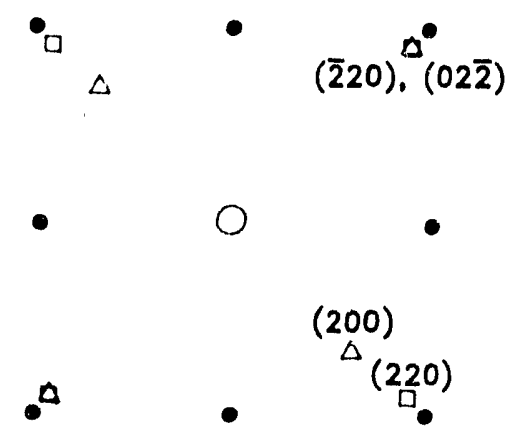

$\triangle$

XBP, $900-9360$

Figure 6.21: Selected area diffraction pattern, taken from a plan-view specimen annealed at $400^{\circ} \mathrm{C}$ for 120 minutes. The substrate (001) pattern is visible, with highly textured polycrystalline spots present which can be indexed as a Pt(In:Cia) 2, (00) and (011). 


\subsection{DISCUSSION}

\subsection{Pt/GaAs}

\subsubsection{X-ray Diffaction}

\section{as-deposited}

In the as-deposited sample (Figure 6.1), Pt peaks are evident at the $2 \Theta$ angles of $39.7^{\circ}, 46.0^{\circ}, 81.3^{\circ}$ and $85.6^{\circ}$, in adcition to the $\mathrm{GaAs}(200)$ and $(400)$ peaks at $31.7^{\circ}$ and $66.1^{\circ}$, respectively. No peaks indicative of reaction between the substrate and the $\mathrm{Pt}$ were observed in the as-deposited case. The $\mathrm{Pt}$ peaks correspond to the (111), (200), (311), and (222) planes, with the intensity of the (111) peak higher than reported for a randomly oriented $\mathrm{Pt}$ powder. The reported relative intensities for a random sample are: (111):(200):(311):(222) 100:55:35:12 [JC88], while the data give 100:36:10:5. These relative intensities are consistent with a preference for the (111) orientation for deposited $\mathrm{Pt}$, which has been previously reported for $\mathrm{Pt} / \mathrm{GaAs}$ [KM175].

The preferred orientation of the initial $\mathrm{Pt}$ deposition can affect subsequent phases, giving them a residual preferred orientation that is not de $e_{r}$ endent on the substrate orientation. Kumar found that in the $\mathrm{Pt} / \mathrm{GaAs}$ system, $\mathrm{PtAs} \mathrm{s}_{2}$ first formed with preferred crientation attributed to the effect of the $\mathrm{Pt}$ preferred orientation, and subsequently developed its own relationship with the substrate.

\section{0 minutes}

The $\mathrm{Pt} / \mathrm{Ga}$.As system reacts quite quickly at $400^{\circ} \mathrm{C}$. In Figure 6.2 , peaks from the reaction products are visible following the 10 minute anneal. These peaks indicate the development of $\mathrm{PtAs}, \mathrm{PtGa}$, and $\mathrm{Pt}_{3} \mathrm{Ga}$, with a considerable amount of residual $\mathrm{Pt}$. $\mathrm{Pt}_{3} \mathrm{Ga}$ is very difficult to distinguish from pure $\mathrm{Pt}$ (which is $\mathrm{FCC}$ ). $\mathrm{Pt}_{3} \mathrm{Ga}$ is an $\mathrm{Ll}$... ordered phase, with $\mathrm{Pt}$ atoms on the $\mathrm{FCC}$ cube corners, and $\mathrm{Ga}$ on the faces. It has a 
lattice parameter of $.3889 \mathrm{~nm}$, which is only $0.9 \%$ smaller than that of $\mathrm{Pt}$. In order to distinguish the two phases, the superlattice reflections, which have very low intensity, must be examined. The $\mathrm{Pt}_{3} \mathrm{Ga}(100)$ peak at $22.85^{\circ}$ is the best to determine if the $\mathrm{Pt}_{3} \mathrm{Ga}$ phase is present. In figure 6.2, there are peaks present at the superlattice positions, but all can be attributed to $\mathrm{Pt}$ or $\mathrm{PtAs}_{2}$, except for the (100). Therefore, $\mathrm{Pt}_{3} \mathrm{Ga}$ is a likely phase for these annealing conditions. The location of the Pt peaks has shifted to smaller d-spacings (by $\sim 1.3 \%$ ). This is consistent with the diffusion of $\mathrm{Ga}$ in to the $\mathrm{Pt}$ (which reduces the lattice dimensions), and by the overlap of the $\mathrm{Pt}$ and $\mathrm{Pt}_{3} \mathrm{Ga}$ peaks. $\mathrm{Pt}$ with $\mathrm{Ga}$ in solution will be denoted as $\mathrm{Pt}[\mathrm{Ga}]$.

\section{5 minutes}

Following the 15 minute anneal (Figure 6.3), the reaction product peaks have become stronger, while the $\mathrm{Pt}$ signal has decreased. The relative intensities of the $\mathrm{Pt}[\mathrm{Ga}](111)$ at $40.2^{\circ}$ and the $\mathrm{PtGa}(210)$ at $41.3^{\circ}$ have reversed. The The GaAs (200) peak is of considerably lower intensity than the GaAs (400) in this spectrum. This difference is to be expected in the GaAs (and $\operatorname{In}_{x} \mathrm{Ga}_{1-\mathrm{x}} \mathrm{As}$ ) system, where the intensity of the (200) arises from the difference in atomic scattering factor of $\mathrm{Ga}$ and As, as opposed to the intensity of the (400), which arises from the sum. The intensity of reflections from single crystals are much more sensitive to very small changes in orientation of the sample during XRD scans than are polycrystalline phases, so the intensity of the (200) peak is often very low.

Examination of this spectrum indicates the presence of the same phases found previously: $\mathrm{Pt}|\mathrm{Ga}|, \mathrm{PtAs}, \mathrm{PtGa}$, and $\mathrm{Pt}_{3} \mathrm{Ga}$.

\section{0 minutes to 30 minutes}

After the 20 minute and 30 minute anneals, very little change is observed in the $\mathrm{x}$-ray spectra compared to Figure 6.3, except for changes in the relative intensities of 
the peaks. This indicates that no new phases have appeared, and that none of the old phases have disappeared.

\section{0 mir utes}

Figure 6.4 shows the spectrum following a 40 minute anneal. There are two significant changes in this sample. First, the $\mathrm{Pt}$ peaks are no longer evident in the spectrum. Second, the $\mathrm{Pt}_{3} \mathrm{Ga}$ phase is also no longer visible, as evidenced by the absence of any peak at $23.0^{\circ}$. This data confirms the result of other investigators (see section $4.3, \mathrm{p} .40$ ) as to the final reaction products in this system: GaAs, PtAs 2 , and $\mathrm{PtGa}$. A summary of phase formation during the $\mathrm{Pt} / \mathrm{GaAs}$ reactions is presented in Table III.

When more than one reacted phase is present, the ratios of peak intensities cannot be easily compared with the standard powder spectra. The effect of overlapping peaks from different phases on the intensities cannot be separated. However, some information can be determined once the phases have been identified. The relative intensities of the non-overlapped PtAs, peaks, the (200), (210), (211), (220), and (311) can be compared. The relative intersity of the $\mathrm{PtAs}_{2}(200)\left(30.0^{\circ}\right)$ peak is higher than reported for a randomly oriented powder, with the intensity of the $\mathrm{PtAs}_{2}$ (311) $\left(50.7^{\circ}\right)$ lower than expected. The average ratio $I_{(200)} / I_{(311)}$ for the data is $1.8 \pm 0.2$, as compared with 0.6 for a rardomly oriented powder. This change in relative intensities is consistent with texturing of the $\mathrm{PtAs}_{2}$ product phase. 


\begin{tabular}{|c|c|}
\hline as-deposited & $\mathrm{Pt}, \mathrm{GaAs}$ \\
\hline 10 to $30 \mathrm{~min}$. & $\mathrm{Pt}[\mathrm{Ga}], \mathrm{Pt}_{3} \mathrm{Ga}, \mathrm{PtGa}, \mathrm{PtAs}, \mathrm{GaAs}$ \\
\hline $40 \mathrm{~min}$. & $\mathrm{PtGa}, \mathrm{PtAs}{ }_{2}, \mathrm{GaAs}$ \\
\hline
\end{tabular}

\section{Table III}

Phases present in $\mathrm{Pt} / \mathrm{GaAs}$ reactions after anneals at $400^{\circ} \mathrm{C}$, as determined from $x$-ray diffraction spectra. 


\subsubsection{Rutherford Backscattering}

Rutherford Backscattering spectra from the $\mathrm{Pt} / \mathrm{GaAs}$ as-deposited, 10 minute, and 40 minute anneals are shown in Figure 6.5. The spectrum for the as-deposited sample indicates that the $\mathrm{Pt}$ did not react significantly with the substrate during the deposition procedure. The low-energy shoulder of the peak and the high-energy shoulder of the substrate signal are sharp, with no evidence of a tail that would indicate interdiffusion is occurring. In addition, the top of the $\mathrm{Pt}$ and substrate peaks are fairly level, without large changes in intensity that would be indicative of changes in composition.

The spectrum from the 10 minute anneal shows an intermediate case where unreacted $\mathrm{Pt}$ is still present in the spectrum. The $\mathrm{Pt}$ peak still begins at the channel for surface $\mathrm{Pt}$, but shows a step down on the low-energy side. The step indicates that the $\mathrm{Pt}$ has only partially reacted, and the reduced intensity of the $\mathrm{Pt}$ signal is consistent with a reduced thickness of unreacted $\mathrm{Pt}$. The signal from the substrate elements has begun to intrude in the gap that appeared between the $\mathrm{Pt}$ and substrate signals in the as-deposited spectrum, indicating that at least one of these elements has diffused in to the Pt.

The spectrum for the 30 minute anneal shows that there is no residual unreacted $\mathrm{Pt}$, within the resolution limit of the system $(\sim 10 \mathrm{~nm})$. The Pt exhibits a step in its intensity, which is consistent with a change in composition across the reacted layer.

Results of the Rutherford Backscattering data are summarized in Figure 7.1 . In this study, the thickness of the GaAs that has reacted was monitored in order to examine the kinetics of the $\mathrm{Pt} / \mathrm{GaAs}$ reaction. The data exhibit a parabolic relationship between the amount of material reacted and the annealing time. This is consistent with a diffusion-controlled reaction, as has been previously reported for $\mathrm{Pt} / \mathrm{GaAs}$. 


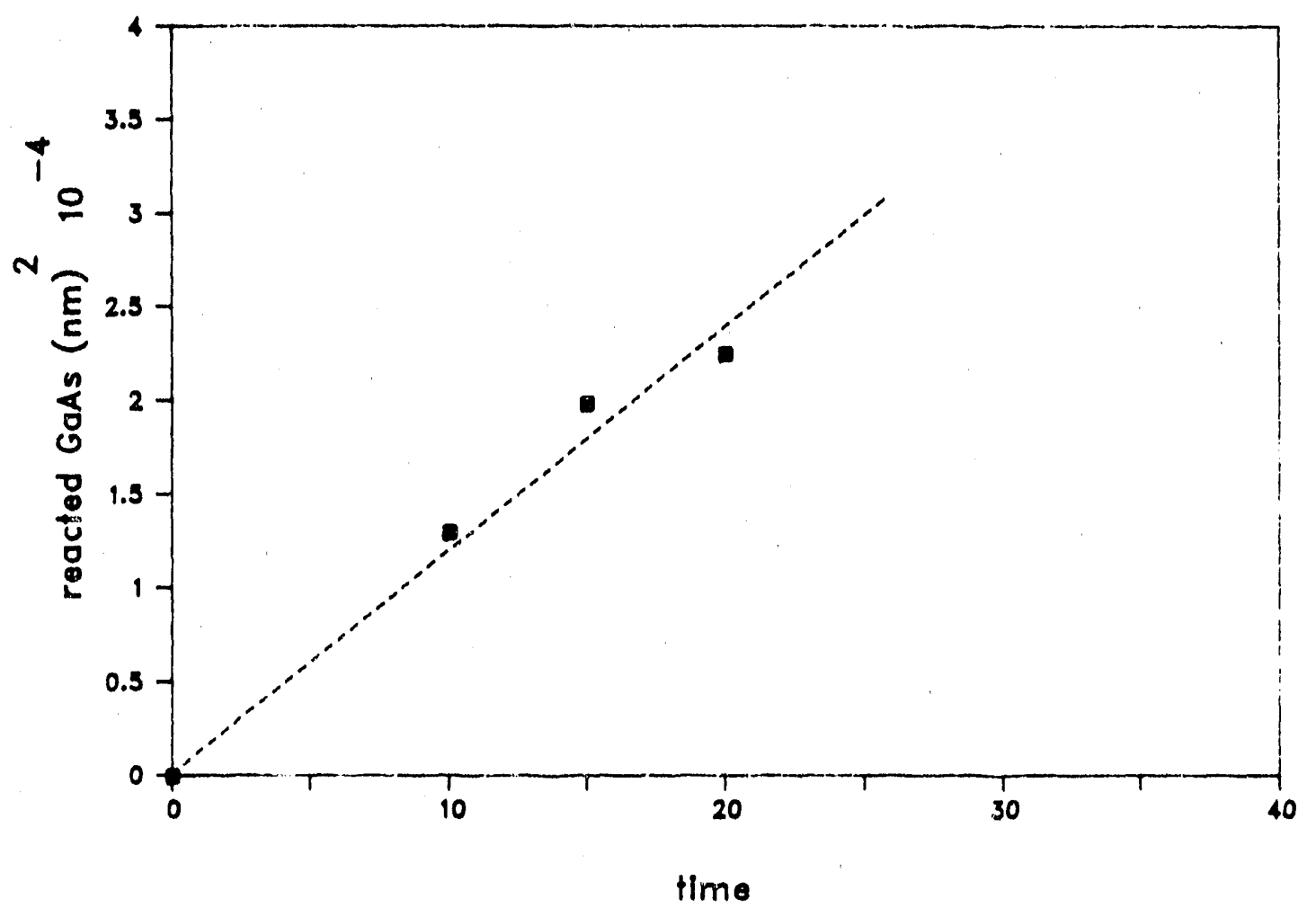

Figure 7.1: Plot of $x^{2}$ vs. annealing time, where $x$ is the thickness of Gaits that has reacted. Annealing temperature: $400^{\circ} \mathrm{C}$. 
The dotted line in Figure 7.1 is a linear regression of the data points. The slope of this line, which is $D_{\text {eff }}$ for this system (within a factor of 2 ), is $\sim 2 \times 10^{-13}\left(\mathrm{~cm}^{2} \mathrm{~s}^{-1}\right)$. Compared with the estimates of diffusivities for various diffusion modes and media in Table I (page 48 ), this value is $\sim 7$ orders of magnitude higher than for the lattice diffusivity of $\mathrm{PtAs}_{2}$, and $\sim 3$ orders of magnitude for the lattice diffusivity of $\mathrm{PtGa}$. If grain boundary diffusion is assumed, the measured $(\mathrm{d} / \delta) \mathrm{xD}_{\text {eff }}$ is $\sim 2 \times 10^{-11}\left(\mathrm{~cm}^{2} \mathrm{~s}^{-1}\right)$. Compared with the values for grain boundary diffusivities in Table I, this value is $\sim 3$ orders of magnitude higher than for the grain boundary diffusivity of $\mathrm{PtAs}_{2}$, and on the same order of magnitude for the grain boundary diffusivity of PtGa. These data cannot conclusively determine the dominant diffusion mode in the $\mathrm{Pt} / \mathrm{GaAs}$ system because of the many simplifying assumptions. However, the results indicate that the grain boundary diffusion mode is likely to have made the major contribution to the total diffusion.

\subsubsection{Auger Depth Profile}

Figure 6.6 shows the SAM depth profile for a $\mathrm{Pt} / \mathrm{GaAs}$ sample that has been annealed for 60 minutes at $400^{\circ} \mathrm{C}$. This profile indicates the distribution of the elements in the sample, and hence the depth distribution of the phases found by XRD. It should be noted that these depth profiles tend to be less sharp than the corresponding microstructure, because of differential sputtering rates (vs. phase and morphology) and due to the dependence of the electron escape depth on the Auger energies. The ion milling procedure will also cause intermixing of the elements in the system, and tend to "push" some elements deeper into the sample. Consequently, the milling times indicated on the $x$-axis of the Auger depth profile is not indicative of the absolute depth in the specimen, but can only be used to identify relative positions.

In Figure 6.6, the reacted layer is encountered after $\sim 5$ minutes of milling, as indicated by the sudden increase in the $\mathrm{Ga}$ signal, and more gradual increase in the $\mathrm{Pt}$ signal. The absence of an increase in the As signal indicates that this element, and 
hence the PtAs 2 phase is not present at the reacted layer surface. Combining the results of the $x$-ray difraction studies with the Auger data, it can be concluded that the PtGa phase is located in the surface layer.

The As signal increases at $\sim 12.5$ minutes, indicating the presence of $\mathrm{PtAs}_{2}$. The gradual increase in As, and the simultaneous gradual decrease of $\mathrm{Ga}$ is consistent with a rough interface. This would be expected with grain sizes within an order of magnitude of the layer thickness, and some interpenetration of the two phases. The fact that the Ga signal never decreases to zero within this range indicates that a significant amount of $\mathrm{Ga}$ is present in this layer. The $\mathrm{Ga}$ has to he in the form of $\mathrm{PtGa}$ grains, as no other possibility is consistent with the $x$-ray data. Any other phase would give rise to unexplained peaks in the spectrum; and dissolution of $\mathrm{Ga}$ in $\mathrm{PtAs}_{2}$ would shift the diffraction peaks of the arsenide. Close examination of Figure 6.6 shows an increase in the $\mathrm{Ga}$ signal and simultaneous decrease in the As signal at $\sim 21$ minutes. This could arise from the presence of a particularly large PtGa grain at this point in the microstructure.

The $\mathrm{Pt}$ signal remains fairly flat throughout the range of the reacted layer, although it appears slightly higher in the PtGa region. This is consistent with the higher concentration of $\mathrm{Pt}$ in the $\mathrm{PtGa}$ as compared with $\mathrm{PtAs}_{2}$ phases, but could also arise from different sputtering yields of $\mathrm{Ga}$ and $\mathrm{As}$ in the respective phases.

The data indicate that the interface between the reacted layer and the GaAs substrate is also rough. The $\mathrm{Ga}$ and $\mathrm{As}$ signals increase from the levels in the reacted layer to that of the substrate in $\sim 5$ minutes of milling. This indicates the protrusion of $\mathrm{PtGa}$ and $\mathrm{PtAs} z$ grains into the substrate.

To summarize, the Auger data indicate that the reaction products are layered in the following sequence: $\mathrm{GaAs} / \mathrm{PtAs} / 2 / \mathrm{PtG}$. The data also indicate a concentration of $\mathrm{Ga}$ in the $\mathrm{PtAs} \mathrm{s}_{2}$ layer, in the form of PtGa. In addition, the interfaces between the $\mathrm{PtGa}$ and $\mathrm{PtAs}$, layers, and the reacted layer/GaAs are rough. 


\subsubsection{Summary}

These experimental results are consistent with the work of previous investigators on the $\mathrm{Pt} / \mathrm{In}_{\mathrm{x}} \mathrm{Ga}_{1-\mathrm{x}}$ As system, for the case of $\mathrm{x}=0$ :

1. The reaction kinetics are parabolic for thin films, indicating diffusion control.

2. Grain boundary diffusion is likely the dominant mode at $400^{\circ} \mathrm{C}$.

3. $\mathrm{Pt}[\mathrm{Ga}], \mathrm{Pt}_{3} \mathrm{Ga}, \mathrm{PtGa}, \mathrm{PtAs} \mathrm{s}_{2}$, and $\mathrm{GaAs}$ are present at intermediate stages.

4. $P t G a, P t A s_{2}$, and GaAs are the end phases of the thin film reaction.

5. The PlAs, phase is tertured.

6. The reaction products are layered in the following sequence: $\mathrm{PtGa} / \mathrm{PtAs}_{2} / \mathrm{GaAs}$; although there is a significant amount of $\mathrm{PtGa}$ in the $\mathrm{PtAs}_{2}$ layer. 


\section{2 $\mathrm{Pt} / \mathrm{In}_{.53} \mathrm{Ga} .47 \mathrm{As}$}

In Figures 6.7 through 6.13, $\mathrm{x}$-ray diffraction spectra for depositions of $70 \mathrm{~nm}$ of $\mathrm{Pt}$ on In ${ }_{53} \mathrm{Ga}_{47} \mathrm{As}$, annealed at $400^{\circ} \mathrm{C}$ for various times are presented. In all cases, the In ${ }_{53} \mathrm{Ga}_{47} \mathrm{As}$ substrate peaks at $30.5^{\circ}(200)$ and $63.2^{\circ}(400)$ are observed.

\subsubsection{X-Ray Diffraction}

\section{as-deposited}

In the as-deposited case (Figure 6.7), the $\mathrm{Pt}$ peaks are present at $39.7^{\circ}$ (111), $45.9^{\circ}(200), 80.8^{\circ}(311)$, and $85.4^{\circ}$ (222). These are consistent with the as-deposited Pt peaks on GaAs in Figure 6.1, with the discrepancy in the higher angle peaks due to the difficulty of identifying the peak position for very low intensity peaks. Note again the very high intensity of the $\mathrm{Pt}$ (111) peak, indicative of a preferred (111) orientation. The measured intensity ratios go as 100:5:4:5, as compared to 100:55:35:12 for a randomly oriented sample, and 100:36:10:5 for $\mathrm{Pr} / \mathrm{GaAs}$. This indicates an even higher preference for the (111) orientation than for $\mathrm{Pt} / \mathrm{GaAs}$. No reaction between the substrate and $\mathrm{Pt}$ deposition was observed by $\mathrm{x}$-ray diffraction in the as-deposited samples for either case.

\section{0 minutes}

As in the case of $\mathrm{Pt} / \mathrm{GaAs}$, this annealing schedule (Figure 6.8 ) resulted in the reaction of the $\mathrm{Pt}$ with the substrate, although the generally lower intensities of the reaction product peaks in $\mathrm{Pt} / \mathrm{In}_{53} \mathrm{Ga}_{47}$ As suggest that the reaction is not as extensive at this early stage of annealing.

Comparing Figures 6.2 and 6.8 , some similarities can be observed. The positions of the $\mathrm{Pt}$ peaks have again shifted to smaller d-spacings (by $\sim 1.0 \%$ in Fig. 6.8), which is consistent with the diffusion of $\mathrm{Ga}$ into the $\mathrm{Pt}$ layer. The In atom is $\sim 11 \%$ larger 
than $\mathrm{Pt}$ (and $\sim 14 \%$ larger than $\mathrm{Ga}$ ), which would cause an expansion of the $\mathrm{Pt}$ lattice if this element were the only element to diffuse in to the $\mathrm{Pt}$. It is possible that both $\mathrm{Ga}$ and In are present, which could result in smaller shrinkage of the $\mathrm{Pt}$ lattice than was observed in the $\mathrm{Pt} / \mathrm{GaAs}$ case $(\sim 1.3 \%$ in Figure 6.2$)$. This possibility cannot be distinguished by $x$-ray diffraction.

Comparison of the non-substrate, non-Pt peaks with the $\mathrm{PtAs}_{2}$ standard spectrum indicates that this phase is present. Several peaks can be attributed to $\mathrm{PtAs}_{2}$ : (111) at $25.9^{\circ},(200)$ at $30.3^{\circ},(220)$ at $42.6^{\circ}$, and (311) at $50.6^{\circ}$. At this early stage of annealing, it is impossible to determine if any texturing is developing in the $\mathrm{PtAs}_{2}$, as only the (220) peak does not overlap with other phases. For the most part, the peak intensities are very low, with one exception. The peak at $30.3^{\circ}$, on the lower angle shoulder of the $\mathrm{In}_{53} \mathrm{Ga}_{47} \mathrm{As}(200)$, is consistent with $\mathrm{PtAs}_{2}(200)$ and with significant intensity. For longer annealing times, additional $\mathrm{PtAs}_{2}$ peaks develop that will allow for comparison of the recorded intensities with the standard, randomly oriented powder spectra.

As was discussed in section 7.1.1, the only peak available for uniquely identifying $\mathrm{Pt}_{3} \mathrm{Ga}$ in these systems is the $\mathrm{Pt}_{3} \mathrm{Ga}(100)$ peak at 22.85 ${ }^{\circ}$. In Figure 6.8, a very low intensity peak has appeared at $22.6^{\circ}$ A peak at this angle is present in the spectrum, indicating that this phase also develops in the $\mathrm{Pt} / \mathrm{In}_{.53} \mathrm{Ga}_{47} \mathrm{As}$ reactions.

$\mathrm{PtGa}$ is present following the $400^{\circ} \mathrm{C}: 10$ minute anneal of $\mathrm{Pt}$ on GaAs. The existence $\mathrm{PtGa}$ cannot be definitely determined from the data in Figure 6.8. Any peaks which may be attributed to the PtGa phase are either too small at this stage to be convincing, or overlapping with other phases in the system For example, the peak at $25.9^{\circ}$ ) could be attributed to the $\mathrm{PtAs}_{2}$ (111) or the $\mathrm{PtGa}(110)$.

There are peaks in this spectrum which could correspond to $\mathrm{Pt} \mathrm{In}_{2}$, although they are at slightly higher angles. These include a very strong peak at $58.2^{\circ}$, near the $\operatorname{PtIn}(400)\left(57.9^{\circ}\right)$, and a much smaller peak at $28.2^{\circ}$, near the $\operatorname{PtIn} \operatorname{In}_{2}(200)\left(28.0^{\circ}\right)$. 
The peaks in the data are at smaller d-spacings than would be expected for this phase, by in average of $\sim 0.6 \%$. A shift to smaller d-spacings could arise from the presence of $\mathrm{Ga}$ in this phase, i.e. $\mathrm{Pt}(\mathrm{In}: \mathrm{Ga})_{2}$. Indications are that at lower temperatures, nearly pure $\mathrm{PtIn}_{2}$ forms, but as the annealing temperature increases, a significant solubility of $\mathrm{Ga}$ develops, and the lattice parameter decreases.

The possibility of a solid solution between $\mathrm{FtGa}_{2}$ and $\mathrm{PtIn}_{2}$, based on their identical crystal structures and the similarity of the group III elements, was discussed in section 4.1 (p. 32). The In atomic radius is $14 \%$ larger than that of Ga. These facts suggest that it is possible for the $\mathrm{PtIn}_{2}$ structure to accommodate some Ga atoms in a substitutional solid solution, with a corresponding decrease in lattice parameter.

To summarize, the probable phases present following the 10 minute anneal: $\mathrm{Pt}|\mathrm{Ga}|, \mathrm{Pt} \cdot \mathrm{As}_{2}, \mathrm{Pt}(\mathrm{In}: \mathrm{Ga})_{2}$, and $\mathrm{Pt}_{3} \mathrm{Ga}$.

\section{0 minutes to 30 minutes}

The spectra taken following the 20 and 30 minute anneals (not shown) are very similar to Figure 6.8. No new phases have developed, and no previous phases have disappeared. The reaction products peaks are increasing in intensity, especially the $\mathrm{Pt}(\mathrm{In}: \mathrm{Ga})_{2}(400)$ at $58.1^{\circ}$. By extrapolating from the indexed $\mathrm{Pt}(\mathrm{In}: \mathrm{Ga})_{2}$ peaks, it should be possible to determine the lattice parameter, and estimate the composition of this phase. At these annealing stages, however, the presence of residual $\mathrm{Pt}$ peaks prevents an accurate determination of the peak positions. Peaks are developing at $31.7^{\circ}$ and $41.1^{\circ}$, although their exact positions are difficult io determine because of their very low intensity and their positions on the shoulders of other peaks. They can be attributed to the $\mathrm{PtGa}(111)$ and (210) planes; other PtGa peaks may be present but would be overlapped by $\mathrm{PtAs} s_{2}$ or $\mathrm{Pt}(\operatorname{In}: \mathrm{Ga})_{2}$ peaks.

The probable phases present following 20 to 30 minute anneals: $\mathrm{Pt}\{\mathrm{Ga}\}, \mathrm{Pt} . \mathrm{As}_{2}$, $\mathrm{Pt}(\mathrm{In}: \mathrm{Ga})_{2}$, and $\mathrm{Pt}_{3} \mathrm{Ga}$, with $\mathrm{PtGa}$ possibly present. 


\section{BO minutes}

The reaction products following a 60 minute anneal (Figure 6.9 ) at $400^{\circ} \mathrm{C}$ are the same as for the previous anneals. In addition, the PtGa peaks (at $31.7^{\circ}$ and $41.1^{\circ}$ ) discussed for the 20 to 30 minute anneals are much more pronounced, indicating the presence of this phase.

Substantial $\mathrm{PtAs}_{2}$ diffraction peaks are now present; the (111) at $25.9^{\circ}$, the (210) at $33.6^{\circ}$, the $(211)$ at $36.8^{\circ}$, the $(220)$ at $42.9^{\circ}$, and the (311) at $50.7^{\circ}$. Many of these peaks overlap with $\mathrm{PtGa}$ and $\mathrm{Pt}(\mathrm{In}: \mathrm{Ga})_{2}$, so comparison of the relative intensities can be made only for the (210) and (220), which are rather low intensity peaks. The intensities of these two peaks is the same, giving $I_{(210)} / I_{(220)} \sim 1$, while the intensity ratio reported for standard powder specimens is 0.6 . The standards also predict that the ratio $\mathrm{I}_{(210)} / \mathrm{I}_{(311)}=0.3$, while the ratio calculated from the data in Figure 6.9 gives a value of $\sim 0.3$, despite the fact that the intensity of the (311) has contributions from the $\mathrm{Pt}(\mathrm{In}: \mathrm{Ga})_{2}$ phase. This result suggests that the $\mathrm{PtAs}_{2}$ phase may exhibit some preferred orientation, but the effect is most likely very slight.

\section{0 minutes}

Following the 180 minute anneai (Figure 6.10), virtually all of the $\mathrm{Pt}$ has disappeared. There are indications of a small peak at $46^{\circ}$, the $\mathrm{Pt}(200)$. Otherwise, the reaction product peaks are well defined. One of the reasons for performing $x$-ray diffraction on these samples is to determine if phase formation changes as a function of annealing time. If the phase formation is not consistent, kinetic data is difficult to interpret. The $\mathrm{x}$-ray data for anneals at $400^{\circ} \mathrm{C}$ indicate this is true, with the possible exception that PtGa cannot be positively identified until after the first 10 minutes. The phase formation sequence for the $\mathrm{Pt} / \mathrm{In}_{53} \mathrm{Ga}_{47}$ As system annealed at $400^{\circ} \mathrm{C}$ is summarized in Table IV. 


\begin{tabular}{|c|c|}
\hline as-deposited & $\mathrm{Pt}, \mathrm{In}_{53} \mathrm{Ga}_{47} \mathrm{As}$ \\
\hline $10 \mathrm{~min}$. & $\mathrm{Pt}|\mathrm{Ga}|, \mathrm{Pt}_{3} \mathrm{Ga}, \mathrm{Pt}(\mathrm{In}: \mathrm{Ga})_{2}, \mathrm{PtAs}_{2}, \operatorname{In}_{.53} \mathrm{Ga}_{47} \mathrm{As}$ \\
\hline 20 to $180 \mathrm{~min}$ & $\mathrm{Pt} \mid \mathrm{Ga}), \mathrm{Pt}_{3} \mathrm{Ga}, \mathrm{PtGa}, \mathrm{Pt}\left(\mathrm{In}: \mathrm{Ga}_{2}\right)_{2,}, \mathrm{PtAs}_{2}, \mathrm{Ir}_{53} \mathrm{Ga}_{47} \mathrm{As}$ \\
\hline final phases & $\mathrm{PtGa}, \mathrm{Pt}(\mathrm{In}: \mathrm{Ga})_{2}, \mathrm{PtAs}_{2}, \mathrm{In}_{53} \mathrm{Ga}_{47} \mathrm{As}$ \\
\hline
\end{tabular}

\section{Table IV}

Phases present in $\mathrm{Pt} / \mathrm{In}_{53} \mathrm{Ga}_{47}$ As reactions after anneals at $400^{\circ} \mathrm{C}$, as determined from $x$-ray diffraction spectra. 


\section{Long-term Anneals}

The indexed spectrum in Figure 7.2 corresponds to a fully reacted $\mathrm{Pt} / \mathrm{In}_{53} \mathrm{Ga}_{.47} \mathrm{As}$ microstructure $\left(500^{\circ} \mathrm{C}: 30\right.$ minutes). The final product phases in this system: In ${ }_{53} \mathrm{Ga}_{47} \mathrm{As}, \mathrm{PtAs}, \mathrm{Pt}(\mathrm{In}: \mathrm{Ga})_{2}$, and $\mathrm{PtGa}$. Only the $\mathrm{PtAs}_{2}(210)$ and (220) peaks do not overlap with other phases, making determination of texturing in this phase difficult. The ratio $I_{(210)} / I_{(220)} \sim 1.6$, as compared to 0.6 for a randomly oriented sample. The intensity of the $\mathrm{PtAs}_{2}$ (200) peak can be estimated from the spectrum, giving $\mathrm{I}_{(200)} / \mathrm{I}_{(220)} \sim 1.5$, as compared to 1.2 for a randomly oriented sample. Both of these results suggest some texturing of the $\mathrm{PtAs}_{2}$ phase, but to a much smaller degree than was found in the Pt/GaAs case.

An important result of the study of long-term anneals is the existence of a solid solution between $\mathrm{PtIn} 2$ and $\mathrm{PtGa}$, or $\mathrm{Pt}(\mathrm{In}: \mathrm{Ga})_{2}$. Prominent peaks that can be attributed to this phase are present near $28^{\circ}(200), 40^{\circ}(220), 58^{\circ}(400)$, and $86^{\circ}$ (440) in these spectra. These data can be extrapolated to the unit cell dimension to give $a_{0}$. Assuming Vegard's law for small concentrations of $\mathrm{Ga}$ in $\mathrm{PtIn}_{2}$, an expression for the lattice parameter of the ternary phase $\mathrm{PtIn}_{2 \mathrm{x}} \mathrm{Ga}_{2-2 \mathrm{x}}$ is: $\mathrm{a}_{0}=.5923 \mathrm{~nm}+.0443 \mathrm{x}$. Conversely, the amount of $\mathrm{Ga}$ in the phase can be determined by: $\mathrm{x}=\left(\mathrm{a}_{0}-.5923 \mathrm{~nm}\right) \div$ .0413

The XRD data for these annealing conditions indicate that the lattice parameter of $\mathrm{PtIn}_{2 \mathrm{x}} \mathrm{Ga}_{2-2 \mathrm{x}}$ decreases as the annealing temperature increases, indicating a higher solubility of $\mathrm{Ga}$. In Figuie 7.3, the lattice parameter and $\mathrm{Ga}$ solubility of the $\mathrm{Pt}(\mathrm{In}: \mathrm{Ga})_{2}$ phase is shown as a function of annealing temperature.

A consequence of the shift in $\mathrm{Pt}(\mathrm{In}: \mathrm{Ga})_{2}$ peaks as a function of annealing temperature is the uncovering or covering of peaks from other phases. The peak's near $40^{\circ}$, $50^{\circ}$, and $58^{\circ}$ are a demonstration of this behavior. The $\mathrm{PtGa}(210)$ peak appears at $\$ 11^{\circ}$, on the high-angle shoulder of the $\mathrm{Pt}(\mathrm{In}: \mathrm{Ga})_{2}(220)$. As the annealing temperature increases, the difference between these two peaks shrinks, from $1.2^{\circ}$ to $0.8^{\circ}$ to 


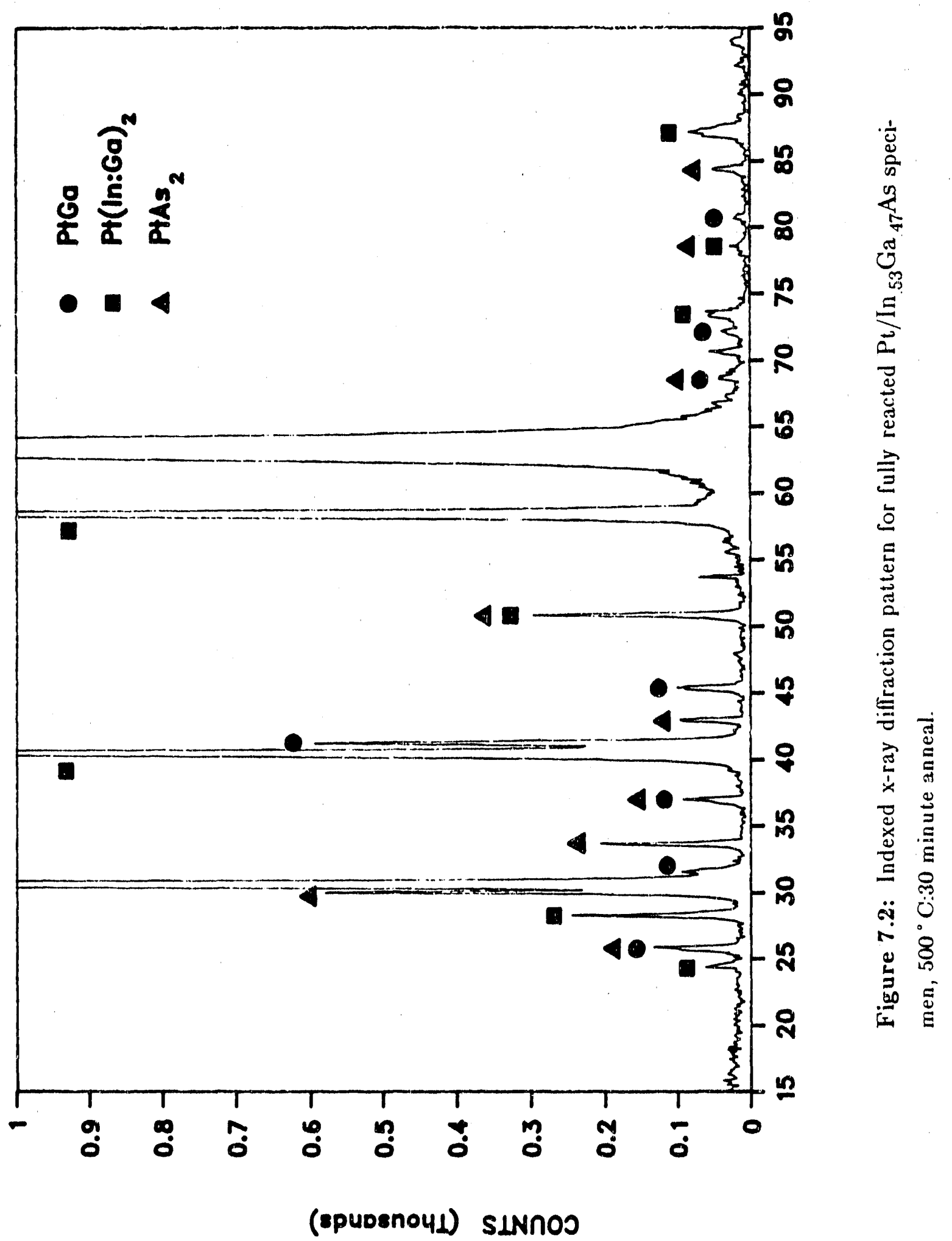




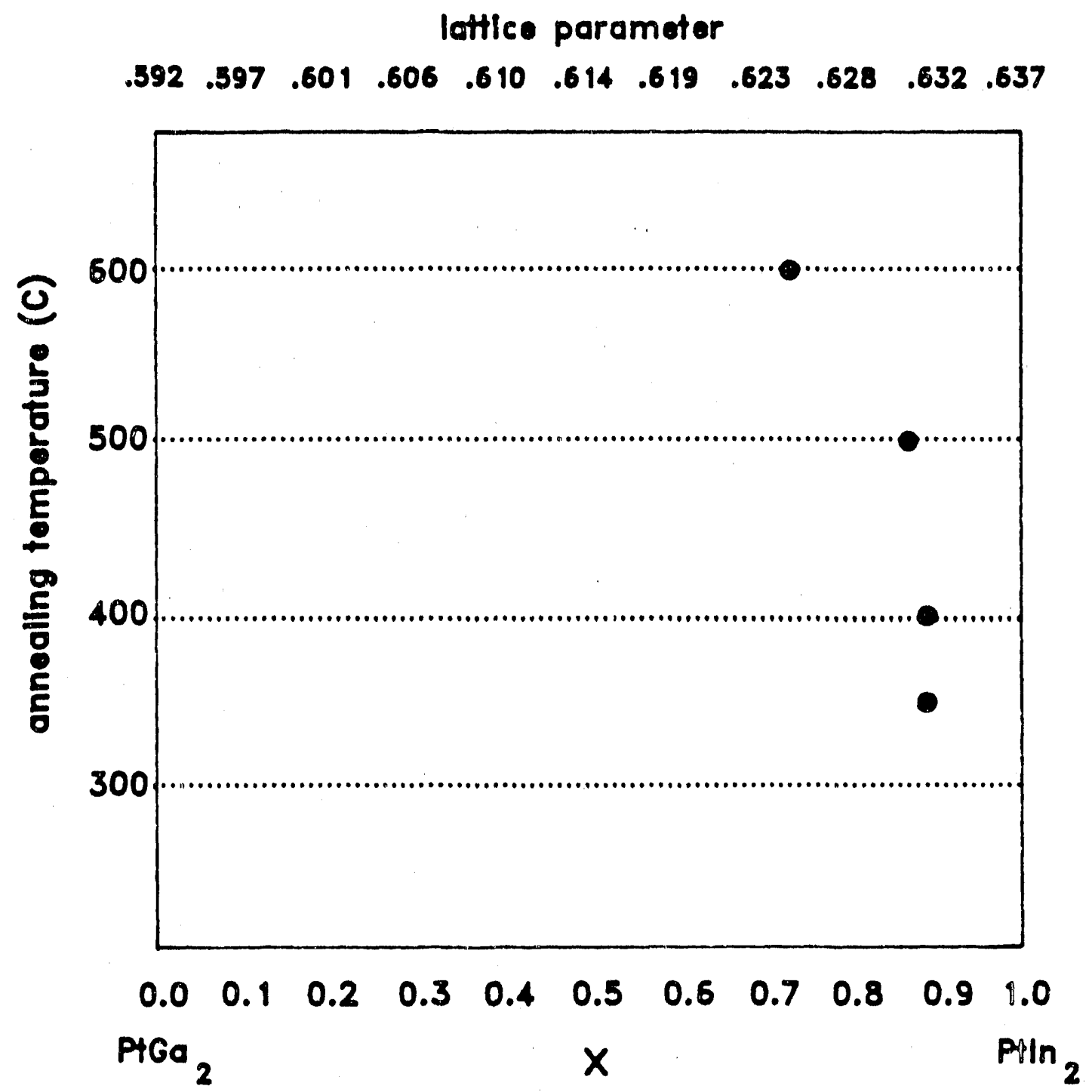

Figure 7.3: Variation in the lattice parameter and composition of $\mathrm{PtIn_{2x }} \mathrm{Ga}_{2-2 \mathrm{2}}$ with annealing temperature. 
Conversely, the peak near $58^{\circ}$ consists of the $\mathrm{PtAs}_{2}(231)$ at $57.8^{\circ}$ and the $\mathrm{Pt}(\mathrm{In}: \mathrm{Ga})_{2}$ (400). As the annealing temperature increases, the $\mathrm{PtAs} \mathrm{s}_{2}$ peak appears first as a bulge on the low-angle shoulder of the peak at $500^{\circ} \mathrm{C}$, and completely emerges at $600^{\circ} \mathrm{C}$, as the $\mathrm{Ga}$ concentration of $\mathrm{Pt}(\mathrm{In}: \mathrm{Ga})_{2}$ increases.

The peak near $51^{\circ}$ consists of the $\mathrm{PtAs}_{2}(311)$ at $50.7^{\circ}$ and the $\mathrm{Pt}(\mathrm{In}: \mathrm{Ga})_{2}$ (222). However, there is no significant change in this peak as the annealing temperature changes. This is probably due to the low intensity of the (222) peak; note that the $\mathrm{Pt}(\mathrm{In}: \mathrm{Ga})_{2}$ near $25^{\circ}$ is very small.

The high intensity of some of the $\mathrm{Pt}(\operatorname{In}: \mathrm{Ga})_{2}$ peaks suggest the possibility of texturing. The (220) $\left(40.0^{\circ}\right)$ and (400) $\left(58.2^{\circ}\right)$ peaks are very strong, while the (200) $\left(28.2^{\circ}\right)$ and $(440)\left(86.2^{\circ}\right)$ are of moderate strength. No diffraction data is available for $\mathrm{Pt}(\mathrm{In}: \mathrm{Ga})_{2}$; by assuming that the $\mathrm{Ga}$ is randomly oriented on the In sites, the relative intensities should be similar to those of $\mathrm{PtIn}_{2}$ and $\mathrm{PtGa}_{2}$. A comparison of the relative intensities of these peaks is provided in Table V. These data indicate that there is a preference for the (400), and to a lesser degree, the (220) peaks in the $400^{\circ} \mathrm{C}$ and $500^{\circ} \mathrm{C}$ anneals when compared to $\mathrm{PtIn}_{2}$ and $\mathrm{PtGa} \mathrm{a}_{2}$. For the highest temperature examined in this study, $600^{\circ} \mathrm{C}$, the preference is quite pronounced, with the $(220)$ peak much more intense than expected. However, the possibility that the Ga and In are ordering on the group III sublattice can not be discounted as an explanation for the change in peak intensities. 


\begin{tabular}{|c|c|c|c|c|c|}
\hline plane & $\mathrm{PtIn}_{2}$ & $400^{\circ} \mathrm{C}$ & $500^{\circ} \mathrm{C}$ & $600^{\circ} \mathrm{C}$ & $\mathrm{PtGa}_{2}$ \\
\hline$(200)$ & 20 & 7 & 10 & $<1$ & 20 \\
\hline$(220)$ & 100 & 80 & 80 & 100 & 100 \\
\hline$(400)$ & 60 & 100 & 100 & 1 & 50 \\
\hline$(440)$ & 50 & 4 & 5 & 3 & 50 \\
\hline
\end{tabular}

\section{Table V}

Comparison of relative intensities of $\mathrm{Pt}(\mathrm{In}: \mathrm{Ga})_{2}$ for different annealing temperatures. Relative intensities for $\mathrm{PtIn}_{2}$ and $\mathrm{PtGa}_{2}$ are from reference [JC88). 


\subsubsection{Rutherford Backscattering}

The RBS spectrum in Figure 6.14 shows that no reaction has occurred between the $\mathrm{Pt}$ and the $\mathrm{In}_{53} \mathrm{Ga}_{{ }_{47}} \mathrm{As}$ during the deposition process, within the resolution of the device $(\sim 10 \mathrm{~nm})$. This can be concluded by the sharp, abrupt transitions associated with the $\mathrm{Pt}$ low-energy and the In high-energy shoulders. In addition, the $\mathrm{Pt}, \mathrm{In}$, and GaAs signals become level, indicating no change in composition with depth with the metallization and substrate layers.

Figure 6.15 shows a fully reacted microstructure. The intensity of the $\mathrm{Pt}$ has diminished considerably, and the signals from the Pt and substrate peaks have merged. Unfortunately, because of the large number of elements in this system, and the overlap of the characteristic backscattering energies of the elements, it is virtually impossible to determine profile of the elements as a function of depth, and the relative compositions of the phases. Auger is much more desirable for determining this information.

A plor of the square of the thickness of $\mathrm{In}_{53} \mathrm{Ga}_{.47} \mathrm{As}$ reacted and annealing time is provided in Figure 7.4. This plot differs significantly from the $\mathrm{Pt} / \mathrm{GaAs}$ case, which is provided in the same plot. In the initial stages of the $\mathrm{Pt} / \mathrm{In}_{.53} \mathrm{Ga}_{.47} \mathrm{As}$ reaction, the reaction kinetics follow a parabolic relationship with a slope of $\sim 1 \times 10^{-13} \mathrm{~cm}^{2} \mathrm{~s}^{-1}$. The reaction rate in this stage is close to the $\mathrm{Pt} / \mathrm{GaAs}$ case, where the slope is $\sim 2 \times 10^{-13} \mathrm{~cm}^{2} \mathrm{~s}^{-1}$. For annealing times longer than $\sim 60$ minutes, the reaction slows significantly, and can be characterized with a new slope of $\sim 2 \times 10^{-14} \mathrm{~cm}^{2} \mathrm{~s}^{-1}$, a decrease of a factor of 5 .

Compared with the estimates of diffusivities for various diffusion modes and media in Table I (page 48), bcth stage I and stage II are unlikely to involve lattice diffusion, especially through $\mathrm{PtAs}_{2}$. The $\mathrm{PtIn}_{2}$ lattice diffusion is the closest, which is still 2 orders of magnitude too slow. If grain boundary diffusion is assumed, $(d / \delta) \times D_{e f f}$ is $\sim 1 \times 10^{-11}\left(\mathrm{~cm}^{2} \mathrm{~s}^{-1}\right)$ in stage 1 , and $\sim 2 \times 10^{-12}\left(\mathrm{~cm}^{2} \mathrm{~s}^{-1}\right)$ for stage II. Both of these diffusivities are about one order of magnitude slower than predicted for grain boundary 
diffusion through $\mathrm{PtGa}$ and $\mathrm{PtIn}_{2}$, and two orders of magnitude faster than estimated for $\mathrm{PtAs}_{2}$

As was discussed for $\mathrm{Pt} / \mathrm{GaAs}$, these results cannot conclusively determine the diffusion mode in $\mathrm{Pt} / \mathrm{In}_{53} \mathrm{Ga}_{{ }_{47}}$ As. However, the results suggest that the grain boundary diffusivity dominates the diffusion in this system. Also, a continuous $\mathrm{PtAs}_{2}$ layer is unlikely, because the low diffusivities associated with this phase are inconsistent with the reaction kinetics data. 


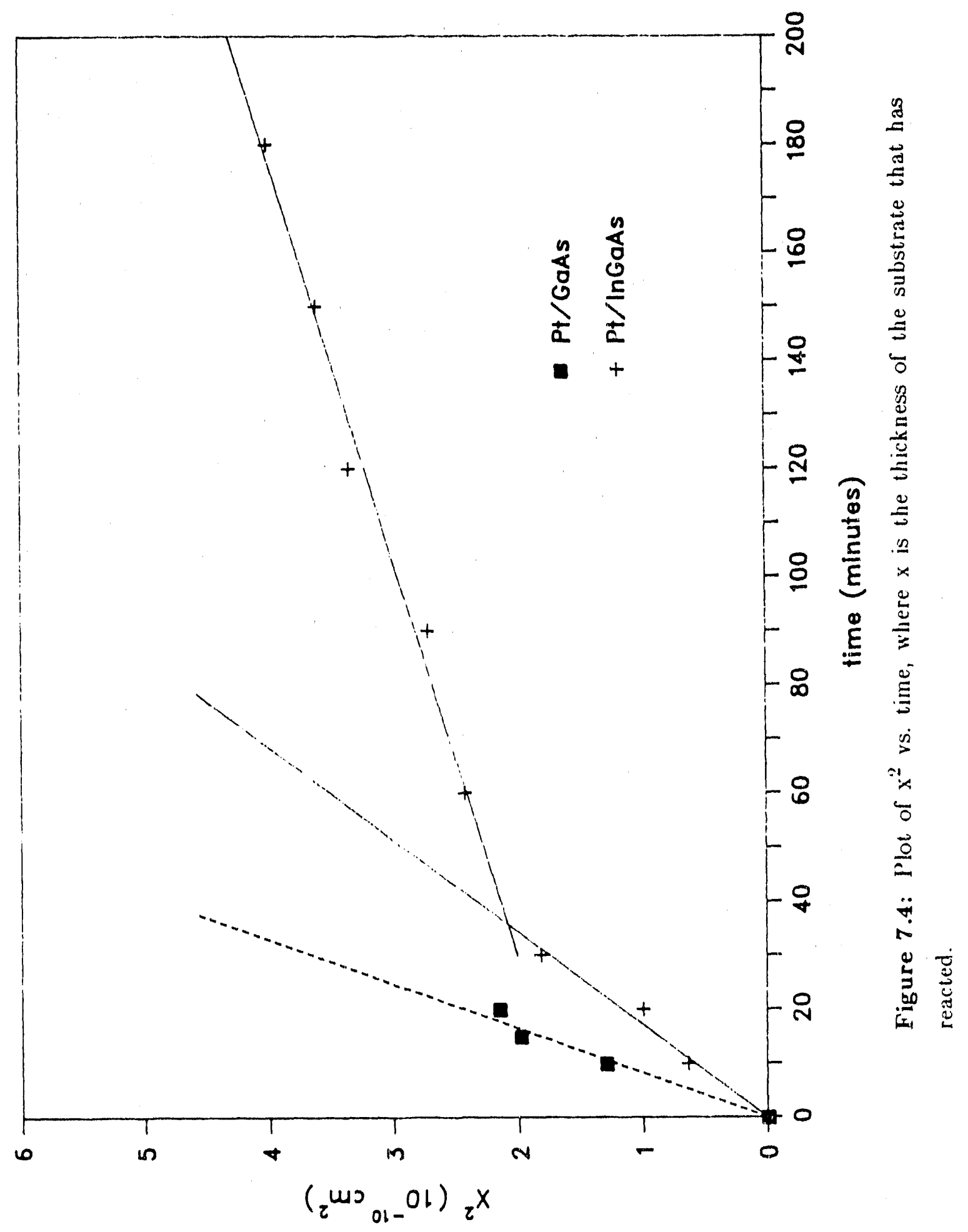




\subsubsection{Auger Depth Profile}

There are some important features of the Auger profiles in Figures 6.16 through 6.19 that appear for all conditions, but to varying degrees. Once the $\mathrm{Ga}$, As, and In signals indicate that the substrate has been reached, they do not level off at a constant value. In general, the In signal will reach a maximum level first before decreasing and leveling off. This could be indicative of an In rich layer at the substrate surface, or could be the result of ion milling effects. The likelihood of these two possibilities will be addressed for each profile below. Another common feature is that the $\mathrm{Ga}$ and $\mathrm{As}$ signals exchange their peak-to-peak values deep within the substrate. Due to the position of this feature in the sample, it probably arises from milling effects.

\section{as-deposited}

Although Figure 6.16 shows penetration of the $\mathrm{Pt}$ signal in to the substrate, the RBS data indicates that there is no interaction between the substrate and the $\mathrm{Pt}$ following deposition. The RBS is more reliable in this case, as the ion milling during Auger profiling cause intermixing of microstructural features. Another note: the baseline (i.e. zero signal) as indicated in these profiles corresponds to a peak-to-peak value of 0.5 .

The variations in the $\mathrm{Ga}$, As, and In signals within the substrates are very slight in the as-deposited sample, and are most likely due to sputtering effects as discussed above. RBS does not detect any interaction for this sample, so the shape of these profiles indicate the effects of Auger data collection on the spectra. The variations of the onset of each element in Figure 6.16 should be noted. Whether as a result of differential milling rates or different electron escape depths, the In signal shows an onset much earlier than $\mathrm{Ga}$ and As, which appear simultaneously. It should be noted that the atomic numbers of the $\mathrm{Ga}$ and $\mathrm{As}$ are very close (31 and 33 ), while In is much higher (49). A similar comparison can be made of the energies of the Auger electrons: Ga $1070 \mathrm{eV}^{\prime}$ and is $1228 \mathrm{eV}^{\prime}$ vs. $404 \mathrm{eV}$ for In. 


\section{$5000^{\circ} \mathrm{C}: 30$ minutes}

The depth profile in Figure 6.17 is discussed here to examine a completely reacted microstructure. Several different layers can be deduced from this figure. The first layer that is encountered ( 1.5 to 2 minutes) is a $\mathrm{Pt}$ :In phase, indicated by the peak in the In signal. The actual composition of the Pt:In phase cannot be determined from the Auger profile, as the peak-to-peak values depend on several factors other than composition.

Following the peak of the In signal is a sharp dip. The minimum of this depression in the In signal coincides with a peak of the $\mathrm{Ga}$ signal, indicating a layer of a Pt:Ga phase (between 2 minutes and 3 minutes). Based on the diffraction data, this phase layer most likely consists of PtGa. Although the In signal does not disappear at the minimum, Auger depth profiles are not as sharp as the microstructures they correspond to. An alternating sequence of thin layers will appear as seen in Figure 6.17 ; i.e., the Auger signals will not drop to zero between layers if they are thin enough. By the standards of Auger spectra, the transitions between the $\mathrm{Pt}: \mathrm{In}$ and $\mathrm{Pt}: \mathrm{Ga}$ signals are fairly sharp, indicating that the interfaces between these phases are not as rough as found in the $\mathrm{Pt} / \mathrm{GaAs}$ system.

The $\mathrm{Ga}$ quickly diminishes following its peak, decreasing to a very low value in the next layer ( 3 minutes to 5 minutes). As the Ga decreases, the As and In signals rise, indicating a layer containing these two elements in addition to the $\mathrm{Pt}$ which present throughout the reacted layer. As was discussed in section 7.1.3 for $\mathrm{Pt} / \mathrm{GaAs}$, the only possible As phase consistent with the $\mathrm{x}$-ray diffraction data is $\mathrm{PtAs}_{2}$. Also, The $\mathrm{Ga}$ and In cannot be present in solution in significant amounts in this phase without affecting the $\mathrm{PtAs}_{2}$ lattice parameter, and shifting the diffraction peaks.

The remaining elements in this layer indicated by the Auger $(\mathrm{Ga}, \mathrm{In}$, and $\mathrm{Pt})$ are probably in the form of $\mathrm{Pt}(\mathrm{In}: \mathrm{Ga})_{2}$. This would be consistent with the $\mathrm{x}$-ray diffraction data for two reasons. First, the diffaction peaks show texturing of the Pt(In:Ga $)_{2}$ 
product phase, which indicates that the phase develops near the In ${ }_{.53} \mathrm{Ga}_{47}$ As substrate in terface. Second, both the $\mathrm{Ga}$ and In signals are at a maximum at the onset of the As signal, and diminish with nearly parallel slopes as the As increase, indicating a constant composition. This would be consistent with a two-phase mixture of $\mathrm{Pt}(\mathrm{In}: \mathrm{Ga})_{2}: \mathrm{PtAs}{ }_{2}$, with a decreasing fraction of the ternary compound as the substrate is approached.

The final layer in the reacted microstructure cannot be identified as clearly. As was discussed at the beginning of this section, the Auger signals of the substrate do not remain constant as would be expected. However, in the case of Figure 6.17, the peak in the In signal at the onset of the substrate is quite pronounced, and unlikely to result solely from milling effects. The presence of this peak, clearly after the Pt signal has disappeared suggests that the reaction of the $\mathrm{Pt}$ with the In ${ }_{53} \mathrm{Ga}_{47} \mathrm{As}$ has resulted in the formation of an $\operatorname{In}_{n}$-rich $\operatorname{In}_{\mathrm{x}} \mathrm{Ga}_{1-\mathrm{x}}$ As region at the substrate/reacted layer interface. This region could result from differential diffusion rates of the $\mathrm{Ga}$, As, and In from the substrate during reaction. The In-rich region would result if the diffusion of In out of substrate was slower than diffusion of $\mathrm{Ga}$, which would be consistent with previous studies (see section 4.3, page 49).

\section{$400^{\circ} \mathrm{C}: 30$ minute}

The layering present in the specimen annealed at $500^{\circ} \mathrm{C}$ has not yet developed in Figure 6.18. In addition, a significant amount of unreacted $\mathrm{Pt}$ is still present, as indicated by the large $\mathrm{Pt}$ signal while the $\mathrm{Ga}, \mathrm{As}$, and In have not appeared. In general, the $\mathrm{Pt}$ signal reaches an initial peak, and then decreases continuously before disappearing at the substrate. Although it is difficult to draw conclusions about composition from Auger data, these results are consistent with an initially high $P t$ concentration in the reacted layer (e.g. $\mathrm{PtGa}$ ), which decreases closer to the substrate (e.g. PtAs 2 and $\left.\mathrm{Pt}(\mathrm{In}: \mathrm{Ga})_{2}\right)$. The $\mathrm{x}$-ray diffraction data for this specimen (section 7.2.1) indicated the presence of $\mathrm{Ga}$ in the unreacted $\mathrm{Pt}$. The Auger profile is not sensitive enough to detect the presence of this element in Figure 6.18. 
The depth profile of the in this figure is beginning to develop a form similar to that of the fully reacted sample, especially for $\mathrm{Ga}$ and As. A peak in the Ga signal is present at the reaction front (at $\sim 2.7$ minutes) followed by a dip, and finally increasing up to the substrate level. The As signal beg:ns increasing at the same level as the Ga maximum, and reaches a broad peak just at the minimum of the Ga dip. These results are consistent with a $\mathrm{Pt}: \mathrm{Ga}$ layer on top of a $\mathrm{PtAs}_{2}$ layer, which is what is found in the $\mathrm{Pt} / \mathrm{GaAs}$ system for the identical annealing and deposition thickness. However, the In profile has yet to develop into the profile found in the completely reacted case. The In Auger signal appears at the same point as the Ga signal. Therefore, the diffusing In atoms have reached the same point in the reacted microstructure.

It is interesting to note the amount of the $\mathrm{Pt}: \mathrm{Ga}$ phase in the $\mathrm{PtAs}_{2}$ layer. In the case of $\mathrm{Pt}$ on GaAs, the fully reacted microstructure showed a large fraction the the $\mathrm{PtGa}$ phase with this layer. In the case of $\mathrm{Pt}$ on $\mathrm{In}_{5.3} \mathrm{Ga}_{{ }_{47}} \mathrm{As}$, however, this layer showed very little $\mathrm{Ga}$, but instead a large concentration of an In-rich ternary phase related to $\mathrm{PtIn}$.

As in the previous figure, there is a prominent peak in the In profile just at the reacted layer/substrate interface. Again, this could be indicative of the buildup of In at this interface, possibly in the form of $\operatorname{In}$-rich $\operatorname{In}_{\mathrm{x}} \mathrm{Ga}_{1-\mathrm{x}} \mathrm{As}$.

The $\mathrm{x}$-ray diffraction data showed that the phases present in both the $500^{\circ} \mathrm{C}$ and $400^{\circ} \mathrm{C}$ anneals for 30 minutes were the same. The difference in the Auger profiles would therefore indicate only a change in the distribution of the phases in the microstructure. The distribution for this anneal would likely take the form of two and three-phase mixtures. The phase profile for this anneal should be: $\mathrm{Pt}|\mathrm{Ga}|$ / $\mathrm{Pt}: \mathrm{In}+\mathrm{PtGa} / \mathrm{PtAs} \mathrm{s}_{2}+\mathrm{Pt}(\mathrm{In}: \mathrm{Ga})_{2}+\mathrm{PtGa} / \mathrm{In}_{\mathrm{x}} \mathrm{Ga}_{1-\mathrm{x}} \mathrm{As} / \mathrm{In}_{53} \mathrm{Ga}_{47}$ As. 


\section{$400^{\circ} \mathrm{C}: 120$ minutes}

The Auger profile shown in Figure 6.19 shows the transition between the early stages of reaction in Figure 6.18, and the final reacted structure in Figure 6.17. The onset of the Pt signal before the development of the other elements shows that the sample has not yet fully reacted. In addition, the $\mathrm{Pt}$ profile through the reacted layer is consistent with a gradually decreasing concentration of this element within the reacted layer as the substrate is approached.

As in the previous sample, both the $\mathrm{Ga}$ and $\mathrm{As}$ profiles show the same general features of the fully reacted profiles for $\mathrm{Pt} / \mathrm{GaAs}$ and $\mathrm{Pt} / \mathrm{In}_{.53} \mathrm{Ga}_{.47} \mathrm{As}$. In this case, however, the In profile has begun to show the features of the fully reacted case. A peak is developing in the In signal at the start of the reaction front, preceding the onset of the Ga signal, and indicating the development of a Pt:In phase at the surface. Deeper in the microstructure, a plateau in the In signal is developing, coincident with the $\mathrm{PtAs} \mathrm{A}_{2}$ layer. This indicates the presence of the $\mathrm{Pt}(\mathrm{In}: \mathrm{Ga})_{2}$ phase which was found in the fully reacted case. Finally, the prominent peak at the reacted layer/substrate interface is still present. These results show that the layering found in the final reacted layer is developing, while unreacted $\mathrm{Pt}_{\mathrm{t}}$ is still present in the system.

\section{Auger summary}

The Auger profiles indicate some important similarities between the $\mathrm{Pt} / \mathrm{GaAs}$ and $\mathrm{Pt} / \mathrm{In}_{53} \mathrm{Ga}_{47} \mathrm{As}$ cases. Both show a PtAss layer growing on the semiconductor substrate, intermixed with a significant fraction of a $\mathrm{Pt}-\mathrm{A}^{\prime \prime I}$ phase. Instead of the $\mathrm{PtGa}$ lound in $\mathrm{Pt} / \mathrm{GaAs}$, the ternary substrate reaction results in a ternary $\mathrm{Pt}(\mathrm{In}: \mathrm{Ga})_{22}$ phase, and with a higher fraction of the phase present. This is not suprising, in light of the differences between $\mathrm{Ga}$ and $\mathrm{In}$, which suggested that $\mathrm{Ga}$ would diffuse more readily than In, leaving more In behind near the substrate to react. It should be noted that the presence of a small amount the $\mathrm{Ga}$ in this layer in the form of $\mathrm{PtGa}$ cannot be discounted. 


\subsubsection{Transmission Electron Microscopy}

The SAD patterns in Figures 6.21 and 6.22 confirm the texturing of the $\mathrm{Pt}(\mathrm{In}: \mathrm{Ga})_{2}$ phase. The reaction product diffraction spots in Figure 6.21, from a crosssection, can be indexed as $\mathrm{Pt}(\mathrm{In}: \mathrm{Ga})_{2}$, with $[220](001)_{\mathrm{Pt}(\mathrm{In}: \mathrm{Ga})_{2}} \|[020](101)_{\mathrm{In} .5 s_{.49} \mathrm{Ga}_{47} \mathrm{As}}$.

The pattern in Figure 6.22 (plan view) corresponds to two different orientations of $\mathrm{Pt}(\mathrm{In}: \mathrm{Ga})_{2}$ overlayed on the substrate (001). The orientation relationships are: $[220](001)_{\mathrm{P} t(\operatorname{In}: G a)_{2}} \quad \| \quad[220](001)_{\mathrm{In}_{., 4} \mathrm{Ga}_{4,4} \mathrm{As}}, \quad$ and $\quad[200](011)_{\mathrm{Pt}(\operatorname{In}: G a)_{2}} \|$

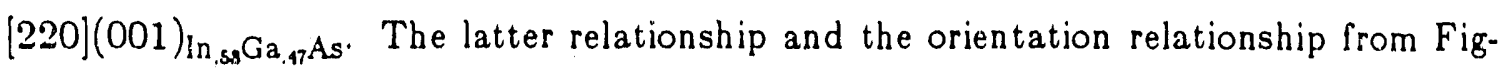
ure 6.21 are equivalent. The texturing of this product phase is difficult to justify on a simple geometrical model, because the lattice mismatch between the substrate and the $\mathrm{Pt}(\mathrm{In}: \mathrm{Ga})_{2}$ is $\sim 7.6 \%$. Consequently, other factors must account for this relationship, as was described in section 3 , page 22.

\subsection{Summary}

\section{Kinetics}

The difference in the reaction kinetics between $\mathrm{Pt} / \mathrm{GaAs}$ and $\mathrm{Pt} / \mathrm{In}{ }_{53} \mathrm{Ga}{ }_{47} \mathrm{As}$ is very significant. One of the purposes of this study was to determine if the system could be made more stable by changing the substrate composition and lattice parameter. The results of this study show that the kinetics are significantly different for the ternary substrate case, and can be divided into two stages. In the initial stages, the reaction rate approaches that of $\mathrm{Pt} / \mathrm{GaAs}$. In the later stages, however, the kinetics are considerably slowed. This is an important result, indicating that this system does result in slower metal/semiconductor reactions, enhancing the potential for producing a stable contact.

Because of the complexity of the system, it is difficult to determine the cause of the change in reaction rate; although the phases present in the system are essentially 
the same until the unreacted $\mathrm{Pt}$ disappears completely, they exist in several layers. Changes in the morphology of any of these layers can result in the kinetics observed.

\section{Substrate Composition}

The Auger depth profiles indicate the formation on an In-rich layer at the reacted layer/substrate interface. This could take the form of a continuous $\operatorname{In}_{x} \mathrm{Ga}_{1-\mathrm{x}}$ As layer, or of $\operatorname{In}_{\mathrm{x}} \mathrm{Ga}_{1-\mathrm{x}} \mathrm{As}$ precipitates. The presence on an In-rich region just below the reacted layer would have profound significance. As was discussed in section 2.2, page 15, the Schottky barrier height of a contact to $\mathrm{In}_{\mathrm{x}} \mathrm{Ga}_{1-\mathrm{x}}$ As decreases as the In concentration of the substrate increases. Consequently, the microstructure that these results show develops in the $\mathrm{Pt} / \operatorname{In}_{.53} \mathrm{Ga}_{.47} \mathrm{As}$ system can have application in ohmic contacts, where low Schottky barrier heights are critical.

\section{Phase Formation}

The $\mathrm{Pt} / \mathrm{In}_{53} \mathrm{Ga}_{47} \mathrm{As}$ reaction products are similar to those found in the $\mathrm{Pt} / \mathrm{GaAs}$ and $\mathrm{Pt} / \mathrm{InP}$ systems. $\mathrm{Pt} / \mathrm{GaAs}$ reacts to form $\mathrm{PtAs}_{2}$ and $\mathrm{PtGa}$, and $\mathrm{Pt} / \mathrm{InP}$ reacts to form $\mathrm{PtP}_{2}$ and $\mathrm{PtIn}_{2}$. The system in this study formed a combination of these phases, $\mathrm{PtAs}_{2}, \mathrm{PtGa}$, and $\mathrm{Pt}(\mathrm{In}: \mathrm{Ga})_{2}$. In addition, the same phases were present at the intermediate stages of the reaction, i.e. $\mathrm{Pt}_{3} \mathrm{Ga}$, and $\mathrm{Pt}|\mathrm{Ga}|$.

One question that should be raised is the lack of an intermediate Pt:In compound. The x-ray diffraction data do not indicate the presence of any such phase, although the Auger depth profiles show that there is a $\mathrm{Pt}: \mathrm{In}$ compound on the surface. There are several possible explanations for this result. First, neither the Auger nor the RBS is sensitive enough to detect the presence of the small amount of $\mathrm{Ga}$ that may exist in the surface compound. Therefore, the Pt:In comnound on the surface may be $\mathrm{Pt}(\mathrm{In}: \mathrm{Ga})_{2}$, which would be consistent with the x-ray data. Second, the diffracting volume (i.e. thickness) of the surface Pt:Ir layer may be too small for its $x$-ray peaks 
to be visible above the background noise (less than $\sim 10 \mathrm{~nm}$ ). Third, the diffraction peaks of the Pt:In layer may be overlapped by the large number of peaks that already exist in these spectra. For example, $\mathrm{Pt}_{3} \mathrm{Ga}$ has only one non-overlapped peak.

In order to resolve this issue, there are several experiments that can be recommended for future study. For example, much thicker depositions (hundreds of nanomelers) could be made, and annealed to full reaction. Based on the results of this study, this would require higher reaction temperatures (e.g. $600^{\circ} \mathrm{C}$ ) and/or much longer annealing times (several hours). In this study, 3 hours was insufficient to completely react $70 \mathrm{~nm}$ of $\mathrm{Pt}$ at $400^{\circ} \mathrm{C}$. The greater thickness may result in a thicker $\mathrm{Pt}: \mathrm{In}$ layer on the surface to study, although changing the conditions of the experiment to this extent may result in the formation of other phases.

\section{$\operatorname{Pt}(\operatorname{In}: \mathbf{G a})_{2}$}

The $\mathrm{Pt}(\mathrm{In}: \mathrm{Ga})_{2}$ product phase is certainly the most interesting phase in the system. Two orientation relationships are present for the $400^{\circ} \mathrm{C}, 120$ minutes anneals:

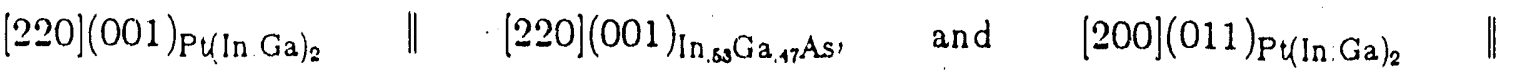

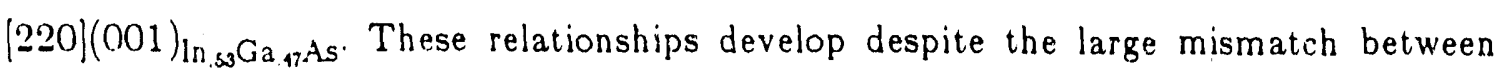
this phase and $\mathrm{In}{ }_{53} \mathrm{Ga}_{47} \mathrm{As}$, about $7.6 \%$.

The $x$-ray diffaction data indicate that the relative amounts of grains in these relationship changes with higher annealing temperatures. As shown in Table V, at $400^{\circ} \mathrm{C}$ and $500^{\circ} \mathrm{C}$ the intensities of the (220) and (400) reflections are approximately the same. At $600^{\circ} \mathrm{C}$, however, the $(400)$ becomes significantly higher, suggesting that the second orientation relationship, $[200](011)_{\mathrm{P} u(I n G a)_{2}} \|[220](001)_{\left[\mathrm{n}_{.43} \mathrm{Ga}_{.47} \mathrm{As} \text {, becomes }\right.}$ preferred at this temperature. This change in preferred orientation may arise from a change in lattice parameter of $\mathrm{Pt}(\operatorname{In}: \mathrm{Ga})_{2}$, which decreases by $\sim 1 \%$ in going from $400^{\circ} \mathrm{C}$ to $600^{\circ} \mathrm{C}$ anneals. The mismatch with the substrate changes from $7.6 \%$ to $6.6 \%$ in going to the higher annealing temperature. 


\section{Phase Separation}

The fully reacted $\mathrm{Pt} / \mathrm{In}_{.53} \mathrm{Ga}_{47} \mathrm{As}$ microstructure formed a layered sequence with many similarities to the $\mathrm{Pt} / \mathrm{GaAs}$ case. For the binary substrate, the layering was $\mathrm{PtGa}_{\mathrm{t}} / \mathrm{PtAs} \mathrm{s}_{2}+\mathrm{PtGa} / \mathrm{GaAs}$. For the ternary substrate, the result was $\mathrm{Pt}: \mathrm{In} / \mathrm{PtGa}$ $/ \mathrm{PtAs}_{2}+\mathrm{Pt}(\mathrm{In}: \mathrm{Ga})_{2} / \mathrm{In}_{\mathrm{x}} \mathrm{Ga}_{1-\mathrm{x}} \mathrm{As} / \mathrm{In}_{.53} \mathrm{Ga}_{{ }_{47}} \mathrm{As}$. There are three significant differences: the additional Pt:In phase on the surface, the presence of $\mathrm{Pt}(\operatorname{In}: \mathrm{Ga})_{2}$ as the $\mathrm{Pt}-\mathrm{A}^{\mathrm{III}}$ phase in the $\mathrm{PtAs}_{2}$ layer, and the change in substrate composition below the reacted layer. 


\subsection{Conclusions}

The main conclusions of this study can be summarized as follows:

1. The reaction kinetics can be divided into two stages, where the reaction slows by a factor of 5 after $\sim 60$ minutes of annealing. The reduction in reaction rate has considerable potential for the formation of stable metal/seminconductor contacts.

2. An In-rich region develops at the reacted layer/substrate interface, which could be quite beneficial for the formation of ohmic contacts.

3. At $400^{\circ} \mathrm{C}$, the $\mathrm{Pt}(\mathrm{In}: \mathrm{Ga})_{2}$ product phase exhibits two orientation relationships with the substrate: $[220](001)_{\mathrm{Pt}(\mathrm{In}: \mathrm{Ga})_{2}} \| \quad[220](001)_{\mathrm{In}_{, s} \mathrm{Ga}, 47} \mathrm{As}, \quad$ and $[200](011)_{\mathrm{Pt}(\operatorname{In}: \mathrm{Ga})_{2}} \|[220](001)_{\ln . s s_{\text {Ga.47 }} \mathrm{As}}$ with the latter enhanced at higher annealing temperatures.

\subsection{Future Work}

The results of this study suggest several interesting projects for future study. The most important would be to examine the effect of changes in the $\mathrm{In}_{\mathrm{x}} \mathrm{Ga}_{1-x}$ As substrate composition during these reactions. The txact nature of the In-rich region at the reacted layer/substrate interface, and its effect on electrical properties is very impor$\operatorname{tant}$. An increased In concentration in the substrate just below the metallization is likely to reduce the Schottky barrier height, which would be beneficial for the forma* tion of ohmic contacts.

An additional study that concerns the electrical behavior of this system involves the elimination of $\mathrm{PtAs}_{2}$ as a product phase. Due to the volatility of As, it may be possible to reduce the amount of this phase in the reacted microstructure by annealing in an open system, i.e. without encapsulation. $\mathrm{Pt}(\mathrm{In}: \mathrm{Ga})_{2}$ is likely to have better electrical properties than $\mathrm{PtAs}_{2}$ (which is a narrow band gap semiconductor), thus the conductivity of the reacted metallization might be enhanced. 
As different compositions of $\operatorname{In}_{x} \mathrm{Ga}_{1-\mathrm{x}}$ As become available, studies of the reactions for different lattice parameters will be possible. $\mathrm{Pt}(\mathrm{In}: \mathrm{Ga})_{2}$ may be induced to form epitaxially for appropriate conditions, or this phase could be deposited by MBE. In this way, it may be possible to decrease the $\mathrm{Pt} / \mathrm{In}_{\mathrm{x}} \mathrm{Ga}_{1-\mathrm{x}}$ As reaction kinetics even further than has been achieved in this study. 


\subsection{REFERENCES}

[AV89] F. A. d'Avitaya, A. Perio, J.-C. Oberlin, Y. Campidelli, and J. A. Chroboczek, Applied Physics Letters, 54(22), 2198, (1989).

[BB74] A. Baghdadi, A. Finley, P. Russo, R. J. Arnott, and A. Wold, Journal of the Less-Common Metals, 34, 31, (1974).

[BG78] J. E. E. Baglin, F. M. D'Heurle, and W. N. Hammer, Journal of Applied Physics 50(1), 266, (1979).

[BG82] J. E. E. Baglin, H. A. Atwater, D. Gupta, and F. M. D'Heurle, Thin Solid Films 93, 255, (1982).

(BH87) G. Bahir, J. L. Merz, J. R. Abelson, and T. W. Sigmon, Journal of Electronic Materials, 16(4), 1987, 257.

[BA83] J. M. Ballingall, Journal of Vacuum Science and Technology B2(3), 675, (1983).

[BD.47] J. Bardeen, Physics Review 71, 717, (1947).

[BR78]. P. A. Barnes and A. Y. Cho, Applied Physics Letters 33(7), 651,(1978).

[BN80] R. W. Bené, R. M. Walser, G. S. Lee, and K. C. Chen, Journal of Vacuum Science and Technology 17(5), 911, (1980).

[BN82] R. W. Bené, Applied Physics Letters, 41(6), 529, (1982).

[BR72] H. H. Berger, Solid-State Electronics 15, 145, (1972).

[BE84a] R. Beyers, R. Sinclair, M. E. Thomas, Journal of Vacuum Science and Technology B 2(4), 781, (1981).

[BE84b| R. Beyers, Journal of Applied Physics 56(1), 147, (1984).

[BE85] R. Beyers, Thin Films: The Relationship of Structure to Properties, MRS Symposia Proceedings, Volume 47, C. Aita and K. SreeHarsha, eds., p. 143, (Materials Research Society, Pittsburgh, 1985).

(BE87) R. Beyers, K. B. Kim, and R. Sinclair, Journal of Applied Physics 61(6), 2195, (1987).

[BO86] G. Bomchil, G. Goeltz, and J. Torres, Thin Solid Films 140, 59, (1986).

[BT82] A. P. Botha and R. Pretorius, Thin Solid Films 93, 127, (1982). 
[BW73] R. W. Bower, D. Sigurd, and R. E. Scott, Solid-State Electronics 16, 1461, (1973).

[BS83] D. Brasen, R. F. Karlick, and V. M. Donnelly, Journal of the Electrochemical Socicty, 130(7), 1473, (1983).

(BR67) N. Braslau, J. B. Gunn, and J. L. Staples, Solid-State Electronics 10, 381, (1967).

[BR81] N. Braslau, Journal of Vacuum Science and Technology, 19(3), 803, (1981).

[BR83] N. Braslau, Thin Solid Films 104, 391, (1983).

(BR86) N. Braclu'd, Journal of Vacuum Science and Technology A, 4(6), 3085, (1986).

[Bl82 L. J. Brillson, C. F. Brucker, A. D. Katnani, N. G. Stoffel, R. Daniels, and G. Margaritondo, Journal of Vacuum Science and Technology, 21(2), 1982, 564.

[BI86a L. J. Brillson, M. L. Slade, R. E. Viturro, M. K. Kelly, N. Tache, G. Margar* itondo, J. M. Woodall, P. D. Kirchner, G. D. Pettit, and S. L. Wright, Applied Physics Letters, 48(21), 1.58, (1986).

[Bl86b] L. J. Brillson, M. L. Slade, R. E. Viturro, M. K. Kelly, N. Tache, G. Margaritondo, J. M. Woodall, P. D. Kirchner, G. D. Pettit, and S. L. Wright, Jour$n$ al of Vacuum Science and Technology B 4(4), 919, (1986).

|CB82 D. R. Campbell, S. Mader, and W. K. Chu, Thin Solid Film? 93, 341, (1982).

[C.A7 1 C. Canali, J. W. Mayer, G. Ottaviani, D. Sigurd, and W. van der Weg, Applied Physics Letters 25(1), 3, (1974).

|CA75| C. Canali, S. U. Campisano, S. S. Lau, and J. W. Mayer, Journal of Applied Phy'sics 46(7), 2831,(1975).

(CY72) J. M. Caywood, A. M. Fern, J. O. McCaldin, and G. Ottaviani, Applied Physics Letters 20(8), 326, (1972).

\{CH88\} N. Chand, J. M. Phillips, L. M. Lunardi, S. N. G. Chu, K. W. Wecht, and R. People, Journal of Vacuum Science and Technology B 6(2), 703, (1988).

[CC75] C. C. Chang, S. P. Murarka, V. Kumar, and G. Quintana, Journal of Applied Physics 46(10), 4237, (1975).

[Cl84] P. Chiaradia, A. D. Katnani, H. W. Sang, Jr., and R. S. Bauer, Physics Review Letters 52(14), 1246,(1984).

(CZ82) H. Chen, G. E. White, S. R. Stock, and P. S. Ho, Thin Solid Films 93, 161, (1982). 
[CJ82a] L. J. Chen, J. W. Mayer, K. N. Tu, Thin Solid Films 93, 135, (1982).

[CJ82b] L. J. Chen, J. W. Mayer, K. N. Tu, T. T. Sheng, Thin Solid Films 93, 91, (1982).

[CW86] W. X. Chen, S. C. Hsueh, P. K. L. Yu, and S. S. Lau, IEEE Electron Device Letters ED-7(8), 471,(1986).

[CE89] Y.-K. Chen, R. N. Nottenburg, M. B. Panish, R. A. Hamm, and D. A. Humphrey, IEEE Electron Devices Letters EDDL-10(6), 267, (1989).

[CG81] K. Y. Cheng, A. Y. Cho, W. R. Wagner, and W. A. Bonner, Journal of Applied Physics 52(2), 1015, (1981).

[CN84] A. K. Chin, C. L. Zipfel, M. Geva, P. Skeath, and B. H. Chin, Applied Physics Letters 45(1), 37, (1984).

[CN86] K.K. Chin, T. Kendelewicz, N. Newman, I. Lindau, W. E. Spicer, Journal of Vacuum Science and Technology B 4(4), 955, (1986).

[CKi81] K. C. R. Chiu, J. M. Poate, J. E. Rowe, T. T. Sheng, and A. G. Cullis, Applied Physics Letters 38(12), 988, (1981).

[CP69] K. L. Chopra, Thin Film Phenomena, p. 182, (McGraw-Hill, 1969).

[CO74] D. J. Coleman, Jr., W. R. Wisseman, and D. W. Shaw, Applied Physics Letters 24(8), 355, (1974).

[CT85] J. P. Contour, J. Massies, A. Salétes, and P. Staib, Applied Physics A 38, 45, (1985).

[CR91] Y. L. Corcoran, A. H. King, N. deLanerolle, and B. Kim, Journal of Electronic Materials, in press.

[CU85] B. Coulman, H. Chen, and K. Ritz, Thin Films: The Relationship of Structure to Properties, MRS Symposia Proceedings, Volume 47, C. Aita and K. SreeHarsha, eds., p. 155, (Materials Research Society, Pittsburgh, 1985).

[Di88 J. Ding, B. Lee, R. Gronsky, and J. Washburn, Applied Physics Letters 52(2), 135, (1988).

[EA70] D. E. Eastman, Physics Review B 2, 1, (1970).

[EI87| M. Eizenberg, M. Heiblum, M. I. Nathan, N. Braslau, and P. M. Mooney, Journal of Applied Physics 61(4), 1516, (1987).

[Esi6] J. S. Escher, L. W. James, R. Sankaran, G. A. Antypas, R. L. Moon, and R. L. Bell, Journal of Vacuum Science and Technology 13(4), 874, (1976). 
(FH74) H. H. Farrell, G. H. Gilmer, M. Suenaga, Journal of Applied Physics 45(9), 4025, (1974).

[FH75] H. H. Farrell, G. H. Gilmer, M. Suenaga, Thin Solid Films 25, 253, (1975).

[FA87] R. W. Fathauer, B. D. Hunt, and L. J. Schowalter, Journal of Vacuum Science and Technology B 5(3), 743, (1987).

[FA88] R. W. Fathauer, P. J. Grunthaner, T. L. Lin, K. T. Chang, J. H. Mazur, D. N. Jamieson, Journal of Vacuum Science and Technology B 6(2), 708, (1988).

[FO83] C. Fontaine, T. Okumura, and K. N. Tu, Journal of Applied Physics 54(3), 1404, (1983).

[FR81] J. L. Freeouf and J. M. Woodall, Applied Physics Letters 39, 727, (1981).

[FU65] S. Furuseth, K. Selte, and A. Kjekshus, Acta Chemica Scandinavica 19, 735, (1965).

[FU67] S. Furuseth, K. Selte, and A. Kjekshus, Acta Chemica Scandinavica 21, 527, (1967).

[GI82] J. M. Gibson, J. C. Bean, J. M. Poate, and R. T. Tung, Thin Solid Films 93, 99, (1982).

[GO82] Goesele and K. N. Tu, Thin Solid Films 93, 275, (1982).

[GR80] H. R. Grinolds, and G. Y. Robinson, Solid-State Electronics 23, 973, (1980).

[GU88a] A. Guivarc'h, M. Secoué, and B. Guenais, Applied Physics Letters 52(12), 948, (1988).

[GU88b] A. Guivarc'h, M. Secoué, B. Guenais, Y. Ballini, P. A. Badoz, and E. Rosencher, Journal oi Applied Physics 64(2), 683, (1988).

[GP85] D. Gupta, Thin Films: The Relationship of Structure to Properties, MRS Symposia Proceedings, Volume 47, C. Aita and K. SreeHarsha, eds., p. 11, (Materials Research Society, Pittsburgh, 1985).

[GY'11) J. Gyulai, J. W. Mayer, V. Rodriguez, A. Y. C. Yu, and H. J. Gopen, Journal of Applied Physics 42(9), 3578, (1971).

[H.185] M. A. Hiase, V. M. Robbins, N. Tabatabaie, and G. E. Stillman, Journal of Applied Physics 57(6), 2295, (1985).

[H.N58] M. Hansen and K. Anderko, Constitution of Binary Alloys, Second Edition, (McGraw-Hill, 1958). 
[HB88] J. P. Harbison, T. Sands, N. Tabatabaie, W. K. Chan, L. T. Florez; and V. G. Keramidas, Applied Physics Letters 53(18), 1717, (1988).

[HE83a] H. T. G. Hentzell, R. D. Thompson, and K. N. Tu, Journal of Applied Physics 54(12), 6923, (1983).

[HE83b] H. T. G. Hentzell and K. N. Tu, Journal of Applied Physics 54(12), $6929,(1983)$.

[HI86] K. Hieber and F. Neppl, Thin Solid Films 140, 131, (1986).

[HL65] F. Hulliger and E. Mooser, Progress in Solid State Chemistry, Volume 2, H. Reiss, ed., p. 330, (Pergamon Press, New York, 1965).

[HU87) B. D. Hunt, N. Lewis, E. L. Hall, and C. D. Robertson, Journal of Vacuum Science and Technology B 5(3), 749, (1987).

[HT89] L. D. Hutcheson, Journal of Electronic Materials 18(2), 259, (1989).

[IS76] H. Ishiwara and S. Furukawa, Journal of Applied Physics 47(4), 1686, (1976).

[JC85] Powder Diffraction File, Joint Committee on Powder Diffraction Standards, (International Centre for Diffraction Data, Swarthmore, PA, 1985)

[JI86] H. Jiang, C. S. Petersson, M.-A. Nicolet, Thin Solid Films 140, 115, (1986).

[JO85] H. Jordan, K. S. Sreeharsha, and D. W. Chung, Thin Films: The Relationship of Struclure to Properties, MRS Symposia Proceedings, Volume 47, C. Aita and K. SreeHarsha, eds., p. 175, (Materials Research Society, Pittsburgh, 1985).

[KA73] K. Kajiyama, Y. Mizushima, and S. Sakata, Applied Physics Letters, 23, $458,(1973)$.

[KT89] A. Katz, W. C. Dautremont-Smith, S. N. G. Chu, P. M. Thomas, L. A. Koszi, J. W. Lee, V. G. Riggs, R. L. Brown, S. G. Napholtz, J. L. Zilko, and A. Lahav, Applied Physics Letters, 54(23), 2306, (1989).

[KO87] Y. C. Kao, K. L. Wang, E. deFresart, R. Hull, G. Bai, D. Jamieson, and MA. Nicolet, Journal of Vacuum Science and Technology B 5(3), 745, (1987).

[KHzO] 1. H. Khan, The Growth and Structure of Single-Crystal Films, Handbook of Thin Film Technology, L. I. Maissel and R. Glang, eds., p. 10-1, (McGrawHill, 1970).

[KD61] G. V. Kidson, Journal of Nuclear Materials, 3, 21, (1961). 
[KI85] P. D. Kirchner, T. N. Jackson, G. D. Petit, and J. M. Woodall, Applied Physics Letters, 47(1), 26, (1985).

[KW81] S. P. Kowalczyk, J. R. Waldrop, and R. W. Grant, Journal of Vacuum Science and Technology, 19(3), 611, (1981).

[KK82] W. Krakow, Thin Solid Films 93, 109, (1982).

[KR85] H. Kraülte, E. Woelk, J. Selders, and J. Beneking, IEEE Transactions on Electron Devices ED-32(6), 1119, (1985).

[KU83] T. S. Kuan, P. E. Batson, T. N. Jackson, H. Rupprect, and E. L. Wilkie, Journal of Applied Physics 54(12), 6952,(1983).

[KM75] V. Kumar, Journal of Physics and Chemistry of Solids 36, 535, (1975).

(LH86) A. Lahav, M. Eizenberg, and Y. Komem, Journal of Applied Physics 60(3), 991, (1986).

[LH89] A. Lahav, F. Ren, and R. F. Kopf, Applied Physics Letters, 54(17), 1693, (1989).

[LJ86] J. Lajzerowicz, Jr., J. Torres, G. Goltz and R. Pantel, Thin Solid Films 140, 23, (1986).

[L.76] S. S. Lau, C. Canali, Z. L. Liau, K. Nakamura, M.-A. Nicolet, J. W. Mayer, R. J. Blattner, and C. A. Evans, Jr., Applied Physics Letters 28(3), $148,(1976)$.

[LA77\} S. S. Lau, Z. L. Liau, and M-A. Nicolet, Thin Solid Films 47, 313, (1977).

[L.A85] S. S. Lau, W. X. Chen, E. D. Marshall, C. S. Pai, W. F. Tseng, T. F. Kuech, Applied Physics Letters 47(12), 1298, (1985).

[LE88] D. H. Lee, S. S. Lee, and R. V. Ramaswamy, IEEE Transactions on Electron Devices ED-35(10), 1695,(1988).

[LI75] Z. L. Liau, S. U. Campisano, C. Canali, S. S. Lau, and J. W. Mayer, Journal of the Electrochemical Society, 122(12), 1696, (1975).

[LL84] D. L. Lile, Journal of Vacuum Science and Technology B, 2(3), 496, (1984).

[LN88 J.-C. Lin, K.-C. Hsieh, K. J. Schulz and Y. A. Chang, Journal of Materials Research 3(1), 148, (1988).

[LC85] J. R. Lince, R. S. Williams, Journal of Vacuum Science and Technology B 3(4), 1217, (1985). 
[LC86] J. R. Lince, C. T. Tsai, and R. S. Williams, Journal of Materials Research 1(4), 537, (1986).

[LT85] J. L. Liotard, D. Gupta, P. A. Psaras, and P. S. Ho, Journal of Applied Physics $\mathbf{5 7}(6), 1895,(1985)$.

[LY82] J. R. Lloyd and S. Nakahara, Thin Solid Films 93, 281, (1982).

[LO76] S. G. Louie, J. R. Chelikowsky, and M. L. Cohen, Physics Review B 13, 2461, (1976).

[MD82] O. Madelung, M. Schulz, and H. Weiss, Physics of Group IV Elements and III-V Compounds, Landolt-Bornstein: Numerical Data and Functional Relationships in Science and Technology, Volume 17a, K.-H. Hellwege, editor-inchief, p. 333, (Springer-Verlag, Berlin, Heidelberg, New York, 1982).

[MJ77] G. Majni, G. Ferrari, R. Ferrari, C. Canali, F. Catellani, G. Ottaviani, and G. Della Mea, Thin Solid Films 44, 193, (1977).

[MA85a] E. D. Marshall, C. S. Wu, C. S. Pai, D. M. Scott, and S. S. Lau, Thin Films: The Relationship of Structure to Properties, MRS Symposia Proceedings, Volume 47, C. Aita and K. SreeHarsha, eds., p. 161, (Materials Research Society, Pittsburgh, 1985).

[N1485b] E. D. Marshall, W. X. Chen, C. S. Wu, S. S. Lau, and T. F. Keuch, Applied Physics Letters 47(3), 298, (1985).

MLA87 E. D. Marshall, B. Zhang, L. C. Wang, P. F. Jiao, W. X. Chen, T. Sawada, K. L. Kavanagh, T. F. Keuch, Journal of Applied Physics 62(3), 942, (1987).

[MIR85] D. C. Marvin, N. A. Ives, and M. S. Leung, Journal of Applied Physics 58(7), 2659, (1985).

[MS81] J. Massies, J. Chaplart, M. Laviron, and N. T. Linh, Applied Physics Letters 38(9), 693, (1981).

MLiL6! J. O. McCaldin, T. C. McGill, and C. A. Mead, Journal of Vacuum Science and Technology 13(4), 802,(1976).

[AC87] C. E. MicCants, T. Kendelewicz, K. A. Bertness, P. H. Mahowald, M. D. Williams, R. S. List, I. Lindau, and W. E. Spicer, Journal of Vacuum Science and Technology B, 5(4), 1068, (1987).

[M187] J. F. McGilp, Journal of Materials Research 2(4), 516, (1987).

[MT75] J. W. Matthews, Epitaxial Growth, Part B, J. W. Matthews, ed., p. 560, (Academic Press, New Y'ork, 1975). 
[ME63] C. A. Mead and W. G. Spitzer, Physical Review Letters 10(11), 471, (1963).

[ME64] C. A. Mead and W. G. Spitzer, Physical Review 134(3A), A713, (1964).

[MF87] The Handbook of Binary Phase Diagrams, W. G. Moffatt, ed., (Genium Publishing Corporation, Schenectady, NY, 1987).

[MK81] H. Morkoc, T. J. Drummond, and C. M. Stanchak, IEEE Transactions on Electron Devices ED-28(1), 1,(1981).

[MO88] J. F. Morar and M. Wittmer, Journal of Vacuum Science and Technology B G(3), 1340, (1988).

[MO38] N. F. Mott, Proceedings of the Cambridge Philosophical Society, 34, 568, (1938).

[MU86] M. Murakami, K. D. Childs, J. M. Baker, and A. Callegari, Journal of Vacuum Science and Technology B, 4(4), 903, (1986).

[MU87a] M. Murakami, W. H. Price, Y. C. Shih, N. Braslau, K. D. Childs, and C. C. Parks, Journal of Applied Physics 62(8), 3295, (1987).

[MU87b] M. Murakami, W. H. Price, Applied Physics Letters 51(9), 664, (1987).

[MU88] M. Murakami, Y. C. Shih, W. H. Price, E. L. Wilkie, K. D. Childs, and C. C. Parks, Journal of Applied Physics 64(4), 1974, (1988).

[NA80] Y. Nakano, S.-I. Takahashi, and Y. Toyoshima, Japanese Journal of Applied Physics 19(8), 495,(1980).

[NV86 F. Nava and O. Bisi, Thin Solid Films 140, 167, (1986).

Ni78) M.-A. Nicolet, Thin Solid Films 52, 415, (1978).

[NI81] M.-A. Nicolet and M. Bartur, Journal of Vacuum Science and Technology $19(3), 786,(1981)$.

|OB83| J. D. Oberstar and B. G. Streetman, Thin Solid Films 103, 17, (1983).

[OE83] P. Oelhafen, J. L. Freeouf, T. S. Kuan, T. N. Jackson, and P. E. Batson, Journal of V'acuum Science and Technology B 1(3), 588, (1983).

[OL89] D. A. Olson, K. M. Yu, J. Washburn, and T. Sands, Chemistry and Defects in Semiconductor Heterostructures, Materials Research Society Symposia Proceedings, Volume 148, M. Kawabe, T. Sands, E. Weber, and R. Williams, eds., p. 47, (Materials Research Society, Pittsburgh, 1989). 
[OT72] G. Ottaviani, V. Marrello, J. W. Mayer, M.-A. Nicolet, and J. M. Caywood, Applied Physics Letters 20(8), 323, (1972).

[O'T74] G. Ottaviani, D. Sigurd, V. Marrello, J. W. Mayer, and J. O. McCaldin, Journal of Applied Physics 45(4), 1730, (1974).

[OT86] G. Ottaviani, Thin Solid Films 140, 3, (1986).

[PA85] C. J. Palmstrom and D. V. Morgan, Metallizations for GaAs Devices and Circuits, Gallium Arsenide, M. J. Howes and D. V. Morgan, eds., p. 195, (John Wiley and Sons, 1985).

[PA87] C. J. Palmstrom, C. C. Chang, A. Yu, J. Galvin, and J. W. Mayer, Journal of Applied Physics 62(9), 3755, (1987).

[P.A88a] C. J. Palmstrom, E. W. Chase, D. M. Hwang, J. P. Harbison, C. C. Chang, A. S. Kaplan, and L. Nazar, Journal of Vacuum Science and Technology A 6(3), 1456, (1988).

[P.A88b] C. J. Palmstrom, N. Tabatabaie, and S. J. Allen, Jr., Applied Physics Letters 53(26), 2608, (1988).

(PA89) C. J. Palmstrom, B.-O. Fimland, T. Sands, K. C. Garrison, and R. A. Bartynski, Journal of Applied Physics 65(12), 4753, (1989).

[PH73) J. C. Phillips, Bonds and Bands in Semiconductors, (Academic Press, New York and London, 1973).

|PI83| A. Piotrowska, A. Guivarc'h, and G. Pelous, Solid-State Electronics 28(30), $179,(1983)$.

[PO83] J. Pollmann and A. Mazur, Thin Solid Films 104, 257, (1983).

[PT81] D. A. Porter and K. E. Easterling, Phase Transformations in Metal and Alloys, (Van Nostrand Reinhold, U.K., 1981).

|PR76] R. Pretorius, Z. L. Liau, S. S. Lau, and M.-A. Nicolet, Applied Physics Letters 29(9), 598, (1976).

[PU86] J. H. Pugh and R. S. Williams, Journal of Materials Research 1(2), 343, (1986).

[R.89| M. V. Rao, S. M. Gulwadi, P. E. Thompson, A. Fathimulla, and O. A. Aina, Journal of Electonic Materials 18(2), 131, (1989).

\{RH88\} E. H. Rhoderick and R. H. Williams, Metal-Semiconductor Contacts, (Clarendon Press, Cambridge, 1988). 
[RI88] H. J. Richter, R. S. Smith, N. Herres, M. Seelmann-Eggebert, and P. Wennekers, Applied Physics Letters 53(2), 99, (1988).

[RM87] A. D. Romig, Jr., Bulletin of Alloy Phase Diagrams 8(4), 308, (1987).

[RO85] G. Y. Robinson, Schottky Diodes and Ohmic Contacts, Physics and Chemistry of III.V Compound Semiconductor Interfaces, C.W. Wilmsen, ed., p. 73, (Plenum Press, New York 1985).

[RU82] G. W. Rubloff and P. S. Ho, Thin Solid Films 93, 21, (1982).

[SA85] T. Sands, V. G. Kerimidas, J. Washburn, and R. Gronsky, Materials Letters 3(9,10), 409, (1985).

[SA86a] T. Sands, V. G. Kerimidas, J. Washburn, and R. Gronsky, Applied Physics Letters 48(6), 402, (1986).

[SA86b] T. Sands, V. G. Kerimidas, J. Washburn, and R. Gronsky, Thin Solid Films 136, 105, (1986).

|SA8ia| T. Sands, V. G. Keramidas, A. J. Yu, K.-M. Yu, R. Gronsky, and J. Washburn, Journal of Materials Research 2(2), 262, (1987).

\{SA87b\} T. Sands, V. G. Keramidas, K.-M. Yu, J. Washburn, and K. Krishnan, Journal of Applied Physics 62(5), 2070, (1987).

[SA88a] T. Sands, Materials Science and Engineering, B1, 289, (1988).

[SA88b $\}$ T. Sands, W. K. Chan, C. C. Chang, E. W. Chase, and V. G. Kerimidas, Applied Physics Letters 52, 1338, (1988).

[S.A88c T. Sands, E. D. Marshall, L. C. Wang, Journal of Materials Research 3(5), 914, (1988).

[SA88d] T. Sands, J. P. Harbison, W. K. Chan, S. A. Schwarz, C. C. Chang, C. J. Palmstrom, and V. G. Keramidas, Applied Physics Letters 52(15), 1216, (1988).

S.V.3! H. Sankur, J. O. McCaldin, and J. Devaney, Applied Physics Letters 22(2), $64,(1973)$.

SC78) W. J Schaffer, R. M. Walser and R. W. Bené, Journal of Vacuum Science and Technology' 15(4), 1325, (1978).

SS.M81) H. Schmalzried, Solid State Reactions, Second Edition, (Verlag Chemie, W'einhem, Deerfield Beach, Basel, 1981). 
[SO38] W. Schottky, Naturwissenschaften 26, 843, (1938).

[SE82] T. Sebestyen, SolidState Electronics 25(7), 543, (1982).

[SL85] J. Selders, N. Emeis, and H. Beneking, IEEE Transactions on Electron Devices ED-32(3), 605, (1985).

[SH85] K. Sheppard and R. Weil, Thin Films: The Relationship of Structure to Properties, MRS Symposia Proceedings, Volume 47 (Materials Research Society, Pittsburgh, 1985), 127.

[SW69] P. G. Shewmon, Transformations in Metals, (McGraw-Hill, New York, 1969).

[SG74] D. Sigurd, G. Ottanviani, H. J. Arnal, J. W. Mayer, Journal of Applied Phy$\operatorname{sics} 45(4), 1740,(1974)$.

[SI73] A. K. Sinha and J. M. Poate, Applied Physics Letters 23(12), 666, (1973).

[Si75a] A. K. Sinha, Applied Physics Letters 26(4), 171, (1975).

[SI75b] A. K. Sinha, T. E. Smith, and H. J. Levinstein, IEEE Transactions on Electron Devices ED-22(5), 218,(1975).

[S178] A. K. Sinha and J. M. Poate, Thin Films. Interdiffusion and Reactions, J. M. Poate, K. N. Tu, and J. W. Mayer, eds., p. 416, (John Wiley and Sons, New York, 1978).

[SP80al W. E. Spicer, I. Lindau, P. Skeath, and C. Y. Su, Journal of Vacuum Science and Technology 17, 1019, (1980).

[SP80b] W. E. Spicer, I. Lindau, P. Skeath, C. Y. Su, and P. Chye, Physical Review Letters 44(8), 420, (1980).

[SR85] D. J. Srolovitz and S. A. Safran, Thin Films: The Relationship of Structure to Properties, MRS Symposia Proceedings, Volume 47, C. Aita and K. SreeHarsha, eds., p. 53, (Materials Research Society, Pittsburgh, 1985).

[ST81] R. A. Stall, C. E. C. Wood, K. Board, N. Dandekar, L. F. Eastamn and J. Devlin, Journal of Applied Physics, 52(6), 4062, (1981).

[SU82| I. Suni, G. Goeltz, M.-A. Nicolet, and S. S. Lau, Thin Solid Films 93, 171, (1982).

[SZ81] S. M. Sze, Physics of Semiconductor Devices, (John Wiley and Sons, 1981).

[TA88] N. Tabatabaie, T. Sands, J. P. Harbison, H. L. Gilchrist, and V. G. Keramidas, Applied Physics Letters 53(25), 2528, (1988). 
[TO85] P. H. Townsend and H. A. Vander Plas, Thin Films: The Relationship of Structure to Properties, MRS Symposia Proceedings, Volume 47, C. Aita and K. SreeHarsha, eds., p. 121, (Materials Research Society, Pittsburgh, 1985).

[TM82] R. Tromp, E. J. Van Loenen, M. Iwami, R. Smeenk, and F. W. Saris, Thin Solid Films 93, 151, (1982).

[TS86] C. T. Tsai and R. S. Williams, Journal of Materials Research 1(2), 352, (1986).

[TR81] B.-Y. Tsaur, S. S. Lau, J. W. Mayer, and M.-A. Nicolet, Applied Physics Letters 38(11), 922, (1981).

[TR82] B.-Y. Tsaur, D. J. Silversmith, R. W. Mountain, and C. H. Anderson, Jr., Thin Solid Films 93, 331, (1982).

[TU86] K. N. Tu, Thin Solid Films 140, 71, (1986).

[TN82a] R. T. Tung, J. C. Bean, J. M. Gibson, J. M. Poate, and D. C. Jacobson, Applied Physics Letters 40(8), 684, (1982).

(TN82b) R. T. Tung, J. M. Poate, J. C. Bean, J. M. Gibson, and D. C. Jacobson, Thin Solid Films 93, 77, (1982).

[UE82] O. Ueda, S. Yamakoshi, T. Sanada, I. Umebu, T. Kotani, and O. Hasegawa, Journal of Applied Physics 53(12), 9170, (1982).

|UE83) O. Ueda, S. Yamakoshi, I. Umebu, T. Sanada, and T. Kotani, Journal of Applied Physics 54(11), 6732, (1983).

[UE8-1) O. Ueda, H. Imai, A. Yamaguchi, S. Komiya, I. Umebu, and T. Kotani, Journal of Applied Physics 55(3), 665, (1984).

[VG75] G. J. van Gurp and C. Langereis, Journal of Applied Physics 48(10), 4301, (1975).

[YA6] T. E. Van Eck, P. Chu, W. S. C. Chang and H. H. Wieder, Applied Physics Letters 49(3), 135,(1986).

|ViN2 J. M. Vandenberg, F. J. A. Den Broeder, and R. A. Hamm, Thin Solid Films 93, 277, (1982).

[VTi4] G. Van Tendeloo and S. Amelinckx, Acta Crystallographica A 30, 431, $(1974)$.

[VE82] J. L. Veteran, D. P. Mullin, and D. I. Elder, Thin Solid Films, 97, 187, (1982). 
|VI85] Pearson's Handbook for Crystallographic Data, P. Villers and L. D. Calvert, eds., (American Society for Metals, Metals Park, Ohio, 1985).

[WD85] O. Wada, Journal of Applied Physics 57(6), 1801, (1985).

[WL83] J. R. Waldrop, Applied Physics Letters 43(1), 87, (1983).

[WL85] J. R. Waldrop, Applied Physics Letters 47(12), 1301, (1985).

[WA71] J. N. Walpole and K. W, Nill, Journal of Applied Physics, 42, 5609, (1971).

(WL76] R. M. Walser and R. W. Bené, Applied Physics Letters 28(10), 624, (1976).

[WR81a] H. H. Wieder, A. R. Clawson, D. I. Elder, and D. A. Collins, IEEE Electron Device Letters ED-2(3), 73,(1981).

[WR81b] H. H. Wieder, Applied Physics Letters 38(3), 170,(1981).

(WR83) H. H. Wieder, J. L. Veteran, A. R. Clawson, and D. P. Mullin, Applied Physics Letters $43(3), 287,(1983)$.

[WM179] R. H. Williams, R. R. Varma, and V. Montgomery, Journal of Vacuum Science and Technology, 16(5), 1979, 1418.

(WI85) C. W. Wilmsen, Oxide/III-V Compound Semiconductor Interfaces, Physics and Chemistry of III.V Compound Semiconductor Interfaces, C.W. Wilmsen, ed., p. 403, (Plenum Press, New York, 1985).

|MO81a| J. M. Woodall, J. L. Freeouf, G. D. Pettit, T. Jackson, and P. Kirchner, Journal of Vacuum Science and Technology 19(3), 626, (1981).

(WO81b) J. M. Woodall and J. L. Freeouf, Journal of Vacuum Science and Technology 19(3), 794, (1981).

[WU87) X. W. Wu, L. C. Zhang, P. Bradley, D. K. Chin, and T. VanDuzer, Applied Physics Letters 50(5), 287, (1987).

(YU87a) K. M. Yu, S. K. Cheung, T. Sands, J. M. Jaklevic, and E. E. Haller, Journal of Applied Physics 61(3), 1099, (1987).

[YU87b] K. M. Yu, Ion Beam Characierization of Thin Film Metal/GaAs Interface Reactions, Ph.D. Thesis, (University of California, Berkeley, 1987).

|ZE82| X.-F. Zeng, D. D. L. Chung, Thin Solid Films 93, 207, (1982).

[ZH89] J. G. Zhu, C. B. Carter, C. J. Palmstrom, and K. C. Garrison, Applied Physics Letters 55(1), 39, (1989). 

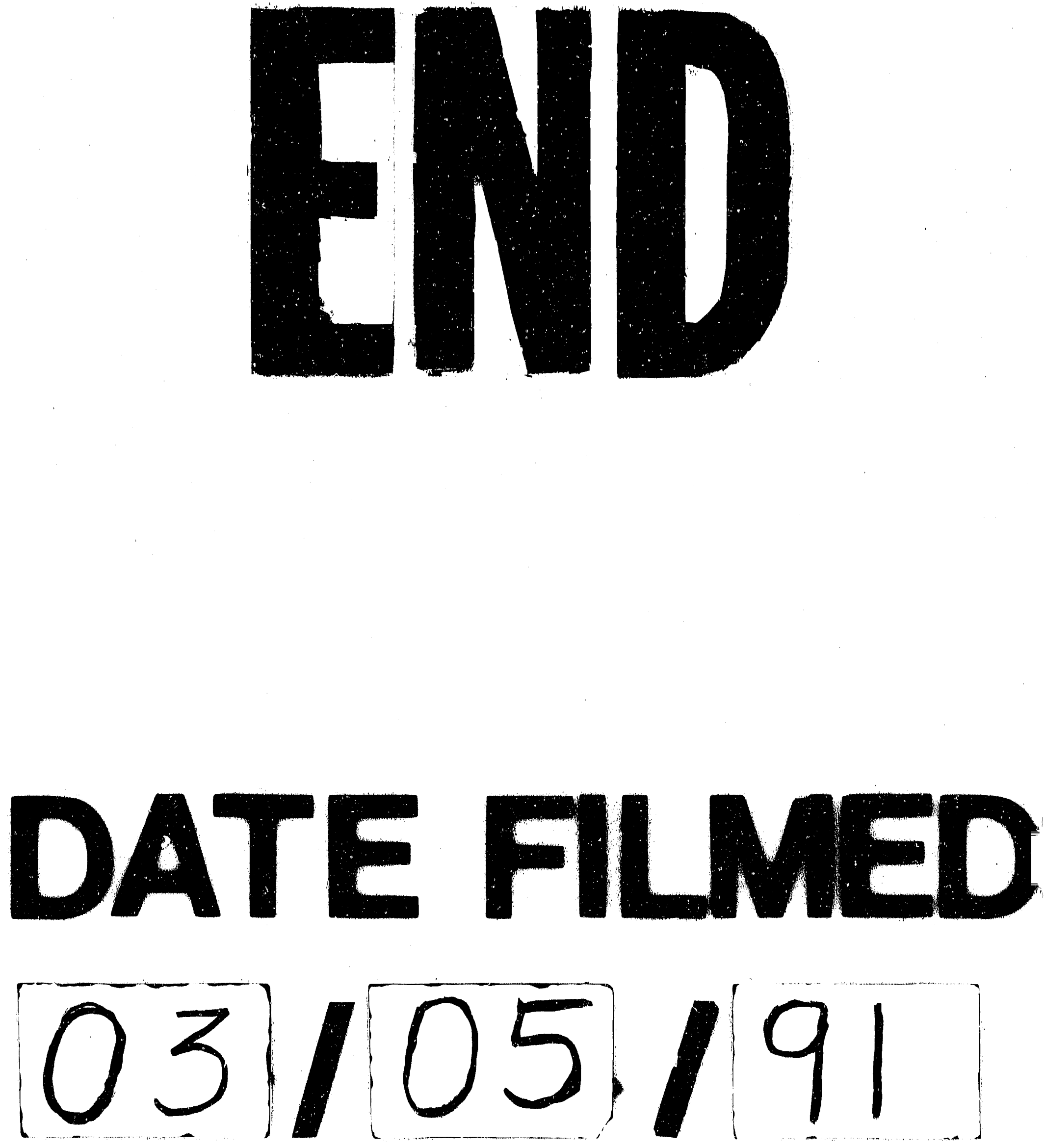
